\title{
Innocence Interrupted: Reconstructing Fatherhood in the Shadow of Child Molestation Law
}

\author{
Camille Gear Rich*
}

\begin{abstract}
This Article shows why criminal law should be regarded as parenting law, because child molestation statutes formally categorized as criminal statutes are increasingly being mobilized by legal decision makers to regulate parents' behavior when they provide mundane, intimate care to their children. The Article further shows how legal decision makers responsible for interpreting these broad child molestation laws tend to interpret the laws in ways that re-instantiate traditional gendered parenting norms. These problems are particularly apparent in what I call parental intimate care cases, cases in which fathers take over nurturing and intimate caregiving tasks that traditionally have been mothers' primary responsibility. The discussion charts these problems by showing how the inquiry authorized by today's broad, far-reaching child molestation statutes invites and even requires judges, juries, prosecutors, and a host of other legal decision makers to rely on gendered notions of cultural "common sense" to resolve child molestation cases involving fathers who provide seemingly mundane intimate care. The Article posits that legal decision makers interpret child molestation statutes in the
\end{abstract}

\footnotetext{
Copyright (C) 2013 California Law Review, Inc. California Law Review, Inc. (CLR) is a California nonprofit corporation. CLR and the authors are solely responsible for the content of their publications.

* Associate Professor of Law, USC Gould School of Law. Special thanks to Kerry Abrams, Scott Altman, Richard Banks, Katherine Bartlett, Rebecca Brown, Emily Buss, Mary Anne Case, Alex Capron, Anne Coughlin, Clare Huntington, Adrienne Davis, Ariela Gross, Tom Lyons, Melissa Murray, Stephen Rich, Nomi Stolzenberg, and Angela Onwachi-Willig for their suggestions and encouragement during the writing process. Special thanks to the faculty of the University of Iowa School of Law, the University of Southern California, the University of Minnesota, the University of Chicago Law School, and Fordham Law School for their workshop comments, as well as the organizers and participants in the January 2011 Feminist Legal Theory Collaborative Research Network Conference and the February 2011 Association of Law Culture and the Humanities Conference. Additional thanks to the many talented research assistants that supported this project: Corrina Freedman, Joseph Clark, Diandra Netto, Taylor Chase Wagnier, and Eunice Lim. Finally, many thanks to Lien Payne for heroic editorial work and assistance. This Article is dedicated to one of my primary sources of insight about mothering, my daughter Lilah Hayley Rich.
} 
parental intimate care cases in ways that conform to gender stereotypes because the concepts of sexual injury at the heart of child molestation law are radically undertheorized. The Article considers the role feminist legal theory has played in this undertheorization problem, addresses the stumbling blocks to future feminist theorizing on this issue, and examines the material consequences of the current undertheorized concepts of sexual injury for the practice and experience of fatherhood.

Introduction.

I. Policing Parents, Policing Gender

A. Regulating the Mundane: The Plain Meaning of Child

Molestation Law

B. Intention Matters: How the Intent Inquiry Encourages the Use of Conservative Gender Norms

1. General Intent and Specific Intent Statutes

2. The Proper Role of Social Norms

3. The Rise of Sexual Privacy Logic

C. Reversing the Groups: Case Studies on the Gender Norm

Enforcement Power of Child Molestation Statutes.

1. Toileting.

a. In re D.C.

b. Hicks v. Larson

c. Montgomery County Department of Health and Human

Services v. P.F.

2. Bathing.

a. In re Julia $B$.

b. In re R.A.

c. State v. Emmett Revisited

3. Kisses

a. People v. Marokity

b. J.S. v. Commonwealth, Department of Public Welfare

II. Feminist and Criminal Responses to Child Molestation

A. Expanding the Concept of Injury: Feminist Interventions in

Child Molestation Law and Scholarship.

B. Fathers Wanted/Fathers Need Not Apply: The Conflict Between

Liberal Feminism and Dominance Feminism over the Role of

Fathers.

C. Post-Dominance Feminists and Fear of the State

III. Reconstructing Fatherhood in the Shadow of Child Molestation

Law: Theoretical and Practical Challenges

A. Child Molestation Law and the Disciplining of Fatherhood

B. Disciplinary Authority in Practice: Anxieties on the Ground 
C. Reimagining Fatherhood

IV. Concerns, Critiques, and Solutions.

A. Recognizing Risk: Masculinity as a Risk Factor for Sexual

Abuse 685

1. Gender Profiling and the Empirical Case Against Fathers

2. A More Nuanced Form of Empiricism: Men, Masculinity, and Fatherhood

B. The Dangers of Gender-Neutral Parenting Models 688

1. Burdening Mothers 688

2. Burdening and Unburdening Culture 689

C. The Role of Social Context in Understanding the Intimate Care

Cases 690

1. Family Dissolution and Reformation 690

2. Family Dissolution and Family Sexual Boundaries. 692

D. Intersectional Disadvantage and Stereotyping of Fathers 693

E. Causation Challenges

1. Potential Versus Actual Abuse 696

2. Extralegal Reasons for Fathers' Failure to Provide Childcare.

Conclusion 697

\section{INTRODUCTION}

When James Lloyd Emmett prepared his son for the child's evening bath, he scarcely imagined that his actions would cause him to be charged with child molestation. ${ }^{1}$ Emmett, to the unsuspecting eye, seemed to be your average father: neither a particularly skilled parent nor a particularly incompetent one. But for unknown reasons-perhaps the child's skin seemed parched that evening - he decided as part of the post-bath ritual to rub down his naked fiveyear-old son with baby oil. ${ }^{2}$ The events recounted here may make some readers uneasy or give others pause. What exactly did Emmett do wrong? Much of this unease stems from the concern that Emmett violated certain unspoken social norms; however, the substance of these norms and the logic that informs them are unclear. One thing is certain: no one sanctioned Emmett for applying the baby oil-indeed, no alarm was even raised until sometime later when the little boy alleged that his father had touched the child with his genitals on a different occasion. ${ }^{3}$ Shortly thereafter, a firestorm of controversy ensued that made the post-bath ritual suspect, led Emmett to be charged with child molestation, and took the case to the highest court in the state of Utah. ${ }^{4}$

1. State v. Emmett, 839 P.2d 783 (Utah 1992).

2. Id. at 784 .

3. Id. at 783 .

4. Id. 
What should we make of Emmett's story? Was Emmett an innocent father engaged in a routine caregiving task or a pedophile engaged in an act of child molestation? Some are prepared to argue that the post-bath rub down was categorically inappropriate; it constituted sexual abuse regardless of the particular kind of touching that occurred. ${ }^{5}$ For others, its inappropriateness would turn more precisely on how Emmett touched his son during the rubdown. They would ask whether he knowingly or intentionally touched the boy in an inappropriate fashion. ${ }^{6}$ Still others would argue that the meaning of the rubdown turns on Emmett's specific intent. ${ }^{7}$ They would ask whether Emmett's objective was to experience sexual arousal in rubbing down his son, even if no clearly illicit touching occurred. These critics would point to the boy's allegations regarding another instance of inappropriate touch as evidence suggesting that something clearly illicit was intended during the rubdown incident as well. These questions are extremely difficult, yet resolving them seems key to the resolution of Emmett's case. By answering these questions, arguably, we can better sort out exactly how we define child molestation. By sorting through these issues, we can more precisely determine when parental care takes an ugly turn and constitutes sexual abuse.

The questions outlined in the previous discussion track a classic debate in child molestation law, one that explores the relative merits of general versus specific intent child molestation statutes. ${ }^{8}$ While these technical questions are

5. Incidents like the post-bath rubdown, described above, have been a source of concern for many child protection advocates. These activities are typically problematized in the context of cobathing scenarios that involve similar kinds of touching. See Paul Okami, Childhood Exposure to Parental Nudity, Parent-Child Co-Sleeping, and "Primal Scenes": A Review of Clinical Opinion and Empirical Evidence, 32 J. SEX RES. 51 (1995) (discussing mental health, legal, and social services professionals' view that parent-child co-bathing and similar behavior constitute sexual abuse); see also Paul Okami et al., Early Childhood Exposure to Parental Nudity and Scenes of Parental Sexuality ("Primal Scenes"): An 18-Year Longitudinal Study of Outcome, 27 ARCHIVES SEXUAL BeHAV. 361, 362 (1998) (reporting that empirical evidence to support the view that co-bathing is abusive is "exceedingly scant" at this time). For other examples, see Eliana Gil, Family Dynamics, in SEXUALIZED CHILDREN: ASSESSMENT AND TREATMENT OF SEXUALIZED CHILDREN AND CHILDREN Who Molest 101 (Eliana Gil \& Toni Cavanagh Johnson eds., 1993) (arguing that covert sexual behaviors like co-bathing can have just as adverse effects on a child as overt sexual acts); see also William Friedrich et al., Normative Sexual Behavior in Children: A Contemporary Sample, 101 PEDIATRICS e9 (1998), http://pediatrics.aappublications.org/content/101/4 /e9.full.pdf+html.

6. This approach tracks the inquiry conducted under "general intent" child molestation statutes, which attaches liability when one "knowingly" or "intentionally" touches a child in an area statutorily defined as sexual in nature. See, e.g., ALASKA STAT. $§ 11.81 .900(58)(A)(2010)$.

7. This approach tracks the logic of "specific intent" child molestation statutes, under which liability attaches when a person acts with the specific intent to sexually arouse himself or his victim. See, e.g., CAL. PENAL CODE $\S 288$ (a) (West 2012) (prohibiting acts taken "with the intent of arousing, appealing to, or gratifying the lust, passions, or sexual desires of that person or the child"); see also LA. REV. STAT. ANN. $\S 14: 81$ (2010) (requiring "the intention to arous[e] or gratify[] the sexual desires of either person").

8. See A.B.A. NAT'L Legal Res. Ctr. For Child Advoc. And Prot., Recommendations FOR IMPROVING LEGAL INTERVENTION IN INTRAFAMILY CHILD SEXUAL ABUSE CASES 13-17 (1982) [hereinafter ABA REPORT] (emphasizing general versus specific intent distinction); see also Kay L. 
important, it would be a mistake to allow this elements-based inquiry to dominate our concerns. For, as this Article shows, the general versus specific intent debate cannot get at the heart of the controversy in Emmett, or in many of the other child sexual abuse cases involving parental intimate care. Instead the debate produces false assurances that tend to hide the degree to which these cases are determined by social "common sense"-our unexamined gut-level understandings of gendered parenting norms. ${ }^{9}$ For, as this Article shows, regardless of whether one examines Emmett as a general or specific intent case, the formal legal inquiry used in child molestation cases invites legal decision makers to assess the appropriateness of parental conduct by referring to traditional gendered understandings defining the proper caregiving role of mothers as distinguished from fathers. In short, fathers like Emmett, who, to coin a phrase, dare to mother by performing traditional intimate caregiving tasks, find they must negotiate gender stereotypes that promote sexual suspicion about fathers who provide intimate care.

Naming sexual abuse statutes' role in enforcing gendered notions of parenting forces us straight into the heart of the lion's den. ${ }^{10}$ In analyzing this problem we must engage with certain unresolved questions in feminist legal theory and criminal law scholarship. Thus far, criminal justice scholars have focused their attention on ensuring that child molestation statutes are broad

Levine, Negotiating the Boundaries of Crime and Culture: A Sociolegal Perspective on Cultural Defense Strategies, 28 LAW \& SOC. INQUIRY 39, 72 (2003) (arguing for further tailoring of the inquiry under specific intent statutes to ensure that cultural minorities accused of abuse based on foreign cultural caregiving practices have the opportunity to demonstrate that benign intent motivated their deviation from American cultural norms); Vicki J. Bejma, Casenote, Protective Cruelty: State v.

Yanez and Strict Liability as to Age in Statutory Rape, 5 Roger Williams U. L. ReV. 499 (2000) (arguing that specific intent statutes are necessary to prevent child molestation offenses from becoming strict liability crimes).

9. For purposes of this discussion, I use the term "gendered parenting norms" to refer to the current conventional cultural distinctions between "male" and "female." These gendered norms, as manifested in parenting cases, tend to make caregiving and nurturing the primary province of mothers and leave fathers with far narrower responsibilities for their children. For example, the traditional model of fatherhood is very much informed by male gender norms as it does not focus on care and instead defines successful fatherhood based on a father's breadwinning capacities or whether he plays sports with his children.

10. The term "parenting" itself is of relatively recent vintage, a feminist intervention designed to assist us in moving beyond historically established gendered patterns of caregiving. See, e.g., Sara Ruddick, Thinking About Fathers, in CONFLICTS IN FEMINISM 222 (Marianne Hirsch \& Evelyn Fox Keller eds., 1990). While I am largely sympathetic to the idea that we should abandon gender-specific parenting descriptions, such as mothering and fathering, and instead rely on the term "parenting" as part of the liberal feminist project to move toward gender-neutral parenting roles, I continue in this Article to use the term "mothering" to refer to caregiving and nurturing work because this term acknowledges the historical reality that women have been largely responsible for caretaking and that this fact has certain material consequences. Id. at 229-30. For further discussion of the consequences of untethering gendered parenting understandings from biological sex and the problems associated with utopian ideals of androgynous parenting, see Darren Rosenblum, Unsex Mothering: Toward a New Culture of Parenting, 35 HARV. J.L. \& GENDER 57, 60 (2012). 
enough to catch both actual and would-be perpetrators. ${ }^{11}$ Similarly, feminists have called for more broadly defined child molestation laws to ensure that children are believed when they claim injury and that the state has the tools required to take corrective action. ${ }^{12}$ However, both communities of scholars have proceeded without full consideration of the ways in which the expansion of the category of sexual injury has simultaneously increased the regulatory power of the state to define normal parenthood and re-instantiate traditional gender norms. Moreover, under the current inquiry, fathers who dare to mother face special risks. Many legal decision makers claim to support a greater role for men in children's lives, but the intimate care cases reveal that they are still fundamentally uncomfortable with men who perform tasks traditionally categorized as maternal care. ${ }^{13}$ That is, despite the accolades that some "handson" fathers receive, socially vulnerable fathers often find that their caregiving efforts become the basis for accusations of sexual impropriety. ${ }^{14}$ By "socially vulnerable" fathers, I am referring to fathers that for a variety of reasons find themselves routinely subject to or threatened with state actors' evaluative scrutiny of their caregiving practices. These fathers include working-class and poor fathers whose families rely on state assistance, fathers in divorcing and separating families subject to custody evaluations, as well as fathers from racial or sexual minority groups that the state tends to view through the lens of historically established sexual stereotypes. I argue that the skeptical treatment that socially vulnerable fathers receive demonstrates the continuing sexual suspicion associated with male caregivers more generally and the deep

11. See, e.g., Jennifer M. Collins, Lady Madonna, Children at Your Feet: The Criminal Justice System's Romanticization of the Parent-Child Relationship, 93 IowA L. REV. 131, 146-49 (2007) (praising decision to punish parent perpetrators under sexual abuse statutes); Leigh B. Bienen, Defining Incest, 92 Nw. U. L. REV. 1501, 1563-77 (1998) (describing with approval the shift from prosecuting parents under incest statutes to using general purpose sexual abuse provisions). Bienen also recognizes that child protection efforts have resulted in child molestation provisions that define prohibited sexual contact in an overly inclusive manner, primarily because of concern that narrow definitions might inadvertently fail to cover certain problematic behaviors. Id.

12. See Mary E. Becker, The Abuse Excuse and Patriarchal Narratives, 92 Nw. U. L. REV. 1459, 1478 (1997) (arguing that courts unnecessarily filter sexual abuse cases through patriarchal social norms); Lynne Henderson, Without Narrative: Child Sexual Abuse, 4 VA. J. Soc. POL'Y \& L. 479 (1997) (arguing that courts' unnecessarily limited definition of child sexual abuse causes them to disbelieve child victims' abuse narratives); Liz Kelly, What's in a Name?: Defining Child Sexual Abuse, 28 FEMINIST REV. 65, 66 (1988) (calling for broader definitions of sexual abuse that match victims' experiences).

13. Andrea Doucet provides the starting point for my specific definition of "mothering." Summarizing the work of other scholars, she argues that "mothering" is fundamentally defined as the exercise of authority and responsibility for the "day-to-day primary care of a child." ANDREA DOUCET, Do Men Mother? Fathering, CARE, AND Domestic ResPonsibility 9 (2006) (discussing the work of Diane Ehrensaft and Sara Ruddick). In this discussion, I further instrumentalize her definition, focusing on certain core, sensitive caregiving and nurturing activities: providing affection, bathing, and offering toileting assistance.

14. Part IV describes the experiences of socially vulnerable fathers in more detail. 
ambivalence that pervades contemporary society about whether men should perform caregiving roles. ${ }^{15}$

This Article proceeds in four parts. Part I explores the extraordinary regulatory power child molestation law has over parenting, as it regulates even the most mundane caregiving practices. Part I also reveals the ways in which judges, prosecutors, and a host of other legal decision makers are invited by the formal legal inquiry in child molestation cases to incorporate traditional gendered parenting norms into their analyses when cases involve parental intimate care. ${ }^{16}$ My goal is to ensure that our "innocence is interrupted": to reveal the ways in which child molestation law depends upon, and further instantiates, gender-specific parenting norms that threaten the project of gender equality.

Part II of the Article explores why feminist scholars, whose primary project is to reveal and disrupt social subordination based on gender, have failed to address the risk of gender bias against men posed by the current interpretation of child molestation statutes. ${ }^{17}$ I suggest that feminists have avoided forthright discussion of this bias because they are reluctant to engage with the diametrically opposed visions of fatherhood that have been put forth by different camps of feminist scholars. Specifically, dominance feminists' primary efforts to reform child molestation law in the 1970 s centered on convincing legislators to recognize the sexual risk posed by fathers, as well as expanding the category of harm recognized as child sexual abuse. ${ }^{18}$ However, dominance feminist efforts conflicted with the simultaneous efforts by liberal feminists to have men recognized as competent caregivers so that women could

15. See, e.g., Karen Harrison-Speake \& Frank N. Willis, Ratings of the Appropriateness of Touch Among Family Members, 19 J. NONVERBAL BEHAV. 85 (1995) (discussing study polling adults on appropriateness of different kinds of touch including parents kissing children on the lips, cosleeping with their children, and giving their children baths). The majority of study participants provided higher approval ratings for mothers than for fathers who performed caregiving activities. See also Toni Cavanagh Johnson \& Richard I. Hooper, Boundaries and Family Practices: Implications for Assessing Child Abuse, 12 J. ChILD SEXUAL ABUSE 103 (2003) (reporting that respondents in their study also granted female caregivers more leeway to perform intimate caregiving tasks for older children than the discretion granted to male caregivers).

16. See generally Myriam S. Denov, The Myth of Innocence: Sexual Scripts and the Recognition of Child Sexual Abuse by Female Perpetrators, 40 J. SEX RES. 303 (2003) (showing how sexual scripts defining mothers as sexually passive distort the ability of social workers, psychologists, and legal decision makers to identify maternal sexual abuse).

17. The account of liberal feminism offered here differs in substantial part from the recent account of feminism offered by Janet Halley, which characterizes feminist theory in general as "a subordination theory set by default to seek the social welfare of women, femininity, and/or female or feminine gender by undoing some part or all of their subordination to men, masculinity, and/or male or masculine gender." See JANET HALLEY, SPLIT DECISIONS: How AND WhY TO TAKE A BREAK FROM FEMINISM 4 (2006). I adopt a broader understanding of liberal feminism as a theoretical account that questions the distinctions made between male and female, and seeks to liberate both genders from reductionist understandings of their social role based on biological sex.

18. See generally Becker, supra note 12; see also Henderson, supra note 12, at 479-82 (urging courts to recognize more narratives covering a broader class of injuries committed by male caregivers). 
shift some of the burdens of childcare to men. Additionally, dominance feminists' efforts were in conflict with liberal and cultural feminist scholars who argued that caregiving, and providing childcare in particular, would encourage fathers to embrace an ethic of care that was essential to men's moral development. ${ }^{19}$ Last, dominance feminists did not anticipate the rise of postdominance feminist scholars, a group that raises concerns about autonomycompromising state regulation of private-sphere, intimate family relationships, including those between parents and children. ${ }^{20}$ Post-dominance feminist scholars worry that the sexual suspicion of fathers compromises women's power to renegotiate the current, default gendered parenting norms that traditionally have made women primarily responsible for providing intimate care to children.

Part II concludes by arguing that feminist legal scholars can no longer afford to simply bracket their disagreements about fatherhood, as their disengagement has stymied the development of a contemporary feminist critique of child molestation law and compromised liberal feminists' efforts to develop a cohesive affirmative vision of the caregiving father. I suggest that liberal feminists, as the primary advocates for reimagining fatherhood, have a special responsibility to press for engagement with this issue. Until feminists of all stripes are asked to forthrightly engage with claims about the sexual threat posed by fatherhood (and masculinity more generally), feminists will be unable to offer courts assistance in sorting through the intimate care cases involving caregiving fathers. Moreover, in order to have a truly rich debate about the future of fatherhood, each constituency of feminist legal scholars must consider how their views regarding the proper scope of mothering and fathering affects the evolution of fatherhood and, by extension, the project of gender equality.

Part III offers a portrait of fatherhood, as reconstructed in the shadow of child molestation law. Using insights from Foucault, Part III explores the broad regulatory power exercised through amorphous child molestation statutes, arguing that they particularly tax socially vulnerable fathers who, for a variety of reasons, are subject to or threatened with informal state review of their

19. For a discussion of the liberal feminist vision of "nurturing" fatherhood, see NANCY E. DOWD, REDEFINING FATHERHOOD 41 (2000) (discussing emergent norms for a more "nurturing fatherhood" but noting that a precise definition of what this entails remains unclear); Andrea Doucet, 'Estrogen-filled Worlds': Fathers as Primary Caregivers and Embodiment, 54 SoC. REV. 696, 697 (2006) (discussing emergence of fatherhood norms that challenge traditional masculinity and prioritize caring); Oriel Sullivan, Changing Gender Practices Within the Household: A Theoretical Perspective, 18 GENDER \& SOC'Y 207, 213-14 (2004) (discussing the emergence of "nurturant new father" as an alternative to fatherhood associated with traditional masculinity). The ethic of care is also an important element in cultural feminism, a branch of feminist theory discussed in more detail in Part II.

20. See generally Melissa Murray, Strange Bedfellows: Criminal Law, Family Law, and the Legal Construction of Intimate Life, 94 IOWA L. REV. 1253 (2009) (highlighting ways in which the State uses criminal law to subsidize certain kinds of "private" family relationships); Jeannie Suk, Criminal Law Comes Home, 116 YALE L.J. 2 (2006) (raising concerns about prosecutors' enforcement of protective orders in ways that compromise the autonomy choices of domestic violence victims). 
routine intimate caregiving practices. This group of course contains fathers from marginalized groups, including gay, minority, and poor fathers. ${ }^{21}$ However, as the cases here show, it also contains its fair share of seemingly socially privileged fathers, as privileged fathers find that in the context of divorce, separation, and custody inquiries, state actors are quite willing to raise murky and difficult questions about sexual impropriety when they review a father's attempts to provide intimate care to his children. Indeed, because the law itself is unclear about how we should determine when male caregivers have engaged in legally prohibited action in the parental intimate care cases, individual fathers find precious little safe harbor when they are accused of inappropriate conduct. These conditions ultimately incentivize all men to internalize the law's sexual suspicion of men who take on caregiving roles. ${ }^{22}$ As Part III shows, in the absence of clear normative understandings about how sexual injury occurs in the intimate care cases,${ }^{23}$ fathers will tend to doubt and police their own behavior or avoid intimate care entirely. Part III concludes by providing qualitative evidence from fathers themselves, explaining how the experience of fatherhood is shaped by sexual anxiety and fear of misplaced accusation.

Part IV attempts to anticipate the most likely comments, critiques, and concerns raised about the feminist critique of child molestation law offered in this discussion. Because the feminist literature on this topic of child molestation law is underdeveloped, the arguments in this section are drawn from a series of immensely helpful workshop conversations I had over the past year with scholars across the country as I attempted to make the case for why child molestation law should attend to the special needs of men who mother. Part IV.A addresses the concern that my analysis should give more weight to the substantial empirical evidence showing that children are at increased risk for sexual abuse with male caregivers. After demonstrating the role gendered assumptions play in data collection efforts, I question the practice of using gender as a proxy for risk of sexual abuse - the larger normative claim this data

21. The categories of especially vulnerable fathers listed above are overlapping and include fathers who are burdened by stereotypes associated with more than one disfavored identity category.

22. See Michel Foucault, DisciPline AND Punish 195-228 (Alan Sheridan trans., Vintage Books 2 d ed. 1995) (1977) (discussing disciplinary constraints of the Panopticon).

23. See Alvin Rosenfeld et al., Determining Incestuous Contact Between Parent and Child: Frequency of Children Touching Parents' Genitals in a Nonclinical Population, 25 J. AM. ACAD. CHILD PSYCHOL. 481, 481 (1986) ("'L] ittle empirical research has been done to find out how parents in nonclinical samples are raising their children with regard to affectional and sexual behaviors in their families, or to ascertain how they feel about what they and their children do."); Harrison-Speake \& Willis, supra note 15, at 86 (recognizing that there "are no empirically derived norms on touch among family members," making it "difficult or impossible to state whether a given touch is deviant"). Harrison-Speake and Willis find certain norms in their community sample, but other studies demonstrate significant variation depending on political ideology, cultural background, and religion. See, e.g., Ron Craig et al., Examining Norms for Potentially Suspect Parent-Child Interactions (2000) (unpublished study), available at http://psychology.edinboro.edu/rcraig/pdf/craigapa2000.pdf. 
is used to support. Part IV.B considers whether the extension of principles of gender neutrality to the topic of nurturing care creates special risks for mothers, namely that it will threaten the discretion they currently enjoy as they care for children.

Part IV.C addresses the claim that unique family pressures in custody and divorce cases shape the parental intimate care cases, making them unlikely proxies for understanding the cultural pressures on fatherhood more generally. I demonstrate that divorce and custody proceedings (what I call family dissolution cases) should be viewed as one of the primary sites where culturally established gendered parenting norms are challenged, but that these same challenges emerge in other contexts as well. Part IV.D continues by exploring how race, sexual orientation, and class bear on the stereotypes activated when assessing fathers' care in the parental intimate care cases. ${ }^{24}$ In addition to calling for more research in this area, I show how the analysis of these considerations is complicated by the presence of inconsistent or conflicting stereotypes about each vulnerable group. ${ }^{25}$ Part IV.E addresses concerns about the causal claims made in the piece, as some have argued that men are primarily influenced by extralegal pressures rather than child molestation law, and therefore that the law plays a relatively small role in discouraging men who mother. The Article recognizes that law certainly is not the only variable that discourages men from providing intimate care. However, it also sheds light on the broad array of parties that mobilize claims about child molestation law to discipline men's conduct. The Article explains that, even if one concludes that the law's role in disciplining men who mother is limited, the topic of child molestation law still merits special concern precisely because the law both feeds on existing cultural stereotypes about gender and gives these gender stereotypes the force of law.

The Article also attempts to make feminists more attentive to a group of unexpected but important political allies in the struggle for gender equality: men who provide intimate care to their children out of necessity, rather than by choice. Most of these men, prior to becoming fathers, have not given much thought to the material consequences of our gendered understanding of childcare. However, the intimate care cases draw in a large, diverse group of

24. Minority fathers may be particularly at risk for scrutiny by social workers and other legal decision makers. For example, working-class minority fathers may feel the threat of scrutiny more than comparatively socially privileged fathers, given the greater likelihood that they have had the state intervene in their families or have been subject to incarceration. Similarly, gay fathers as well may feel they face special risk of scrutiny because they must as a daily matter provide nurturing and care to their children, but are often stereotyped as child molesters.

25. Additionally, the intersectional nature of fathers' identities further complicates the analysis of fathers' experiences when they are members of multiple minority groups, as in these circumstances it will not always be clear which aspect of a father's identity the evaluator will focus on when analyzing a father's caregiving behavior or, more likely, how the two or more identity categories work together to create more specific forms of bias. 
fathers and encourage them to actively engage with the project of gender reconstruction. These men include gay fathers (who may not have a female coparent available to provide care); single, divorced, and widowed fathers (who often must provide care on their own); as well as poor and working-class fathers (who often cannot afford to contract for female caregivers when a child's mother is not present to provide care). Of course, current gendered parenting understandings also burden heterosexually partnered working mothers who are saddled with additional childcare obligations despite the availability of an otherwise competent male partner willing to share the childcare role. ${ }^{26}$ But feminists would benefit from paying some attention to the strong discouragement child molestation prosecutions communicate to the men who are engaged in care but are ambivalent about feminism more generally. Feminists should care about these men not only because principles of fairness are at stake, but also because these men are accidental soldiers in the struggle for gender equality. These men, acting as fathers, will have conversations in male-dominated spaces that feminists otherwise will find hard to enter.

The Article concludes by arguing that we must disrupt structures in child molestation law that encourage the taxing of fathers who engage in mothering activities. I explain that, until we fundamentally resolve our understanding regarding the role fathers should play in intimate care, we will suffer negative social, economic, and structural effects, stunt the evolution of parenting roles, and prevent the practice of parenting from being a driving force that challenges the evolution of gender itself. ${ }^{27}$

I.

\section{Policing PARENTS, Policing Gender}

It is the rare legal scholar in the current cultural environment that dares to question the scope and trajectory of child molestation law. Rather, as cultural studies scholars like James Kincaid have observed, there appears to be near universal agreement on the basic questions that inform the discussion of child

26. See Carla Shows \& Naomi Gerstel, Fathering, Class, and Gender: A Comparison of Physicians and Emergency Medical Technicians, 23 GENDER \& SOC'Y 161, 162 (2009) (collecting studies showing that most fathers still leave the majority of childcare and parenting duties to mothers). This research finding dovetails with more general research findings indicating that over the past thirtyfive years or so-from 1960 to 1997 - men have only increased their share of household domestic labor by an average of twenty minutes per day. See Frank F. Furstenberg, Jr., Fathering in the Inner City: Paternal Participation and Public Policy, in FATHERHOOD: CONTEMPORARY TheOrY, RESEARCH, AND SOCIAL POLICY 119, 120-21 (William Marsiglio ed., 1995) (noting that in traditional families, some fathers still spend comparatively little time participating in childcare); Sullivan, supra note 19 , at 215 .

27. See Shows \& Gerstel, supra note 26, at 163 (“[M]en's involvement in gender relations at home, especially parenting, provide an important locus of institutionalized inequality and significant site for the (re)construction and expression of various masculinities."'). 
molestation law. ${ }^{28}$ These questions tend to take the following forms: "How can we spot the pedophiles and get rid of them?" or, alternatively, "How can we protect our children?" 29 Because of the relatively narrow band of questions that get explored in the legal literature on child molestation, legal scholars rarely question whom these laws target and how they define molestation. Any scholar who does so risks appearing suspect, cavalier, or critically misguided. Yet increasingly, child molestation law plays a significant role in shaping parents' actions that bear little relation to the obviously wrongful acts that motivated these statutes' passage. As post-dominance feminist scholars like Professor Melissa Murray have explained, criminal law should be regarded as family law when it regulates the scope and substance of intimate relationships, immunizing certain kinds of conduct between intimates and prohibiting other kinds of behavior. ${ }^{30}$ Part I extends this insight to an analysis of child molestation law, revealing that child molestation law is parenting law. It shows that child molestation statutes currently are being used to power a particular interpretive project for parenting standards, one that proceeds in fits and starts, but ends up maintaining conservative, traditional gender-specific parenting roles.

\section{A. Regulating the Mundane: The Plain Meaning of Child Molestation Law}

Does child molestation law really regulate parenting? The idea seems counterintuitive given American legislators' well-documented preoccupation with stranger danger - the molestation risk posed to children by the stranger lurking in the park. ${ }^{31}$ However, review of child molestation statutes shows that some state legislators are equally focused on the risks posed by a child's nearest and dearest. ${ }^{32}$ Numerous state child molestation statutes explicitly refer

28. See JAmes R. KinCAID, ERotic InNOCEnCE: The CUlture OF Child Molesting 7-8, 21 (1998) (expressing concern that scholars fail to critically analyze how molestation concerns are deployed to legitimate otherwise controversial social interventions); $c f$. Katherine Beckett, Culture and the Politics of Signification: The Case of Child Sexual Abuse, 43 SoC. PROBS. 57, 59-60 (1996) (arguing that framing of the child sexual abuse problem often hides highly contested aspects of the problem).

29. KINCAID, supra note 28 , at 9.

30. See Murray, supra note 20, at 1255-58.

31. See Joel Best, Threatened Children: Rhetoric And Concern About ChildVICTIMS 73 (1990) (discussing Americans' preoccupation with molestation incident to child abduction); KINCAID, supra note 28, at 180-85. For a discussion of the influence the term "stranger danger" has had on policy discussions about child molestation, see NANCY MCBRIDE, NAT'L CTR. FOR MisSING AND EXPLOITED CHILDREN, CHILD SAFETY IS MORE THAN A SLOGAN: "STRANGERDANGER" WARNINGS NOT EFFECTIVE AT KEEPING KIDS SAFER (2011), available at http://missingkids.com/en_US/publication s/PDF10A.pdf.

32. See Bienen, supra note 11, at 1568-69 (arguing that incorporation of incest into general category of child sexual abuse offenses constituted an important shift in the evolution of child molestation law). As Bienen explains, these new sexual offense statutes effectively constituted a "transformation of family, with its emphasis upon blood relations, into a concept of 'position of authority,' [and] was one of the most profound philosophical changes" as it focused attention on the existence of exploitation in family relationships rather than a biological connection. Id. at 1569; see also Ruby Andrew, Child Sexual Abuse and the State: Applying Critical Outsider Methodologies to 
to parents when defining molestation crimes. ${ }^{33}$ Others refer to parents using "position of trust" provisions as they define child molestation, or in sentencingenhancement statutes that turn on parents' abuse of authority or trust. ${ }^{34}$ Other states show their concern about parents by extending the statute of limitations for molestation crimes involving a parent. ${ }^{35}$ These statutory provisions directed toward parents typically serve the purpose of increasing the range of penalties available to sanction sexually predatory parents, as well as signaling society's special contempt for individuals who would molest their own children.

The express references to parents in state child molestation statutes after the 1980s marked a break from the conventions of the prior period in which sexually offending parents were only charged if they violated narrowly constructed incest statutes, ${ }^{36}$ a criminal offense that carried relatively weak

Legislative Policymaking, 39 U.C. DAVIS L. REV. 1851, 1870 (2006) (“[P]enalties for sexual assault of children [increase] when the perpetrator holds a 'position of trust' with respect to the child victim.").

33. For example, some states, like Ohio, treat parental sexual abuse as simply one of several kinds of sexual battery. See OHIO REv. CODE ANN. § 2907.03(A)(5) (West 2009) ("No person shall engage in sexual conduct with another, not the spouse of the offender, when ... [t] other person's natural or adoptive parent, or a stepparent, or guardian, custodian, or person in loco parentis of the other person."). Other states refer to parents when defining the crime of child molestation. See, e.g., W. VA. CODE ANN. § 49-1-3(14)(A) (LexisNexis 2011) ("As to a child who is less than sixteen years of age, any of the following acts which a parent, guardian or custodian shall engage in ... [including] sexual intercourse; sexual intrusion; or sexual contact."). For other examples, see 325 Ill. COMP. StAT. 5/3 (2013); Ky. Rev. Stat. ANN. § 600.020 (West 2012); LA. Child. Code ANN. art. 603 (2004); MD. CoDE ANN., FAM. LAW § 5-701 (LexisNexis 2006); N.J. STAT. ANN. § 9:68.84 (West 2012); N.M. STAT. ANN. § 32A-4-2 (West 2009); N.C. GEN. STAT. § 7B-101 (2012); R.I. GEN. LAWS § 40-11-2 (2011); S.C. CODE ANN. § 63-7-20 (2011); S.D. CODIFIED LAWS § 26-8A-2 (2008); VA. CODE ANN. § 63.2-100 (2012). Some states continue to treat child sexual abuse as a kind of "incest." See, e.g., HAW. REV. STAT. ANN. § 350-1 (LEXISNeXIS 2010); IDAHO CODE ANN. § 161602 (2009).

34. For example, Colorado's child molestation law contains an abuse of trust provision that specially refers to parents. See COLO. REV. STAT. §§ 18-3-401, 18-3-405 (2011) (describing position of trust provision in sexual abuse statute and defining "position of trust" as "any person who is a parent or acting in the place of a parent and charged with any of a parent's rights, duties, or responsibilities concerning a child ..."); see also MISS. CODE ANN. § 97-3-95(2) (2012) (identifying parents and stepparents as parties that can be charged under abuse of trust provision); $c f$. Hart v. State, 829 N.E.2d 541, 544 (Ind. Ct. App. 2005) (applying Indiana's judicially created abuse-of-trust aggravating circumstance and explaining that "[t]here is no greater position of trust than that of a parent to his own young child").

35. For a general discussion of the statute of limitations for child molestation charges against parents under the criminal law, see Nat'l Crime Victim Law Inst., National Survey of Criminal Statutes of Limitation for Felony Child Sexual Abuse Charges (Jul. 16, 2012), http://law.lclark.edu/live/files /12741-national-survey-of-criminal-statutes-of (providing 50-state survey and discussing special provisions under Arkansas, Florida, and Iowa law among others providing additional time for child molestation prosecutions involving parents). For a discussion of civil child molestation provisions, see Nat'l Conference of State Legislators, State Civil Statutes of Limitations in Child Sexual Abuse Cases (July 2012), http://www.ncsl.org/issues-research/human-services/state-civil-statutes-of-limitations-inchild-sexua.aspx (discussing special provisions under Florida law for incest victims).

36. Scholars have criticized incest provisions for creating a lesser standard of justice for related victims. See, e.g., Andrew, supra note 32, at 1870; Bienen, supra note 11, at 1562-77 (praising the shift from specific incest prohibitions to standards that include parent-child abuse under more general definitions of sexual abuse); Collins, supra note 11, at 146-49 (recognizing that parents are regulated 
penalties. ${ }^{37}$ The new trend, which encouraged legislators to treat parental sexual abuse as a variation within the broader category of child sexual abuse, was consistent with the American Bar Association's 1982 recommendations for prosecuting child sexual abuse $\mathrm{e}^{38}$ and marked a major philosophical change in the treatment of offending parents. ${ }^{39}$ Statutory authority that more explicitly acknowledged parent-offenders was welcomed by many child welfare advocates, as there is substantial empirical evidence showing that children are typically sexually abused by someone who is known to them. ${ }^{40}$ Yet this shift in approach, in another respect, may have made matters more confusing. Research shows that children are more likely to be abused by a family member, family friend, or intimate, rather than a stranger, ${ }^{41}$ but studies also suggest that the number violated by what I call a "primary parent" may be quite low. ${ }^{42}$ More concerning, empirical data tends to emphasize the threat specifically posed by male relatives without critical reflection and, consequently, has naturalized the view that gender itself is a risk factor for abuse, ${ }^{43}$ rather than the more

by sexual abuse statutes, but arguing that penalties assigned to parents are weak compared to penalties assigned to unrelated perpetrators).

37. Modern incest provisions in some jurisdictions also were shaped by feminist activism and consequently include a more expansive group of exploitative acts that could also be characterized as child molestation. For discussions of feminist efforts in this area, see Bienen, supra note 11, at 150609. As Bienen explains, the goal was to address more diffuse forms of parent sexual abuse and to extend the criminal law's focus to include more than penetrative heterosexual sexual contact. $I d$. at 1509 .

38. See ABA REPORT, supra note 9, at 13-16.

39. See Andrew, supra note 32, at 1869-70.

40. See London Family Court Clinic, Tipping the Balance to Tell the Secret: The PuBlic DisCovery of Child SeXUAL ABUSE 16 (1995) (noting that persons known to the victim make up 80-85 percent of child abuse assailants, compared to strangers, who make up 15-20 percent).

41. Id.

42. By "primary parent," I am referring to parents that regularly provide nurturing and care. Unfortunately, most current studies tend to define parent primarily by reference to biology. See David Finkelhor et al., Sexual Abuse in a National Survey of Adult Men and Women: Prevalence, Characteristics, and Risk Factors, 14 CHILD ABUSE \& NEGLECT 19, 21 (1990) (reviewing nationally representative sample showing only 3 percent of female victims and no male victims were sexually abused by a "natural" parent). These numbers regarding biological parents may be artificially low, as they rely on self-reports, and victims' reluctance to disclose parental abuse may have distorted these estimates. $C f$. Andrea J. SedlaK et Al., U.S. Dep'T of Health and Human Servs., Fourth NATIONAL INCIDENCE STUDY OF CHILD ABUSE AND NEGLECT (NIS-4): RePORT TO CONGRESS 14 (2010) (relying on child welfare sample and reporting that 36 percent of children are molested by biological parents). Child welfare samples, however, may lead us to inflated estimates regarding the risk posed by biological parents, as they tend to be composed primarily of cases involving abuse and neglect proceedings (as opposed to criminal case referrals) and often involve marginal, socially contested "abuse" behaviors that arguably are not the core concern of many child protection advocates (e.g. parent exhibitionism, incidental exposure to parent sexual activity, or co-bathing). See BEST, supra note 31, at 61-64, 71 (raising definitional and measurement concerns).

43. See, e.g., Leslie Margolin \& John L. Craft, Child Sexual Abuse by Caretakers, 38 FAM. REL. 450, 451, 453 (1989) (reporting that 23 percent of children are sexually abused by a male biological parent and listing gender as a risk factor). Margolin \& Craft ultimately acknowledge that other factors, such as social or institutional connection, appear to be equally if not more probative than gender. $I d$. at $453-54$. For further discussion of the problems inherent in biological, sociological, and 
significant consideration - whether the party involved is a person who attends to the care of his children. In fact, research suggests that children are less likely to be molested by a person who actually attends to their intimate care, ${ }^{44}$ as caregivers are less likely to experience the kind of role confusion that can lead to molestation. ${ }^{45}$ Consistent with this view, I suggest that fathers who, either by default, interest, or necessity, end up routinely providing intimate care to their children will have a fundamentally different and nonsexual orientation toward their children, much more so than fathers who do not participate in these activities. Consequently, there are special incentives to attend to the need for protections in child molestation law for men who play caregiving roles.

Critics may argue that, even if child molestation law "technically" applies to parents, this does not mean that these restrictions effectively "regulate" parenthood, for one assumes that the prohibitions ensconced in child molestation statutes would not trouble the average parent properly discharging his duties. Rather, the claim is that the paradigmatic examples, those standard instances of molestation covered by child molestation statutes-typically explicit sexual acts - have little or nothing to do with proper parenting. Under this view, the only parents that would be affected by child molestation statutes are those marginal parents involved in clearly wrongful or bizarre conduct. To the extent that child molestation law applies to parents, it would seem that it only regulates an outlier group: parents with ill intent who would knowingly sexually violate their children.

psychological studies that treat gender itself as a risk factor, as well as implications of studies for feminist theory, see generally AnNe Cossins, Masculinities, SeXualities and Child SeXual ABUSE 33-86 (2000). Cossins argues that we need to recognize the existence of multiple masculinities and identify particular masculine practices as risk factors in order to develop a more sophisticated understanding of child sexual abuse. $I d$. at $87-95$. This discussion also recognizes that we have sound data establishing that men sexually abuse children more frequently than women; however, it also suggests that gender may be functioning as a sloppy proxy for other risk factors and that the current gender focus leads to unnecessary gender stereotyping that discourages fathers from providing care.

44. See Hilda Parker \& Seymour Parker, Father-Daughter Sexual Abuse: An Emerging Perspective, 56 AM. J. ORTHOPSYCHIATRY 531, 539-40 (1986) (discussing research suggesting that fathers' involvement in providing care is a factor that mitigates against sexual abuse); Linda $\mathrm{M}$. Williams \& David Finkelhor, Paternal Caregiving and Incest: Test of a Biosocial Model, 65 AM. J. ORTHOPSYCHIATRY 101, 106-11 (1995). Specifically, Williams and Finkelhor found that the fathers who provided care to their children in early life, particularly between the ages of four and five, were less likely to engage in sexual abuse than those who did not. Id. at 109. The researchers posit that there is something about providing care, rather than mere proximity to a child, that reduces the likelihood of abuse. Id. at 111; see also Margolin \& Craft, supra note 43, at 450 (recognizing the need for more research on caregiving as a relevant sexual-abuse risk factor).

45. Researchers suggest that child molestation by a primary parent often occurs when a parent fails to see a child in a maternal or parental manner. See, e.g., Pamela C. Alexander, Application of Attachment Theory to the Study of Sexual Abuse, 60 J. Consulting \& CliniCal Psychol. 185, 188 89 (1992) (discussing role reversal as a warning indicator of abuse); Roland Summit \& JoAnn Kryso, Sexual Abuse of Children: A Clinical Spectrum, 48 AM. J. ORTHOPSYCHIATRY 237, 239-50 (1978) (discussing role confusion as one of the causes of sexual abuse). 
This assumption, however, about the disconnect between "normal," everyday parenting practices and the statutory coverage of child molestation provisions proves naïve when one more closely examines the wording of child molestation laws. What one finds is a series of overlapping, broadly worded statutes that approximate touch with sexual assault. These broadly worded statutes potentially criminalize a wide range of "normal" parental behavior, including touch incident to bathing, toileting, and other intimate care activities - particularly those associated with young children. ${ }^{46}$ For example, Arizona has very broad child molestation provisions prohibiting "intentional[] or knowing[] ... sexual contact... with a child." $" 47$ This definition seems uncontroversial until one considers that sexual conduct is defined under the statute as "any direct or indirect touching ... or manipulating of any part of the genitals, anus or female breast by any part of the body or by any object.",48 Technically, under this statute, acts as innocent as a diaper change, a baby massage, or toweling a toddler off after his evening bath could be legally troubling.

Alaska similarly offers a broad definition of child sexual abuse, defining it as when a person "engages in sexual contact" with a child. ${ }^{49}$ This prohibition again seems relatively uncontroversial until one considers Alaska's capacious definition of sexual conduct, which covers any "knowing[] touching, directly or through clothing," of the victim's "genitals, anus or female breast," or "knowingly causing the victim to touch, directly or through clothing, the defendant's or victim's genitals, anus, or female breast." ${ }^{, 50}$ As one Alaska Court noted, this standard makes "nursing a baby, carrying a child on one's shoulders or lap, bathing a child, and changing a child's diapers . . . all acts that can be construed to fall within the literal statutory definition of 'sexual contact.", 51 The court further noted that the child molestation statute's only requirement of intent "is that the acts be knowingly performed." 52 Some states proscribe an even broader range of conduct. California has a statutory scheme prohibiting the "intentional touching of [a child's] genitals or intimate parts," which are defined to include the "breasts, genital area, groin, inner thighs, and buttocks" and "the clothing covering them." 53 Given its broad definitions, one is not

46. See Bienen, supra note 11, at 1575 (arguing that sexual abuse definitions are overinclusive in ways that threaten normal intimacy between family members).

47. ARIZ. REV. STAT. ANN. § 13-1410(A) (2012).

48. Id. $\S 13-1401(2)$.

49. ALASKA STAT. $§ 11.41 .436(5)(2010)$.

50. Id. $\S 11.81 .900(\mathrm{~b})(58)(\mathrm{A})$.

51. Flink v. State, 683 P.2d 725, 738 (Alaska Ct. App. 1984).

52. Id.

53. See CAL. PENAL CODE $\S 11165.1(b)(4)$ (2012). The statute includes a requirement of sexual intent and a reasonable caretaking exception. $I d$. 
surprised to find that California, despite having some special statutory protections for parents, has its fair share of parental intimate care cases. ${ }^{54}$

Given the risks posed by the expansive statutory definitions used in child molestation statutes, one expects that prosecutors would simply exercise "common sense," reserving their energy and attention for true cases of sexually problematic behavior. Unfortunately, it turns out that common sense is not easily discerned. Parents have been charged with child molestation for performing a range of acts, including obviously wrongful acts such as sexual intercourse, but also for touch incident to a host of "normal" caregiving activities. These cases, which almost exclusively involve fathers, cover acts from classic caregiving tasks to the mundane, normally hidden parts of childcare. Cases include disputes in which a father is accused in connection with giving a child a bath; ${ }^{55}$ wiping his daughter after going to the bathroom; ${ }^{56}$ dealing with incontinence issues ${ }^{57}$ giving kisses in the context of play, after a bath, or diaper change, ${ }^{58}$ and even tucking his daughters into bed. ${ }^{59}$ Fathers can and will be charged for a diverse array of practices, ranging from co-bathing to tickling. ${ }^{60}$ Thus, the broad definitions of child sexual abuse are not just abstract potential threats, but actually result in criminal and civil sanctions.

How is it that fathers find themselves caught in these thorny inquiries in child molestation cases involving intimate care? Some would argue that the broad coverage under contemporary child molestation statutes is no mistake. Part of the reform project headed by dominance feminist scholars was intended to bring more parent-child interaction into the domain of sexually troubling

54. See, e.g., In re Julia B., No. A125775, 2010 WL 2620806 (Cal. Ct. App. June 30, 2010) (future stepfather bathing female child without washcloth); People v. Marokity, No. B213631, 2010 WL 779778 (Cal. Ct. App. Mar. 9, 2010) (father kissing children's naked bodies).

55. See, e.g., In re Julia B., $2010 \mathrm{WL} 2620806$, at *1 (future stepfather bathing female child); In re Interest of R.A., 403 N.W.2d 357 (Neb. 1987) (biological father bathing female child); $c f$. State v. Emmett, 839 P.2d 781 (Utah 1992) (father rubbing baby oil on preadolescent son after coming out of the bath); In re Parentage of S., 117 Wash. App. 1036 (2003) (mother's boyfriend co-bathing with five-year-old female child).

56. See, e.g., Montgomery Cnty. Dep't of Health and Human Servs. v. P.F., 768 A.2d 112 (Md. Ct. Spec. App. 2001) (father wiping toddler daughter after going to the bathroom); Bratcher v. Surrette, 848 So. 2d 893 (Miss. Ct. App. 2003) (father toileting toddler son); cf. Hicks v. Larson, 884 N.E.2d 869 (Ind. Ct. App. 2008) (grandfather applying diaper cream to toddler granddaughter).

57. See, e.g., In re D.C., 648 A.2d 816 (Vt. 1993) (father treating daughter's incontinence problem).

58. See, e.g., Marokity, 2010 WL 779778, at*3; cf. J.S. v. Commonwealth, Dep’t of Pub. Welfare, 557 A.2d 801 (Pa. Commw. Ct. 1989) (father giving playtime open mouth kisses to his daughter between the ages of four and eight).

59. See Markiton v. State, 139 N.E.2d 440 (Ind. 1957) (father tickling and hugging his teenage daughters while tucking them into bed).

60. See, e.g., In re Michael M., 591 N.Y.S.2d 681, 683 (N.Y. Fam. Ct. 1992) (father grabbing and wrestling with puberty-age male children); In re Parentage of S., 117 Wash. App. at *1 (mother's boyfriend co-bathing with young female child). 
behavior. ${ }^{61}$ Importantly, this reform project dovetailed with the interests of more conservative child welfare authorities concerned about parent-child interactions. ${ }^{62}$ Paul Okami, a psychologist who studies parent-child intimacy, explains that child protection experts have long been interested in exploring the potentially sexually troubling nature of so-called innocuous parenting behaviors. These behaviors include "parental nudity; parent-child co-bathing or the parent bathing the child; [and] 'excessive' displays of physical affection (such as kissing a child on the lips or belly, frequent hugging, 'sensuous teasing,' or 'flirting' with a child)." ${ }^{, 63}$ Additionally, parents are criticized for exposing their children to behavior that is part of maintaining intimacy with other family members. ${ }^{64}$ This behavior includes "exposing a child through visual or auditory proximity to instances of adult sexual behavior[] and allowing a child to sleep in the parental bed." ${ }^{, 65}$ As cultural studies scholar James Kincaid explains, "[w]e have expanded the category of sexual abuse to include issues that would have been regarded three decades ago as nuisances or nothing: a wide variety of touching, some of it at least ambiguous; suggestive language; exhibitionism that used to be passed off as casual; and voyeurism."

Okami and Kincaid raise concerns about a criminal justice regime that has run off the rails, powered by clinicians and social workers ever eager to pathologize more conduct and compromise parental autonomy. Their work has been marginalized by many child protection advocates, in particular those who view parents with "poor sexual boundaries" as a population at high risk for inflicting sexual abuse on their children. ${ }^{67}$ However, Okami's and Kincaid's insights should concern feminists and other scholars concerned about the social norms enforcement power of child molestation provisions. For child molestation law, in some jurisdictions, can function as a powerful tool in the state's arsenal for establishing moral codes about nudity, decency, and sexuality. Once coupled with the child welfare norms that inform social

61. See Bienen, supra note 11, at 1566 (describing reform efforts of the national women's movement in the 1970s to "recharacteri[ze] . . child sexual abuse within the family" and expand the definition of incest to include "touching and other sexual acts that do not involve penetration").

62. Okami, supra note 5, at 51.

63. Okami et al., supra note 5, at 362-63; see also, e.g., In re Martha R., No. B152839, 2002 WL 1155481, at *2 (Cal. Ct. App. May 31, 2002) (affirming order changing father's visitation rights after he allowed his four-year-old daughter to bathe naked in a hot tub with himself and other adults); T.G. v. Kaplan, 2011 WL 1004645 (N.J. Super. Ct. App. Div. Mar. 23, 2011) (addressing father's civil claim against mother for allegedly unfounded child sexual abuse allegations when father conceded that he had showered naked with his child, and therefore presumably subjected the child to potential harm).

64. Okami et al., supra note 5 at 364.

65. Okami, supra note 5 at 51; see also Okami et al., supra note 5 at 364.

66. KINCAID, supra note 28, at 78 .

67. These concerns about "sexual boundaries" cover a variety of practices that involve exposing children to parental sexuality (primal scenes), parental nudity, or when parents engage in cosleeping, co-bathing, or forms of affectionate behavior that arguably invade a child's need for physical privacy. For further discussion, see Friedrich et al., supra note 5; Gil, supra note 5; Johnson \& Hooper, supra note 15 , at $105-06$. 
workers' understanding of this social problem, the reach of child molestation law seems endlessly expansive. Joel Best, a sociologist working on these questions, shows just how far the child molestation inquiry can reach. Quoting from the Encyclopedia of Social Work, he asks, "[i]s a father who routinely walks around his house naked in front of his children sexually abusing them?",68 Social workers may conclude that "this situation is ambiguous." 69 Yet this practice, which on its face does not seem sexual in the traditional sense, has already triggered actual charges of child sexual abuse in a number of jurisdictions..$^{70}$ Another issue that raises concern is "sexualized attention" or, as some clinicians describe it, "the 'gray area' between sexual abuse and normal interaction." " Activities in this domain include

tickling of various parts of a baby's body, rubbing noses, stroking a baby's buttocks and arm, allowing a baby to put his or her fingers into one's mouth, and playful interactions during diaper changes [when such behaviors are observed] in the context of repetitive patterns of interactions that are non-reciprocal and that appear to reflect parental needs rather than those of the baby. ${ }^{72}$

The primary concern is stimulation of a child's "erogenous zones." ${ }^{, 73}$ Yet, as we will see, identifying, much less regulating, these zones is more difficult than it seems. $^{74}$

Others might suggest that the expansive reach of child molestation statutes in the parental intimate care cases is simply an instance of what public policy scholars call definitional creep, a phenomenon in which standards used to define one social problem get stretched to accommodate a broader range of social problems. ${ }^{75}$ Criminal law scholar William Stuntz has expressed similar concerns, highlighting the seemingly ever-expansive reach of modern criminal law. As Stuntz explains, the categories of prohibited conduct defined by

68. BEST, supra note 31 , at 71.

69. Id.

70. See, e.g., Paquette v. State, 528 So. 2d 995 (Fla. Dist. Ct. App. 1988) (discussing allegations against father that he inappropriately exposed his child to his naked body); Hicks v. Larson, 884 N.E.2d 869, 872 (Ind. Ct. App. 2008) (discussing molestation allegations raised against grandfather based on practice of co-sleeping with granddaughter as well as allowing granddaughter to see him in the bathroom naked in the shower). The topic of family nudity has been explored in recent press coverage as well. See Aviva Rubin, Naked, With Children, MotherLODE: ADVENTURES IN PARENTING, N.Y. TiMES (Apr. 1, 2012, 8:48 PM), http://parenting.blogs.nytimes.com/2012/04/ 01/naked-with-children-but-for-how-long/ (discussing female parent's practice of walking around nude in her house around her eight- and twelve-year-old male children and the process in which families naturally establish boundaries on nudity issues).

71. Okami, supra note 5, at 51.

72. Id.

73. Id. at 52.

74. See Harrison-Speake \& Willis, supra note 15, at 85-86 (recognizing that there are no empirically derived norms that define normal parent child-intimacy and caregiving); Rosenfeld et al., supra note 23 , at 481 .

75. See BEST, supra note 31 , at 65 (describing the same phenomenon as discussed in sociological literature as "domain expansion"). 
criminal statutes tend to be interpreted by legal decision makers in ways that allow them to swallow ever-larger categories of so-called "wrongful behavior." ${ }^{, 76}$ But Stuntz chooses not to focus on the ways that definitional creep can be used in service of social stereotyping, the primary concern of our discussion here. ${ }^{77}$ For we know that child molestation law is not being interpreted in an arbitrary fashion. ${ }^{78}$ The amorphous definitions of sexual conduct in child molestation statutes were initially intended to address parental behavior that approximated in lesser degree the paradigmatic crime of sexual assault. ${ }^{79}$ Over time, however, some legal actors have redeployed these standards in ways that ensure we maintain certain gendered understandings of appropriate parental conduct and relatedly "appropriate" understandings of parental sexual modesty and children's sexual modesty. ${ }^{80}$

The strongest claim that can be made is that child molestation law in the current era of definitional creep has become the cover under which socially conservative actors use the criminal law to police and reform family intimacy practices. The more nuanced claim, made here, is that legal decision makers are interpreting child molestation law based on their unexamined views about gender, and as a result end up instantiating many gendered, socially conservative understandings about parenthood and family sexual modesty. Importantly, the legislative history of these statutes provides precious little evidence that legislators anticipated that child molestation prosecutions would trend in this direction. Instead, debate on child molestation law tended to focus on easier examples - cases involving incest and other kinds of parental sexual abuse that involved penetrative sex. Legislative debate seems to have only

76. William J. Stuntz, The Pathological Politics of Criminal Law, 100 MicH. L. ReV. 505, 509 (2001).

77. Stuntz's focus is on the political consequences of expansive and overlapping criminal offenses as they cede to prosecutors the power to both interpret and enforce the law. Id. at 518-19.

78. See KINCAID, supra note 28, at 79-80 (discussing political reasons for "definitional creep"); BEST, supra note 31, at 65-66 (describing the same phenomenon as "domain expansion").

79. See Kerwin Kaye, Sexual Abuse Victims and the Wholesome Family: Feminist, Psychological, and State Discourses, in Regulating SeX: The Politics of Intimacy AND IDENTITY 143, 147-48 (Elizabeth Bernstein \& Laurie Schaffner eds., 2005) (discussing initial feminist articulation of the problem as involving "father rape"). However, feminists also recognized that much of child sexual abuse does not involve penetrative sex acts that fit the technical definition of rape. Consequently, they welcome the use of broader language in child molestation and sexual battery provisions that allowed them to address behaviors other than forced heterosexual coitus committed by men but were experienced by victims as being sexually intrusive in similar ways.

80. I am the first scholar to raise questions about the gendered implications of broadly framed child molestation law and their consequences for the assignment of caregiving responsibilities. However, other scholars have recognized that these broad definitions can become a problematic source of state intrusion in families. See Bienen, supra note 11, at 1574-75 (recognizing the shift to broader definitions that "significantly expanded the definition of criminal sexual conduct, especially within the family"). Bienen recognizes that some legislators were concerned about criminalization of potentially trivial conduct within the family, but claims, without support, that these family care cases never materialized. Id. 
rarely touched on other kinds of parental intimacies as a source of concern. ${ }^{81}$ Yet it is also clear that legislators should have anticipated this development. As Stuntz explains, when legislators pass broad legislation, they give lower-level legal decision makers equally broad discretion to interpret the scope of a statute. $^{82}$ Interpretive responsibility effectively gets ceded to lower-level legal decision makers, such as prosecutors, police officers, and social service workers, as these legal actors must pick and choose what should be the focus of the criminal law's concern. One sees this dynamic on display in the intimate care cases as judges, jurors, prosecutors, and social workers are often actively working through their own conflicted views about gender and social norms about parenting as they decide how to handle these cases. They engage in these inquiries without being required to consider the broader risk of gender stereotyping in the parental intimate care cases or whether we have any shared understanding of the appropriate scope of parent-child intimacy. ${ }^{83}$

In summary, I argue that legal scholars must recognize that child molestation law is the arena in which gendered understandings of parenting are sedimented and enforced, as legal decision makers scrutinize contact between parent and child for evidence of illicit desire. In this inquiry, men are subject to more scrutiny based on the largely unexamined, but common-sense, view that they pose more sexual risk to children. Indeed, although psychologists' research on parent-child intimacy has historically problematized both mothers' and fathers' conduct, $^{84}$ the criminal cases show a more aggressive preoccupation with fathers' behavior. ${ }^{85}$ Stated alternatively, while many psychologists' analyses raising questions about parent-child intimacy have been gender neutral, their enforcement through the criminal law had a decidedly gender-specific articulation. ${ }^{86}$ This dynamic has immediate practical

81. See, e.g., Ruth E. Felker, Incest: The Need to Develop a Response to Intra-Family Sexual Abuse, 22 DUQ. L. REV. 901 (1984) (discussing concerns about explicit familial sexual abuse but declining to comment on concerns about other, more subtle kinds of parent-child intimacy); Kerry R. Callahan, Comment, Protecting Child Sexual Abuse Victims in Connecticut, 21 CONN. L. REV. 411, 415-16 (1989); Robert T. Mertens, Comment, Child Sexual Abuse in California: Legislative and Judicial Responses, 15 GOLDEN GATE U. L. REV. 437, 449-50 (1985).

82. Stuntz, supra note 76, at 518-19.

83. See Harrison-Speake \& Willis, supra note 15, at 85-86 (recognizing lack of empirically established consensus); Dorothy Scott, The Social Construction of Child Sexual Abuse: Debates about Definitions and the Politics of Prevalence, 2 PsychIATRY, PSYCHOL. \& LAW 117, 120 (1995) (showing that different racial groups historically have held very divergent views on parent-child intimacy).

84. Some psychologists have continued to assert that both parents (male and female) are at risk for engaging in sexual abuse, particularly in its more subtle form. See Summit \& Kryso, supra note 43, at 240 .

85. For examples, see cases discussed supra notes 55-61 (discussing courts' scrutiny of fathers involved in mundane tasks, such as bathing and toileting their children).

86. See Denov, supra note 16, at 303-14 (showing how "sexual scripts" that construct women as sexually passive distort prosecution and reporting rates of maternal sexual abuse); see also Christine Lawson, Mother-Son Sexual Abuse: Rare or Underreported? A Critique of the Research, 17 CHILD ABUSE \& NEGLECT 261 (1993) (discussing methodological problems and reporting bias that prevents 
consequences: fathers may avoid providing intimate care because they are anxious about the pall of sexual suspicion that surrounds men's caregiving activities. Alternatively, men may see social anxieties about the risk of improper behavior as giving them cover to opt out of taking on some of the messier and arduous parts of childcare. These problems suggest that the time is ripe for a discussion of how child molestation law has become an effective tool in reestablishing a certain gender orthodoxy in family relations.

\section{B. Intention Matters: How the Intent Inquiry Encourages the Use of Conservative Gender Norms}

\section{General Intent and Specific Intent Statutes}

Skeptics will argue that, although child molestation statutes may appear to have a dangerously broad reach, legislatures have strived for balance, as these statutes typically include specific protections for "normal" parent-child activities. Yet, close review suggests that these protections are more form than substance, as they tend to drag legal decision makers ever deeper into the effort to problematize mundane conduct. For example, states with general intent statutes, ones that criminalize any intentional touch legally defined as illicit, have created reasonable caregiver exceptions, which allow a parent to raise an affirmative defense that the practice he is accused of should be immunized from prosecution. ${ }^{87}$ States with specific intent statutes feature laws that require that touch be motivated by sexual or otherwise illicit intent before it is eligible for prosecution. These statutes provide that a parent can defend by showing that he is acting based on a desire to provide appropriate care, and therefore that he did not have the "illicit intent" necessary to be convicted under a state's child molestation statute. ${ }^{88}$ Importantly, however, there are no categorical exceptions for "typical" parent-child interactions under either the general or specific intent inquiry. ${ }^{89}$ Instead, in the intimate care cases, standard, mundane childcare

the criminal justice system and social welfare authorities from properly addressing maternal sexual abuse of male children); Tracey Peter, Speaking About the Unspeakable: Exploring the Impact of Mother-Daughter Sexual Abuse, 14 VIOLENCE AGAINST WOMEN 1033 (2008) (discussing maternal sexual abuse cases involving female children). Although the psychological literature tends to concentrate on the ways in which sexual stereotypes discourage reporting of crimes perpetrated by women, my contention is that sexual scripts about men allow the characterization of apparently nonsexual behavior as potentially sexually motivated.

87. See, e.g., Alaska StAT. § 11.81.900(b)(58)(B) (2010); CAL. PENAL CODE $\S$ 11165.1(b)(4) (West 2012); Fla. StAT. ANN. §§ 39.01(67)(d)(1), 415.102(25) (West 2012); TENN. CODE ANN. § 37-1-602(a)(3)(C) (2010); VT. STAT. ANN. tit. 33, § 6902 (2012); WASH. REV. CODE $\S \S$ 26.44.015 (2012); WASH. REV. CODE 26.44.020 (2012).

88. See, e.g., Cal. Penal Code $\S$ 288(a)-(c) (West 2012); LA. REV. Stat. AnN. § 14:81 (2010) (requiring the intent to "arous[e] or gratify[] the sexual desires of either person").

89. The sole exception to this general rule is breastfeeding. In a small number of jurisdictions, mothers enjoy statutory protection that establishes that no child molestation or public indecency charge may be brought based on breastfeeding. See, e.g., FLA. STAT. ANN. § 827.071(1)(h) (West 2012) (recognizing that a child sexual abuse charge must be based on sexual conduct). The statute further 
practices are mined for evidence of whether they are "reasonable" or present a risk of sexual impropriety.

Consider Alaska, for example, a general intent jurisdiction with a statutory "normal caregiver" defense for parents. ${ }^{90}$ On its face, the statutory defense seems to offer broad protection: it requires jurors to decide whether the defendant's action "may reasonably be construed to be normal caregiver responsibilities." The parent must be acquitted unless "no reasonable person would construe the defendant's act as normal caretaking." "92 The statute quite reasonably recognizes that there may be a range of parenting norms in a particular jurisdiction. It therefore ensures that parents subject to a child molestation inquiry are given a fair degree of latitude when jurors assess their conduct. However, in the course of establishing this "protection," the language of the statute only confirms the primary point being made here: even the most routine of childcare practices will still be reviewed to determine if it is being conducted in a manner that matches a range of socially accepted practices. Additionally, because the statutory inquiry does not require legal decision makers to consider how gendered understandings inform their views about parenting norms, it allows them to make decisions about the appropriate scope of fatherly care without considering the social backdrop against which these parenting norms are formed. Fathers are forced to hope that the legal decision makers reviewing their cases come to these inquiries with progressive understandings about gender-neutral parenting, but there is nothing built into the statutory inquiry to ensure that anything other than socially conservative gendered understandings control.

Fathers fare little better under specific intent statues, as these statutes also play the same social norms enforcement role. Regarded by some as a more parent-protective approach to child molestation questions, fathers in the specific intent cases often fall prey to social stereotypes because circumstantial evidence is typically used to prove specific intent, and the evidentiary basis provided is often exceedingly thin. Specifically, courts recognize that perpetrators in child molestation cases often will not make statements that establish their specific intent. ${ }^{93}$ Jurors therefore have little else to rely upon

explains that "[a] mother's breastfeeding of her baby does not under any circumstances constitute 'sexual conduct." Id. This exclusion seems particularly overbroad, as it is clear that some concerns for the child's sense of sexual privacy or objective norms might suggest that we raise concerns about breastfeeding older children. However the existence of breastfeeding exclusions merely proves my larger point, that the law grants more space and discretion for mothers to engage in caretaking and intimacy in a way not enjoyed by fathers.

90. See, e.g., AlASKA STAT. $§ 11.81 .900(\mathrm{~b})(58)(\mathrm{B})(2010)$.

91. See Peratrovich v. State, 903 P.2d 1071, 1074 (Alaska Ct. App. 1995).

92. Id. at 1075 (challenging constitutionality of reasonable caregiver provision on vagueness grounds).

93. See, e.g., State v. Bronson, 732 P.2d 336, 369 (Idaho Ct. App. 1987) (rejecting defendant's challenge to child molestation conviction because specific intent was proven in his case through the common approach of examining the defendant's acts and conduct in context). 
except the context in which the conduct occurred. ${ }^{94}$ While this context-based inquiry might prove helpful in identifying certain cultural scenarios that are explicitly sexual in nature, it becomes a vehicle for sex-role stereotyping when analyzing intimate care interactions. That is, when a father, like the one in Emmett, faces a sexual abuse charge based on mundane caregiving activities like bathing, often nothing about the context suggests something sexual occurred. In these cases jurors implicitly are making a determination about whether a father's touch is welcomed in such circumstances.

\section{The Proper Role of Social Norms}

The social norms inquiry used in child molestation cases need not be deemed inherently problematic. ${ }^{95}$ Problems stem from the fact that its contours have not been adequately fleshed out by scholars or by the courts. For we have not yet fully considered the repercussions of using a social norms framework as a tool for identifying sexual abuse injuries. Are we prepared to disregard the privacy claims of a mother and child when they claim that a father's decision to bathe with a child is not injurious, even when third parties witnessing the event would deem his actions to violate social conventions? ${ }^{96}$ What about when the mother is disturbed by the father's bathing practices, but many third parties would view his actions as normal? When should the parent be charged with a crime? In cases where social norms play a controlling role, prosecutions raise important questions about parental autonomy in negotiating parental roles. In contrast, in cases where the maternal caregiver's views about what constitutes appropriate care play a central role in a court's analysis, the social norms analysis gives legal imprimatur to what psychologists call maternal gatekeeping, ${ }^{97}$ a practice that forestalls the gender-neutral evolution of parenting roles. Additionally, many of the intimate care cases involve caregiving activities, such as diaper changes and bathing, for which no clear,

94. It could be argued that specific intent jurisdictions provide more protection for parents with seemingly idiosyncratic parenting practices. $C f$. Levine, supra note 9, at 46 (arguing that culture affects family caregiving practices and is a necessary part of the intent inquiry in child molestation cases involving cultural minorities). However, idiosyncratic parenting practices are often assumed to reflect sexual interest, leaving parents in both general and specific intent jurisdictions with the same burdens of persuasion.

95. The term "social norms" is used interchangeably with "community norms."

96. See, e.g., In re Parentage of S., 117 Wash. App. 1036 (2003) (concluding that, although mother granted boyfriend permission to co-bathe with her child, the practice was still a basis for sanctions).

97. Psychologists define maternal gatekeeping as actions taken by mothers that make fathers feel inadequate about their ability to provide childcare. See Sarah M. Allen \& Alan J. Hawkins, Maternal Gatekeeping: Mothers' Beliefs and Behaviors That Inhibit Greater Father Involvement in Family Work, 61 J. MARRIAGE AND FAM. 199, 202 (1999) (discussing mothers' resistance to relinquishing responsibility over tasks as being expressed through their establishment of rigid guidelines for the performance of certain tasks); Naomi Cahn, The Power of Caretaking, 12 YALE J.L. \& FEMINISM 177, 206-08 (2000) (describing the internal conflict between mothers' reinforcement of gender roles and their desire for fathers to be more involved in parenting). 
widely accepted social norm has emerged. When mothers engage in these activities, courts tend to grant them a fair degree of discretion; however, when fathers perform these tasks, courts begin to ask questions about whether the caregiver has conformed to some heretofore-unarticulated social norm. At bottom, the social norms cases present a risk of gender stereotyping because courts do not require decision makers to reflect on the ways that parents' roles, which historically have been gender-specific, are instantiated in the cultural imagination. By representing these cases as being about "intent," the formal legal inquiry hides the degree to which gender norms set the context for intimate care and tend to make such care the appropriate province of mothers rather than fathers.

Some may argue that the social norms inquiry, while troubling, is critically necessary, as it is the only way to catch illicitly motivated parents attempting to game the system. For the social norms inquiry provides a way to analyze the actions of the savvy molester who attempts to find a way to sexually titillate himself with a child by tracing the margins of what is legally prohibited. Also, child welfare advocates and feminist legal scholars argue that there is a broad range of conduct that can trigger concerns about sexual intrusion. $^{98}$ The social norms inquiry can provide a key touchstone in determining the law's role in identifying troubling parenting practices. Defenders of the social norms inquiry also argue that the inquiry allows us to sanction those parents who use "normal" childcare as a cover for sexual gratification. ${ }^{99}$ As one California court explained, "It is common knowledge that children are routinely cuddled, disrobed, stroked, examined, and groomed as part of a normal and healthy upbringing. On the other hand, any of these intimate acts may also be undertaken for the purpose of sexual arousal. ${ }^{~ 100} \mathrm{~A}$ social norms analysis gives us a way to more tightly assess mundane activity that may be undertaken for illicit reasons. Last, some will argue that the social norms inquiry provides the best means of ensuring that the state can address parental activity that really functions as a gateway to sexual abuse. Admittedly, some parents may use mundane caregiving as a cover for sexual abuse grooming - as a way of desensitizing their children to intimate conduct that is a precursor to sexual abuse. Arguably, a departure from established caregiving conventions might signal that abuse has or is about to occur.

The concerns outlined above are real and deeply disturbing. Additionally, many of these concerns are well attended to under a legal inquiry that is based on a social norms analysis. However, we should not assume that a child

98. See ABA REPORT, supra note 8, at 13-14 (offering guidelines for potential criminal child sexual abuse statutes).

99. See In re Y.B., No. A115982, 2007 WL 2309798 (Cal. Ct. App. Aug. 14, 2007) (concluding mother used diaper change as cover to explain why she engaged in illicit touch of child's genitals); State v. Blackburn, 643 A.2d 224 (Vt. 1993) (affirming conviction of father who used diaper change and puppet play as cover for illicit sexual touching of child).

100. People v. Martinez, 903 P.2d 1037, 1046 (Cal. 1995). 
protection regime premised on social norms is costless to children and parents. Rather, it is clear that our current inquiry, which attempts to identify grooming or marginal child molestation cases undertaken in the context of routine care, now threatens to sexualize caregiving practices to such a degree that it is no longer clear what constitutes appropriate or morally blameless conduct. Certainly, one of the benefits of a social norms analysis is that many decision makers will recognize that gender norms about parenting are currently in flux, and they may be willing to recognize more progressive gender-neutral parenting norms. Indeed, in some of the parental care cases, courts appear to recognize the growing support for norms that encourage fathers to engage in activities that have historically been the domain of mothers. However, these same courts show a dogged refusal to acknowledge the role that gender plays in making determinations in the intimate care cases. Their failure to make gender a formal part of the social norms analysis leaves fathers at the mercy of the social prejudices of individual legal decision makers as they find them. ${ }^{101}$

\section{The Rise of Sexual Privacy Logic}

Courts that do not use an explicit social norms analysis have offered a different understanding of sexual harm-one based on sexual privacy. However, the sexual privacy inquiry raises related concerns, for close analysis reveals it to be an example of what Reva Siegel describes as "preservation through transformation." " language to further the same interpretive project that the social norms inquiry historically has played: it preserves conservative understandings regarding gender-specific parenting roles.

Sexual privacy is a concept courts use to describe a child's interest in being protected from interactions that make him aware of his sexuality or of the fact that his body might be a site of sexual interest. ${ }^{103}$ The sexual privacy concept is deployed in two ways in child molestation cases. In the first category of cases, an objective definition of sexual privacy is used. Courts cordon off certain kinds of touch as inherently violative, regardless of whether the child

101. For examples, see the cases discussed infra Part I.C.

102. Reva Siegel, Why Equal Protection No Longer Protects: The Evolving Forms of StatusEnforcing State Action, 49 STAN. L. REV. 1111, 1113, 1119 (1997).

103. Some courts have offered insight into the inchoate nature of the sexual privacy issue. For example, one court explained:

Normal interplay between parent and child, particularly in the early stages of a child's development often involve acts of touching, squeezing, patting, and pinching various parts of a child's body including buttocks and at times genitalia. The difference is that what might be socially acceptable when a child is an infant or toddler, becomes less so as a child grows older and becomes more aware of himself as a separate human being. Thus a parent's respect for the child's right to the privacy of his person should increase as the child grows and matures. Some parents however, lack this understanding in child development and persist in dealing with an older child with the same kind of intrusive handling as when the child was an infant.

In re Michael M., 591 N.Y.S.2d 681, 683-84 (N.Y. Fam. Ct. 1992). 
makes a complaint. In this category of cases, the sexual privacy logic functions nearly identically to a traditional social norms analysis. In the second, more dangerous set of cases, a subjective definition of sexual privacy is used. ${ }^{104}$ These touches may concern pre-defined sexual areas of the body or involve other, less socially charged domains. ${ }^{105}$ In these cases the child's complaint of sexual touch plays a key role, as the complaint is viewed as proof positive that the caregiver has acted with illicit intentions.

Indeed, the subjective sexual privacy concept plays a critical role in the parental intimate care cases involving fathers, as the concept allows the court to attribute sexual intent to a parent's routine care whenever a child is disturbed by the parent-child interaction. The atmosphere created by the subjective sexual privacy inquiry in this way tends to drive men away from caregiving, as it is the mechanism by which a father's participation in mothering care can be converted into pathological activity. However, there are reasons to take a more nuanced approach to children's subjective sexual privacy complaints. First, the psychological literature suggests that young children often have difficulty distinguishing between mere unwanted touch and touch motivated by illicit sexual interest. ${ }^{106}$ Consequently, a child may attribute sexual motivation to a caregiver's touch merely because she experiences discomfort. Further complicating matters, the sexual abuse inquiry currently fails to maintain a distinction between a child's complaints about cross-gender contact versus her claims of sexual violation. For example, when a female child complains she does not want a bath from a particular male caregiver, she may be expressing gender-based discomfort, but not alleging sexual violation. Unfortunately, legal decision makers often are quick to make the interpretive move from a claim of

104. Courts occasionally comment on the difficulties associated with identifying prohibited parent behavior. One New York court explained:

[W] hen the challenged conduct is the touching of a child by a parent, the consideration of whether the contact was for sexual gratification must take into account the nature and circumstances of the act, since the same conduct which constitutes an act of sexual abuse by a stranger could be a mere expression of affection on the part of a parent.

In re A.G., 686 N.Y.S.2d 396, 401-02 (N.Y. App. Div. 1997).

105. Some parents adopt this understanding of subjective sexual privacy to guide their interactions with their own children. See Rubin, supra note 70 (discussing family nudity standards as family specific, continually evolving, and ideally determined by the child's comfort level when raised in an atmosphere that does not promote shame about the body). However, the decision to adopt this approach may change if the child actually were to bring claims against a parent based on the sole proposition that the child's subjective sense of sexual privacy was violated.

106. See Deborah A. Daro, Prevention of Child Sexual Abuse, 4 THE FUTURE OF CHILDREN 198, 205 (1994) (“[P]reschool children simply lack the developmental skill to differentiate among gray areas of behavior and will attribute 'goodness' based on the outcome of an act."). Daro compiles a number of studies with mixed findings, but notes that some researchers express "particular concern" about "the substantial number of children, particularly in the youngest age groups, who fail to grasp the knowledge or skills being taught." Id.; see also Belle Liang et al., Differential Understanding of Sexual Abuse Prevention Concepts Among Preschoolers, 17 CHILD ABUSE \& NEGLECT 641, 648 (1993) (recognizing that young children may have difficulty cognitively identifying good touch versus bad touch and suggesting that their understanding of bad touch may be primarily based on affective responses). 
discomfort to a claim of sexual violation, without considering the importance of maintaining this distinction. I argue that we must become better at sorting out these two distinct problems, as well as respond more appropriately to this distinction. The process is imperative if we are to find the space necessary to allow us to renegotiate some of the gendered understandings that are at the heart of both the objective and the subjective sexual privacy inquiry. Last, children develop their personal, subjective views about sexual privacy in the context of "good" and "bad" touch instruction, which may encourage children to adopt gendered understandings of parenting. ${ }^{107}$ This sexual abuse instruction, in the hands of conservative social actors, effectively cordons off certain types of touch and practice as the domain of female caregivers.

In summary, courts that utilize a subjective sexual privacy logic in intimate care cases often claim that they are merely "listening to children." In reality, however, they are sometimes giving legal force to socially constructed, gendered understandings of touch that should be questioned. By uncritically adopting the child's complaint as proof of the caregiver's illicit intent, the court is effectively adopting certain culturally specific understandings about sexual privacy, allowing the child molestation analysis to piggyback on reductionist, often heterosexist, and occasionally homophobic understandings of sexual harm.

An additional concern about subjective sexual privacy analysis is that fathers subject to this kind of complaint have little notice ex ante about what might trigger legal sanction. They also have little ex post recourse when a child finds touch offensive, a particularly troubling result when they are accused based on mundane caregiving behavior. These concerns loom large for socially vulnerable fathers, as they understand that when a child makes a complaint about their behavior, this complaint is much more likely to blossom into full legal proceedings. The potential threat of state intervention can also be used by other legal actors to make these socially vulnerable fathers stop engaging in certain caregiving activities altogether. Also, the subjective sexual privacy inquiry is troubling because it allows courts to avoid facing the broader social implications of how they resolve children's complaints regarding sexually intrusive touch. By framing the inquiry in this way instead of using a social norms analysis, courts avoid considering how-collectively and over the long term-decisions disqualifying fathers from providing certain kinds of care will drive fathers away from caregiving. The uncritical use of children's subjective understandings of sexual privacy presents a risk to the evolution of parenting roles beyond established traditional gender norms.

107. See Daro, supra note 106, at 215 (explaining that children exposed to sexual abuse education sometimes develop "negative attitudes toward not only clearly negative touches (for example, hitting) but also rather benign or natural touches (for example, tickling and bathing)"); Liang et al., supra note 106, at 641, 648 (discussing young children's difficulty applying "good" versus "bad" touch instruction). 
Finally, like the social norms analysis, the sexual privacy logic suffers from being radically undertheorized. Specifically, we have not considered how much respect we are willing to grant a child's subjective sense of sexual privacy. In the parental intimate care cases, a focus on subjective understandings of sexual privacy calls on us to ask: when a child experiences a bath as sexually intrusive or offensive, is her complaint sufficient to establish that sexual abuse has occurred? Should we still respect the child's sense of privacy and conclude that molestation has occurred if the child's mother watches the father giving the child a bath and concludes his actions are harmless and normal? As a culture, we must resolve how far and under what circumstances we are prepared to respect a child's understanding of sexual privacy. Yet, in some jurisdictions prosecutors are primarily motivated by this interest in children's understandings of harm, even in cases involving young children who are just beginning to develop these understandings.

Some will defend the use of a sexual privacy analysis in the intimate care cases. They will argue that, even if our notions of sexual privacy are based on somewhat dated gender norms, persons who hew to these traditional gender understandings still experience psychological injury when their views about sexual privacy are disturbed by cross-gender contact. They may rightly argue that we should not work through our social experiment regarding genderneutral parenting roles on the backs of children, a vulnerable constituency that is relying on adults for protection. Proponents of this view would further argue that, even if our legal enforcement of sexual privacy understandings confirms social stereotypes about gender, this is an unavoidable and acceptable cost of our effort to protect children. While this position is understandable, I believe that it forces us to concede far too much in the project of gender equality. In my view, it will be impossible to disrupt cultural understandings about sex-specific parenting roles if we do not interrogate our views about sexual privacy. Parents simply will not have the space to renegotiate default caregiving norms if children's gendered understanding of sexual privacy functions as the final word on whether a caregiving practice can be ceded to a male caregiver.

In summary, this Section has shown that the subjective sexual privacy analysis represents a dangerous shift for fathers. It has opened the door to a variety of prosecutions for conduct that historically has not been seen as morally problematic. In contrast to the more developed conversations about social norms governing gender-neutral parenting, the role of sexual privacy in these debates has gone unexplored. Since the contours of children's sexual privacy interests are in flux and fundamentally unresolved, fathers do not have clear notice of what would be considered legally appropriate behavior. As a 
consequence, we find that fathers who dare to mother have a limited range of discretion. $^{108}$

\section{Reversing the Groups: Case Studies on the Gender Norm Enforcement Power of Child Molestation Statutes}

This Section presents a series of case studies that reveal the heavy pall of sexual suspicion that hangs over fathers in the parental intimate care cases. Drawing from a range of jurisdictions, this Section shows that when child molestation law is applied in the parental intimate care cases, men who dare to mother are subject to a higher degree of disciplinary scrutiny than their female counterparts. Regardless of whether a social norms analysis or a sexual privacy logic guides courts' inquiries, men who mother are held to a higher standard in defending the legitimacy of their conduct. To highlight the contrast, the cases presented here address activities that some would describe as the basic (if less glamorous) aspects of mothering: toileting, bathing, and the giving of kisses. ${ }^{109}$ Admittedly, the analysis is not comprehensive, as I have chosen to focus on compelling cases involving routine, mundane conduct, rather than attempt to give a full account of how the law is applied in any particular jurisdiction. Also, the analysis is not a pure treatment of how criminal courts apply criminal standards. Instead I explore how civil disputes take up and turn on the criminal law standards, in an effort to show the wide variety of ways in which the criminal law shapes the experience of fatherhood. As we will see, although many accused fathers are not subject to criminal prosecution, the criminal law is used to structure a variety of civil proceedings including child custody and visitation disputes, ${ }^{110}$ termination of parental rights cases, and abuse and neglect proceedings.

108. Psychologists and sociologists who study the relationship between caregiving and sexual abuse have voiced concern about this very problem. Psychologists Johnson and Hooper explain:

The limited age range during which fathers are "allowed" to interact in certain family practices with their own children may be supported by concern in the United States about the potential sexual deviance of men if they are given too much access to children, particularly when nude. In this era of focus on sexual abuse, this concern about men may be subtly eroding their comfort with their young children and may be decreasing the amount of physical contact men have with their children. This could have a negative effect on fatherchild attachments, particularly for father-daughter relationships.

Johnson \& Hooper, supra note 15 , at 121-22.

109. The activities listed above are described as mothering activities based on the wellestablished cultural understanding that mothers are expected to attend to these particular needs. Johnson and Hooper provide an alternative, but similar, framework for sorting through the family intimacy and caregiving cases that become the subject of sexual abuse prosecutions. They distinguish between hygiene practices (bathing and diaper changes), intimacy practices (affection), and sexual privacy (being exposed to parental nudity). The authors found that, for all of these practices, fathers were granted less discretion to engage in the behavior in question and that concerns were greatest with cross-gender pairs involving fathers and daughters. See Johnson \& Hooper, supra note 15, at 115-18.

110. Hicks v. Larson, 884 N.E.2d 869, 874-75 (Ind. Ct. App. 2008) (refusing visitation rights for grandparents in response to sexual abuse allegations). 
As we review each set of cases, you will be asked to reverse the groups ${ }^{111}$ to consider whether a mother in the same position would have been subject to claims of illicit sexual interest. Also consider how the particular interpretive framework used in each case presents distinct risks for fathers, whether a sexual privacy or a social norms analysis is used. On the whole, the examples suggest that the intimate care cases will play an important role, either encouraging or stymieing the movement toward gender-neutral parenting norms. The fathers involved in these cases, regardless of whether they are ultimately vindicated, are likely to find that the scrutiny and sanctions they face pose a substantial impediment to continuing to mother. ${ }^{112}$ That is, regardless of the ultimate outcome in a case, fathers have already been subjected to a disciplinary project that makes them feel suspicious for being a father that provides intimate care.

\section{Toileting}

Mothering can be a dirty business. Its less glamorous side is rarely discussed in law review articles, but when it becomes a site for legal sanction, mothering practices must be closely explored. In addition to classic nurturing activities - singing, games of patty-cake, and play in the park - one of the primary caregiving duties that mothers attend to is the toileting of their children. What happens to fathers who take on these responsibilities? One might expect that the toileting cases would be easy to resolve. Presumably, American toileting practices are fairly standard; consequently, borderline cases that involve illicit activity should be easy to identify. Yet when fathers wade into this field of action, one discovers that toileting requires far more discretion and judgment than the uninitiated might imagine. Moreover, the discretionary judgment freely exercised by mothers becomes far more suspect when exercised by a male caregiver. Indeed, when male caregivers are involved in toileting, legal decision makers are willing to presume sexual interest in rather surprising circumstances.

111. See David A. Strauss, Discriminatory Intent and the Taming of Brown, 56 U. CHI. L. REV. 935, 956-65 (1989). Feminist scholars have conducted a similar kind of analysis by "asking the woman question"- considering how facially neutral statutes have gendered effects when applied, in light of contemporary social conditions. See Katharine T. Bartlett, Feminist Legal Methods, 103 HARV. L. REV. 829, 837-49 (1990). Here we would be called upon to "ask the fatherhood question." However, I have chosen Strauss's "reverse the groups" formulation instead, because this framework asks us to consider the privileges afforded to the culturally dominant group (here mothers) and whether they should be extended to fathers, as well as assume that the law should be broadened to accommodate the distinct practices and interests of an excluded group.

112. See Markiton v. State, 139 N.E.2d 440 (Ind. 1957) (reversing conviction of father for sexually assaulting his daughter). 
a. In re D.C.

In our first toileting case, In re D.C., the Vermont Supreme Court was asked to review how a divorced, non-custodial father had attended to his fouryear-old daughter's constipation problems during a visit to his home. ${ }^{13}$ The stakes were high for the defendant father, as he was appealing a family court decision establishing that his conduct constituted sexual abuse and ordering him to participate in sex offender treatment and submit to a psychosexual evaluation. ${ }^{114}$ The facts in the case were not in dispute. The daughter suffered from a medical condition that caused her to experience recurrent constipation. Sexual abuse allegations were triggered when one day the girl exited the bathroom at her mother's home with feces on her legs. ${ }^{115}$ When her maternal grandfather inquired how she had soiled herself, she responded that she had stuck a small stick into her rectum to relieve the constipation, but that the practice was "okay" because her father had done this to her as well. ${ }^{116}$ The child's mother then reported the father's actions to child welfare authorities. The accused father acknowledged that he had used a "small stick" to relieve the child's constipation, but argued that he was motivated by a nonsexual reason. ${ }^{117}$ The family court, however, determined that, based on the child's disclosure and a psychologist's report indicating that the child had a few features correlated with abuse victims, the father's actions must have been motivated by illicit or sexual intent. Based on these facts, the family court concluded that he had sexually abused his daughter. ${ }^{118}$

Reversing the groups in In re D.C. easily reveals the role gender stereotyping plays in assessing fathers' caregiving practices. One is forced to ask, would a mother who attempted to relieve a child's constipation in this manner find herself so easily branded a child molester? Certainly, there are far better ways to attend to a child's constipation problems than the method the father used here, but would a mother's failure to exercise the best judgment devolve as quickly and surely into the claim that she had chosen this approach for sexual reasons? In re D.C. is also our first opportunity to consider how a father fares when the court adopts an objective social norms analysis. For the daughter did not report being physically or psychologically injured by the father's actions, and therefore no subjective sexual privacy claim was made. ${ }^{119}$ Instead the family court looked at this act of toileting in the abstract and concluded that the father had inserted the stick into his child's anus for sexual

113. 648 A.2d 816 (Vt. 1993).

114. Id. at 817 .

115. Id. at 816 .

116. Id.

117. Id. at $816-17$.

118. Id. at 817 .

119. Indeed, one might conclude the child may have even found the father's approach to relieving her constipation to be helpful, as she turned to the practice herself the next time she experienced constipation. 
reasons. The social norms analysis fails to provide the father with protection precisely because this kind of activity is routinely handled by mothers and there is no clear social standard about how to provide this kind of toileting care. In the absence of such norms, the court's discomfort with a male caregiver providing care subsidizes its finding that sexual interest must have motivated the father's actions. ${ }^{120}$

Importantly, although the father in In re D.C. was ultimately vindicated, the litigation process had a disciplining effect that unquestionably changed his experience of fatherhood. The father learned that any deviation from his former wife's preferred childcare practices could require him to refute suspicions of sexual motivation in the highest court in the state. The dispute also demonstrated to the father how easily routine caregiving tasks could be represented as attempts at sexual titillation, and further, that his former wife could engage the court as an ally in the maternal gatekeeping process.

\section{b. Hicks v. Larson}

Our next example is Hicks $v$. Larson, ${ }^{121}$ a case in which a court extinguished the visitation rights of a maternal grandfather to his two-year-old granddaughter after it concluded that there was evidence that the grandfather had sexually molested her. ${ }^{122}$ The grandfather was subject to a broad range of diffuse allegations regarding his conduct, as he had allowed his granddaughter to sleep alone with him in bed, and let her walk into the bathroom while he was naked in the shower. ${ }^{123}$ But the case ultimately hinged on an instance in which he applied diaper cream to her genitals. ${ }^{124}$ The grandfather argued that there was no basis for extinguishing his rights, as there was no evidence that he had applied the diaper cream to his granddaughter for sexual reasons. ${ }^{125}$ The court disagreed. It explained that the grandfather had only proved that he applied the cream in the context of a diaper change at the instruction of the child's grandmother. ${ }^{126}$ However, he had not proved that this was the sole reason that

120. In re D.C. also demonstrates the ways in which a child's frank speech about bodily functions, or her demonstration of seemingly inappropriate knowledge, can trigger inquiries about a father's activities. The child's frank speech about her constipation and her anatomy is part of what triggered her mother and grandfather to conclude something is wrong. Yet, if a child displayed similar knowledge in connection with a mother's actions, a legal decision maker would be less likely to jump to the conclusion that she had been sexually injured.

121. 884 N.E.2d 869 (Ind. Ct. App. 2008). Importantly, in an earlier grand jury proceeding the grandfather had seemingly been cleared of the allegations regarding his potentially inappropriate behavior. However, the court set this finding aside for the purposes of the civil inquiry regarding his visitation rights. As a consequence, the grandfather was still sanctioned for his conduct by the appeals court in the visitation proceedings, even though he was able to convince a jury of his peers that there was insufficient basis to charge him with misconduct.

122. Id. at 873 .

123. Id. at 872 .

124. Id. at 876 .

125. Id.

126. Id. 
he applied the diaper cream. ${ }^{127}$ Consequently, the child's father had sufficient basis to believe the grandfather had sexually abused the child, and the court entered an order terminating the grandfather's visitation. ${ }^{128}$

In Hicks, reversing the groups again reveals the role gender stereotyping plays in the intimate care cases. Would a grandmother, or mother for that matter, be asked by a court to establish that her sole reason for applying diaper cream was for hygienic reasons? As a practical matter, how could this evidentiary burden be satisfied? Hicks additionally reveals the problems with an objective social norms analysis, as there is no clear standard that governs the application of diaper cream or changing diapers more generally, and consequently no objective standard against which to compare conduct. The court failed to recognize that women who perform these tasks typically are afforded a fair amount of discretion. However, when men take on these responsibilities, their behavior is subject to special scrutiny, and courts are far more willing to read sexual interest into their actions. The court's failure to acknowledge the role gender plays in Hicks makes it appear that the suspicion attached to Hicks's conduct was simply a manifestation of the complaining father and stepmother's well-meaning concern. Instead, the court effectively endorsed a general social anxiety about male caregivers' involvement in intimate care as well as about family sexual boundaries. ${ }^{129}$

\section{c. Montgomery County Department of Health and Human Services v. P.F.}

Our last toileting case, Montgomery County Department of Health and Human Services v. P.F. ${ }^{130}$ shows how the subjective sexual privacy inquiry creates special challenges for fathers, which it does not create for mothers. In Montgomery, a divorced noncustodial father faced diffuse child molestation allegations that stemmed from his decision to wipe his daughter's vagina with napkins after he allowed her to squat to urinate in a public park near the local McDonald's. ${ }^{131}$ The allegations soon evolved into a more concrete claim, that he had inserted his finger into the child's vagina while wiping her. ${ }^{132}$ Child

127. Id.

128. Id.

129. Indeed, certain facts in the Hicks case suggest that family intimacy boundaries were being renegotiated between the children's custodial parents and their biological grandparents. Specifically, the case came to the attention of authorities because the children's stepmother was concerned about the overly casual way in which the grandfather discussed sex with his female grandchild, and she convinced her husband (the children's biological father) to report the grandfather's behavior to authorities. The children's stepmother was particularly concerned because one of her stepdaughters had begun to masturbate and the child reported that her grandfather had told her that it was okay to do so because her deceased mother (his biological daughter) had engaged in similar behavior when she was a child. The little girl explained, "Pawpaw [Grandpa] says Mimi [deceased mother] played with her pee pee when she was little. And I can too." Id. at 872.

130. 768 A.2d 112 (Md. Ct. Spec. App. 2001).

131. Id. at 115 .

132. Id. 
Protective Services was adamant that the father had abused his child, appealing two adverse lower court decisions. Importantly, although the father in Montgomery was ultimately vindicated, the case is telling because it shows that legal decision makers identify subjective sexual privacy complaints using a gender-based filter that treats children's complaints about their mothers as mere white noise. This process is revealed as the court summarizes the child's exchange with the investigating social worker:

When asked if her mother has talked to her about people not touching her, [Susan] said "yes". When asked if anybody touched her that she didn't like, she said "no". When asked if people wiped her in the bathroom, [Susan] said, "No I wear pants." And when asked if anyone had hurt her pee-pee, the girl answered Mom. When asked where, she said at home. [Susan] was [again] asked if anyone had tickled her peepee, she answered "no". And when asked if her Daddy tickled her peepee, the girl said, "No, he put his finger inside my pee-pee." The girl said that it happened at Uncle McDonald's, which is what she calls McDonald's restaurant. She stated that her father was carrying her in his arms, outside of the McDonald's going in. When asked if it hurt, the girl replied that it did. And when asked if her father had stuck his finger under her pants the girl again said, "yes", and when asked if her father put his finger inside her pee-pee she again said, "yes, inside."133

Reversing the groups in Montgomery again makes the gender bias clear. Would a mother who wiped her daughter's vagina after the child relieved herself in a public park then find herself accused of having acted based on sexual interest? Would the child's testimony, as documented here, have morphed into the social worker's claim that the child had complained that her parent had digitally penetrated her while carrying her into a McDonald's? It seems unlikely, particularly given that the administrative worker simply ignored the child's clear statement that her mother's touch had also injured and offended her. Certainly, the mother's toileting decisions might be criticized as poor parenting if she had allowed her child to urinate in a public place, but it is highly unlikely these criticisms would evolve into sexual abuse allegations.

The Montgomery court's decision to ignore the child's complaint about her mother's conduct seems particularly remarkable when we contrast the case against others featured in this discussion, in which a mother's touch is figured as the ideal. Fathers may rightly conclude that mothers are given favored treatment in the intimate care cases. A mother's touch is rendered invisible in the intimate care cases when it is injurious or annoying, but it becomes central to the case when the mother's touch is offered as the ideal reference point against which all acts of fatherly caregiving must be measured. The Montgomery case is also notable because it reveals the risk in subjective sexual privacy cases that a legal decision maker will convert a child's more general

133. Id. (emphasis added). 
complaint about unwanted touch into a claim of sexual violation. Montgomery teaches that fathers' annoying touches are more likely to be interpreted as sexual; mothers' annoying touches are treated as an unavoidable part of childhood.

The cases described in this Section are particularly compelling, but they are not outliers. A review of the intimate care cases shows that a large number concern seemingly mundane toileting scenarios, bathing incidents, or diaper changes that trigger complaints from children, and that these complaints are taken as proof positive that a father has engaged in abuse. ${ }^{134}$ Yet, as anyone who has cared for a child knows, children touch themselves, show irritation, and display a host of behaviors that suggest pleasure, pain, and growing impatience with being touched. One could argue that diaper changes, given the need for genital contact, are a thornier site for analysis. But as the next Section makes clear, the problem of gender role stereotyping resurfaces in a variety of other areas.

\section{Bathing}

In our next set of cases we move away from our less glamorous inquiry into toileting practices to inquire about an activity characterized as the site of bubbles and fun: the child's daily bath. But those unfortunate fathers subject to legal scrutiny find that intimacies exchanged in this space can be a source of legal trouble; it is yet another moment for their innocence to be interrupted about the exchange of touch between father and child. In these cases, one can see the growing power of the subjective sexual privacy analysis in the intimate care cases, and the need for further theorization of this understanding of molestation and harm.

\section{a. In re Julia B.}

The first bathing case featured, In re Julia B., ${ }^{135}$ arose in the context of abuse and neglect proceedings where child welfare authorities alleged that a four-year-old female child was at risk for abuse in her mother's home. The dispute centered on the mother's fiancé's actions during a bath he gave to the child while her mother was taking college classes after work. The little girl complained that during the bath the fiancé had "pushed ... his fingers inside [her] vagina" ${ }^{, 136}$ while washing her, and it hurt. ${ }^{137}$ A physical exam revealed that the child had some irritation that could have been caused by soap or by touch, and that there was evidence of some penetration. ${ }^{138}$ The fiancé admitted

134. See cases discussed supra notes 55-56.

135. No. A125775, 2010 WL 2620806 (Cal. Ct. App. June 30, 2010).

136. Id. at $* 1$.

137. Id. at $* 2$.

138. Id. 
to washing the child without a washcloth, but not to penetration. ${ }^{139}$ He further explained that the child always cried when her vagina was washed by a caregiver because she suffered from perpetual vaginal irritation stemming from her failure to properly wipe herself when going to the bathroom. ${ }^{140}$ The court recognized that the child had suffered irritation in the past, but concluded that the fiancé's actions in this instance were cause for suspicion. ${ }^{141}$ In reviewing the facts associated with the bath, the trial court explained:

There's no reason to shove your finger up inside [a] child. And sure it hurt. And she didn't make this up. And he may have rough hands, that's fine.... [But] the idea of washing someone with your hands, especially a small child, it's inappropriate. It may not be against the law, but it's inappropriate. And if someone has an irritation that everyone is aware of, a soft rag and a gentle washing is sufficient. I can only construe from the circumstance that there was sexual intent. $^{142}$

Before reversing the groups in Julia B., one must first set aside the court's characterization of the child's complaint and return to the child's actual allegations. The court characterized the child's claim as being that the fiancé "shove[d]" his fingers into the little girl, ${ }^{143}$ which is substantially different from the child's statement that the boyfriend "pushed" his fingers inside her while bathing her. ${ }^{144}$ By returning to the child's characterization of the incident, one gets a clearer sense of the disputed issue in the case: whether the fiancé violated the child's sexual privacy interests when he intrusively washed the child's vagina with his bare hand. ${ }^{145}$ When we reverse the groups and focus on this allegation, it seems clear that a mother would not find herself facing child sexual abuse allegations if she engaged in such conduct. That is, we recognize that a mother may in haste bathe a child without a washcloth or in a rough manner, yet her actions are not interpreted to mean that she has acted with illicit intent. Yet somehow people's intuitions change when a scenario involves a male caregiver acting in a motherly role. Suddenly, the child's protestations sound more ominous; the irritated genitals seem more sinister.

Julia $B$. also shows how both subjective sexual privacy complaints and a social norms analysis are influenced by gender norms in the parental intimate

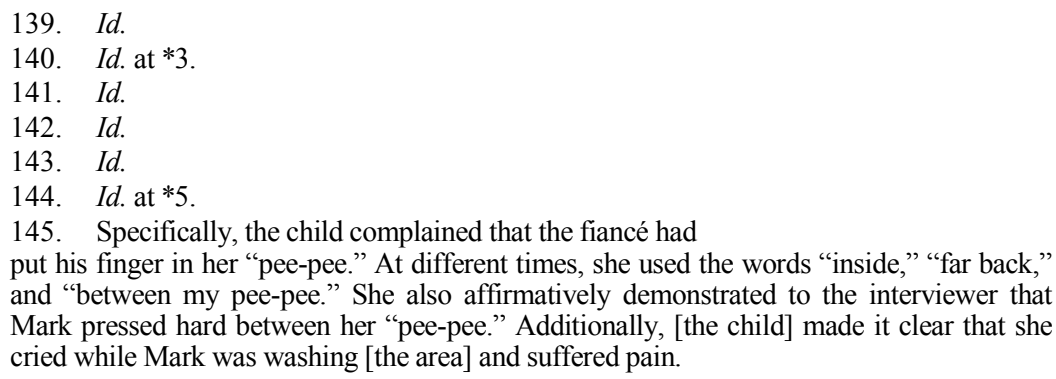


care cases, as the court relied on both concepts in the course of its analysis. Specifically, the court used an objective social norms inquiry when it determined that washing a small child with one's bare hands is entirely inappropriate and, further, that this act was evidence that the mother's fiancé was motivated by sexual interest. Yet, it is clear that there is no established social standard that requires that a child always be washed with a washcloth. Also, the court's ultimate findings rested heavily on this claim about objective bathing norms. It explained that while barehanded washing of a child is not "illegal," the practice of using a washcloth was established enough that the fiancé's failure to do so indicated that the child was at risk and in need of continuing court supervision. ${ }^{146}$ The court's stigmatization of the fiancé's bathing practices led to the fiancé's concession that he would live separately from the mother while the case was pending, in essence assuring the court that the girl he improperly bathed would have little interaction with him. ${ }^{147} \mathrm{He}$ agreed, as he put it, that he would "never bathe the girls again" if the court permitted him to return to the mother's home. ${ }^{148}$

The subjective sexual privacy inquiry in Julia $B$ was similarly influenced by gendered understandings. The court ended up shaping the child's testimony in ways that conflated her claims of pain, irritation, and unwanted touch, and treated them all as evidence of sexual violation. The case shows that fathers are more likely to see a child's complaint of unwanted touch transformed into a claim of sexual violation. Additionally, the court seemed particularly focused on establishing digital penetration in Julia $B$ as proof of abuse, a dynamic that seems to pervade many of the intimate care cases involving fathers. But this focus on penetrative acts is deeply gendered. Because motherhood is a largely hidden domain, many people do not realize that on occasion mothers clean children in ways that require some so-called "penetration" of a child's body. These mothering acts of penetration remain invisible and uncontroversial until a male caregiver engages in such action.

Importantly, nothing in my analysis should be read to mean that legal decision makers should doubt children's claims of injury. It is certainly possible that the child in Julia B. may have experienced psychological pain if she interpreted her bather's touch as a kind of sexual intrusion. ${ }^{149}$ Yet giving full weight to a four-year-old child's sexual privacy complaints offers precious little direction on how the case should be resolved. If we make the child's claims dispositive, does this mean that only the child may determine who

146. Id. at $* 7$ (arguing that child was at risk because mother never checked to see how child was being bathed by her boyfriend or to ensure that he was at a minimum using a washcloth). The court explained that it simply "was not reasonable for [the] mother to have her live-in boyfriend bathe her four-year-old girl." Id.

147. Id. at $* 3$.

148. Id.

149. Id. at *4 (explaining that, even in the absence of proof of sexual interest, the boyfriend "did a very stupid thing" while bathing the child "and it affected a four-year-old"). 
provides intimate care? Psychologists' research raises the concern that young children in particular may describe or interpret caregiving scenarios that they find offensive for other reasons in ways that raise the specter of sexual abuse. ${ }^{150}$ When viewed through the framework of a gender norms analysis, this insight suggests that a child may respond unfavorably to a male caregiver's touch, not because the male caregiver is sexually motivated, but because the child is unfamiliar with certain tasks being attended to by a male caregiver. If we do not engage with this problem, then we ultimately concede that men cannot provide care whenever a child has already internalized conservative gender norms.

In summary, Julia B. stands as a striking example of how legal scrutiny of a male caregiver ensures that the default gendered norms for intimate care are permanently re-established in a mother's home. The mother's attempt to renegotiate these default norms resulted in a clear sanction, as both of her children were declared at risk of abuse because of the incident. ${ }^{151}$ Importantly, when the court analyzed the fiancé's touch, no space was made for a critical view of whether the child's experience of touch had been shaped by gender norms. As a consequence, we are denied an opportunity to engage with one of the most important issues that should be addressed in the case, namely that the fiancé may not have acted with sexual interest, but still, because of gender norm understandings, caused sexual injury to the child he bathed.

$b$. In re R.A.

Some may argue that the Julia B. case is not an ideal case for considering the problems posed by our gendered understanding of caregiving, as there are reasons why a court might be more suspicious of a non-biological father that is involved in giving care. Yet our next case, In re R.A., reveals that biological fathers are equally subject to sexual suspicion when they engage in traditional mothering tasks. Specifically, in In re R.A., a father was charged with neglect based on sexual abuse allegations stemming from bathing his three-year-old daughter. ${ }^{152}$ Here the report of a sexual privacy violation was provided by the little girl's brother, a six-year-old who alleged that he saw his father's finger go up inside his sister's genitals while the father bathed her. ${ }^{153}$ The boy reported that this was the only time he saw his father engage in this kind of activity and that his father had never touched him in a sexual manner. ${ }^{154}$ The three-year-old victim confirmed her brother's report, complaining that her father had penetrated her vagina with his finger during her bath. ${ }^{155}$ Her mother, somewhat

150. See Liang et al., supra note 106, at 644.

151. In re Julia B., 2010 WL 2620806, at*7-8.

152. 403 N.W.2d 357, 360 (Neb. 1987).

153. Id.

154. Id.

155. Id. 
unsure about the complaint, questioned her daughter to be sure that her father had not accidentally touched the little girl while bathing. The three-year-old confirmed that the touch was not accidental. ${ }^{156}$ The mother testified at trial that the child did have frequent vaginal infections, that she had properly instructed the father on bathing techniques and, therefore, that she suspected abuse may have occurred. ${ }^{157}$

Reversing the groups in In re R.A. again helps bring concerns about gender stereotyping to the fore. For a mother that digitally penetrated her child once while washing her would be unlikely to face charges of child molestation, even if a watching sibling raised questions about her behavior. To be clear, the subjective sexual privacy claim in this case may seem stronger, precisely because the wrongful conduct was identified by the injured child's brother and confirmed by the child herself. ${ }^{158}$ However, the brother's corroboration of his sister's complaint raises more questions than it answers, as it is possible that both the little boy and his sister may have been more sensitive to their father's touch in this particular mothering domain. In re R.A. is also significant in that it shows how the court's analysis strengthens gender norms; a mother's caregiving practices are treated as the default ideal, the backdrop against which a father's actions are measured. Indeed, the mother's effort to train the father about proper bathing practices was used to show that the father had been given notice about the proper scope of touch in bathing his female child. ${ }^{159}$ Deviation from her practice was viewed as evidence of illicit behavior. There was no space in the court's analysis for the possibility that a well-meaning father may have deviated from the mother's instructions, and that his misstep may have caused his daughter to feel violated.

In re R.A. also reveals the powerful disciplinary power child molestation law has over fathers in the subjective sexual privacy cases, for the ambiguous norms governing fathers' conduct may cause fathers to be conflicted and confused about how to understand and describe their caregiving behavior to others. Indeed, the father's conflicted state in In re R.A. played a key role in the prosecution's case. The court noted that the father first stated that he was unsure that anything abusive had actually occurred, and then said the horror of having potentially hurt his daughter made him block out the alleged incident. ${ }^{160}$ A counselor who testified in the case explained that, at the time of trial, the father remained confused as to whether he had done anything improper. ${ }^{161}$ Still, in his interview with a police officer the father agreed that he did not think his

156. Id.

157. Id.

158. Id.

159. Id. (describing mother's instruction as to "appropriate" bathing techniques regarding washing the vaginal area).

160. Id. at 361 .

161. Id. The father explained to the officer that "so many people had told him that he had done it" that something must have occurred. Id. 
child was lying, but also stated that he refused to admit to abuse because it was the worst thing anyone could do to a child. ${ }^{162}$ Based on the father's conflicting testimony, the court concluded that sexual abuse had occurred and the father should be required to undergo psychological evaluation. ${ }^{163}$ Certainly, it is possible that the court was correct, and the father in this case was being untruthful and evasive in answering authorities' questions. However, we should also acknowledge the disturbing possibility that the father was so unsure about the caregiving norms that govern fathers' behavior that he ultimately accepted his accusers' pathologizing account of his conduct, even though he initially did not think that he did anything wrong. He accepted his daughter's honestly held complaint of injury, but he was not sure whether it was possible for him to accept her account while still maintaining his view that he was engaged in an innocent act of caregiving. Part III further explores how the ambiguous norms at the root of caregiving fathers' conduct shape a father's consciousness and stir anxiety for fathers about child molestation law.

\section{c. State v. Emmett Revisited}

The final bathing case offered for consideration is State v. Emmett, the case featured at the beginning of this discussion. Recall that Emmett was a cobathing case that arose in a specific intent jurisdiction. ${ }^{164}$ Specifically, the Utah statute under which Emmett was charged required a showing that he sexually touched his child and that that he acted "with the [specific] intent to arouse or gratify the sexual desire" of himself, the child, or a third party witnessing their interaction. ${ }^{165}$ The court then was required to look at context to determine whether specific intent was established in the case. Careful analysis requires that we think more deeply and determine what it was about the post bath rub down that triggered prosecutorial concerns. For the prosecutor merely offered that, after the child's bath, Emmett had rubbed baby oil on the child's skin, including the child's genitals. ${ }^{166}$ What was it about these practices that should have raised concern?

Reversing the groups in Emmett shows that it is much less likely that a mother would have been sanctioned for the conduct in this case. Rather, a more searching inquiry would have been required to problematize the post shower rub down. Viewed from this perspective, the Utah Supreme Court's disposition on appeal seems progressive, as it recognized that something more, beyond the mere fact that the rubdown occurred, was required to establish that the father's behavior was illicitly motivated. ${ }^{167}$ Indeed, on review, the Utah Supreme Court

162. Id.

163. Id. at 366 .

164. State v. Emmett, 839 P.2d 783 (Utah 1992).

165. Id. at 784 n.6.

166. See id. at 783 .

167. Id. at 784 . 
concluded that the shower Emmett engaged in was "hygienic" and therefore innocent - that the father had no illicit intentions in showering with his son. ${ }^{168}$

Some might further argue that the Emmett court should be praised for having adopted an androgynous or gender-neutral understanding of parenthood by focusing on whether the practice was connected to "hygiene." They might argue that this is precisely the kind of gender-neutral analysis feminists need from courts to assist mothering fathers. Gender scholars, however, would likely find the Emmett court's hygiene analysis wanting, as the court characterizes the shower by one of its potential functions rather than delving into the fundamental analytical questions that would determine whether sexual abuse actually occurred. For we know that illicitly motivated parents sometimes use "hygienic" practices as a cover for child molestation; consequently, the discussion of hygiene does not answer the question as to whether sexual abuse occurred. Ultimately, the hygiene language allows the Emmett court to mask the real challenge in the case: addressing the grey and shifting boundary between proper parental care and sexually intrusive touch. By resorting to the language of hygiene, the court avoids discussion of this boundary line and, in particular, the unspoken gender-specific social norms governing the distinction between proper parental care and sexually illicit activity. To be clear, the court could have resolved the case in a more instructive manner if it had explicitly recognized that most legal decision makers would resolve the Emmett case by asking if it is proper for a man to rub lotion on his naked five-year-old son after a bath. The court could have explicitly acknowledged that conservative social norms tend to establish a much narrower field of appropriate conduct for a father in this context than a mother, and further that these conservative norms must be rejected. Instead, by relying on the language of hygiene, the court offered a special near-medical justification for the father's behavior, taking his behavior out of the domain of discretionary intimate care and into a realm of authorized medical touch beyond sexual suspicion. As a consequence, the court squanders an opportunity to talk about the conservative gender norms that shape fathers' interactions with children, and ultimately work to the disadvantage of many male caregivers. ${ }^{169}$

\section{Kisses}

There are few things as pure as a mother's kiss. But what about a father's? The final set of intimate care cases considers the proper scope of fatherly

168. Id.

169. The prosecutor's arguments in Emmett also suggest that gendered parenting norms are central to the case. The prosecutor highlighted the fact that the father applied oil to his child, but the child's mother had authorized neither the purchase of the oil nor its application. Id. at 784. The prosecutor therefore invited the court to play a maternal gatekeeping function, to conclude that mothers define the scope of appropriate parent-child interaction. In order to truly engage with the gender issues, the court should have highlighted the problematic nature of the prosecution's argument as well as the other gender-based intimacy issues that inform the case. 
affection, and the ways in which undertheorized understandings of social norms and sexual privacy inform the intimate care cases. As we will see, in these cases in particular, courts mobilize an undertheorized social norms and sexual privacy analysis that leaves fathers at the mercy of socially conservative assumptions about gender-specific parenting roles.

\section{a. People v. Marokity}

In People v. Marokity, a defendant father appealed his conviction for sexual abuse based on allegations that he engaged in inappropriate displays of affection with his children. ${ }^{170}$ Marokity, a pediatrician that had emigrated to the United States from Hungary, was the father of a young boy and a young girl, ages two and four. ${ }^{171}$ The criminal sexual abuse allegations in his case were based in part on the claim that Marokity would kiss and smell the area around his son's and his daughter's stomachs, thighs, genitalia, and buttocks after bathing them or changing their diapers. ${ }^{172}$ The children's mother complained that Marokity seemed "very excited" and "not really there" when he kissed his children. ${ }^{173}$ The children's mother ordered Marokity to stop kissing the children while they were naked, warning him that he could be sent to jail. ${ }^{174}$ Marokity agreed that he would try, but he indicated that he probably would not be able to stop entirely. ${ }^{175}$ Marokity admitted at trial that he was very affectionate with his children, and that he had kissed them on their thighs and buttocks, but did not recall if he kissed their genitals. ${ }^{176}$ However, he also expressed an unrepentant belief that it was not wrong to kiss their thighs and buttocks or their genitals and that the practice was common in his native Hungary. ${ }^{177}$ The children also testified that Marokity had touched each child's genitals and inserted his fingers into each child's anus, ${ }^{178}$ and the male child indicated that he had experienced pain as a result. ${ }^{179}$ The children's testimony viewed in its entirety

170. No. B213631, 2010 WL 779778 (Cal. Ct. App. Mar. 9, 2010).

171. Id. at $* 1$.

172. Id. at *1,*4.

173. Id. at *1.

174. Id.

175. Id. at *4 (testifying that he "slow[ed] down [the kissing] as much as [he could], but admit[ted], [he] couldn't stop it hundred percent").

176. Id. Marokity explained that he "never touched or kissed either of his children for sexual gratification and saw nothing inappropriate in the way he kissed his children." Id. at *5.

177. Id. at *3, *12.

178. Id. at $* 2, * 3$.

179. The father and some medical experts attempted to place these comments in context by citing hygienic reasons for the father's touch. Specifically, one doctor noted that the four-year-old son suffered from "Phimosis, a condition in which the foreskin on an uncircumcised penis cannot be fully retracted from the penis head, sometimes leading to infections. A person with Phimosis must clean his penis by moving the foreskin back and forth, which can cause discomfort." Id. at *2. Defendant also conceded that he might have inserted his finger into the two-year-old's vagina while cleaning her. Id. at $* 4$. 
was inconsistent and somewhat equivocal, ${ }^{180}$ and Marokity consistently denied wrongdoing. He explained that any genital or anal touching that occurred was the result of normal affection or hygienic practices. ${ }^{181}$ Marokity was ultimately convicted of lewd and lascivious conduct with his children and sentenced to prison. $^{182}$

Like the fathers in other intimate care cases, on appeal Marokity challenged whether sufficient evidence had been presented to establish that his conduct was motivated by sexual interest. He argued that the jury should have been charged to consider his behavior as simple battery, as the evidence presented at trial merely showed that he had engaged in a kind of unwanted touching. ${ }^{183}$ The court, however, rejected this claim on the ground that there was overwhelming evidence in the case to establish that Marokity was motivated by illicit sexual desire. Specifically, the court set aside as de minimus the evidentiary errors that Marokity raised and pointed to Marokity's admissions as evidence of malfeasance. ${ }^{184}$ It noted that Marokity admitted to

180. Prior to trial, Marokity's son suggested that he might have "lied" about the finger allegations, but later confirmed his initial claims. At trial, however, the four-year-old recanted his claims regarding his own complaints and claimed that he could not recall his claims about his sister. Id. at *3. The son's inconsistent testimony could have stemmed from his concerns about sending his father to prison or been evidence that his testimony was inadvertently shaped by the child welfare representatives that questioned him. Id. at *4-5.

181. Id. at *5 (discussing defendant's claim that all touches were normal expressions of affection or intended to assist with cleaning, urination, or diaper changes).

182. Id. at $* 6$.

183. Id. (arguing that the jury should have been instructed on lesser included offense of battery because the evidence may have proved offensive touch in the absence of sexual motivation). The court rejected this claim because it concluded that the gravamen of a lewd and lascivious charge is that the act is "sexually motivated." Id. Therefore, pedestrian, consented-to touches might still constitute lewd and lascivious conduct if the person engaging in the touch has illicit motivations. For example, the consented-to touch of a ten-year-old child's thigh does not technically constitute battery; however, if the touch is motivated by illicit conduct, it is chargeable as lewd and lascivious conduct. Id. at *7-8.

184. Id. at *8-12. Marokity's evidentiary challenges highlight another cultural demand imposed on parents that feminists have remarked upon in other contexts: the demand that parents, particularly mothers, appear as de-sexualized figures in order to be considered valid caregivers. See Martha Albertson Fineman, The Neutered Mother, 46 U. MIAMI L. REV. 653, 658 (1992). Specifically, Marokity argued that the prosecutor unfairly prejudiced his case by introducing evidence showing that Marokity possessed a large store of pornography. The court concluded that, since the possession of pornography was not uncommon, it did not have any effect on Marokity's case. Marokity, $2010 \mathrm{WL}$ 779778 , at $* 9$. The court's conclusion seems to suggest that the possession of pornography is an "expected" male practice - a claim which is open to challenge itself. However, the court failed to consider that Marokity was not being evaluated solely as a man, but as a male caregiver. Presumably a male caregiver that possesses pornography might be judged rather harshly. Additionally, because the court allowed the prosecutor to present to the jury that one of the adult pornography videos may have included child pornography, the defendant's possession of pornography became important to his case. $I d$. at $* 9-10$. This claim regarding the defendant's alleged possession of child pornography was particularly controversial, as no legal determination was made regarding whether it was in fact child pornography. The defendant argued that, even if his material had contained images of adolescent girls, this evidence had no bearing on the question of whether he had sexual desire for his toddler-age children. Id. at *11-12. The court disagreed. Id. 
the illicit touches, even though he claimed they were normal caregiving. ${ }^{185}$ The opinion further noted that he admitted to inappropriate kissing of his children, as well as to his inability to stop the kissing. ${ }^{186}$ The court explained that Marokity's admission that he had an irrepressible urge to kiss his toddlers' naked bodies was clear evidence of deviant desire. ${ }^{187}$ Yet, this conclusion is deeply disturbing given that we treat mothers' irrepressible desire to kiss their progeny as a natural and normal inclination.

The Marokity case is unclear about what it is about the social context in which Marokity's conduct occurred that allows a finding of illicit interest. That is, there is little about the social context in which the kisses and the touching occurred to establish that they were clearly illicit in nature. Arguably, the court must have been moved by the subjective sexual privacy complaints of Marokity's children. However, even assuming these complaints were expressing a truly held sense of sexual intrusion, the case still leaves male caregivers with precious little insight about the proper bounds of parental caregiving and affection. Another, perhaps more disturbing way of reading the case, is that Marokity was punished because his way of expressing affection did not match his wife's understanding of the gender norms that should govern fathers' behavior. Yet why should a court join the mother in enforcing her gendered understanding, effectively giving legal bite to maternal gatekeeping? Sociologists have described maternal gatekeeping in more innocuous contexts as a phenomenon in which mothers undercut fathers' caregiving by raising questions about fathers' conduct when they deviate from the standard of care set by the mother. ${ }^{188}$ Indeed, in the intimate care cases, suspicion often springs from deviation from the mother's customary practice or her instructions. This move naturalizes the assumption that a mother's touch has not caused a child pain or sexual offense, and further establishes that proper caregiving is first and foremost to be determined by mothers.

There is no question that Marokity is a difficult case. It is made more difficult by the "winner's history" phenomenon, as the court presents information about a vast array of allegations regarding the children's sexualized conduct and anger, and claims about the defendant's pornography consumption throughout the opinion. In this context, the children's subjective sexual privacy complaints seem more powerful proof that something illicit occurred. ${ }^{189}$ Also, some would argue that Marokity was correctly decided because, if the court concluded that Marokity kissed his children's genitals, he was guilty of sodomy, a practice that would always be condemned even if the defendant was

185. Id. at *3.

186. Id. at $* 12$.

187. Id. at $* 19$.

188. Allen \& Hawkins, supra note 95, at 202.

189. Marokity, 2010 WL 779778, at *3, *8-9 (discussing disputed evidence regarding defendant's pornography consumption and assessing whether these materials had probative value for the allegations involving his children). 
a woman. Yet this objective view of what counts as sexual violation does not hold in all child molestation cases. Courts have offered special immunity to parents to engage in this practice when the defendant parent invokes a cultural defense to explain his or her conduct. For example, a Dominican mother and an Afghan father were exonerated from charges based on their affectionate contact with their children's genitals in cases where they claimed that these nurturing practices are permitted in their home countries. ${ }^{190}$ These cases establish that the kissing of a child's genitals does not as an objective matter count as sodomy, nor establish that these kisses violate a child's objective sexual privacy interests. Courts' willingness to sanction the kisses that foreign parents give their children makes little sense if we believe that these practices, objectively viewed, constitute molestation.

The cultural defense cases have much to teach us about the social norms function of the intimate care cases. Feminist legal scholar Leti Volpp explains the normalizing function cultural defenses in criminal cases play, allowing courts to localize socially troubling practices as specific to foreign communities and outside of the American polity. ${ }^{191}$ As applied here, her analysis suggests that by identifying troubling parent-child interactions as something other cultures engage in, we can avoid considering the wide range of parenting practices in American families. ${ }^{192}$ Her analysis suggests that Marokity's claims represented a special kind of threat to American families and to fatherhood. Marokity, despite being a Hungarian immigrant, insisted that he was a normal American father, and that his way of expressing affection was a normal American parenting practice. The court rejected this understanding of American fatherhood and, as a result, Marokity faced the full sanction of the criminal law. Yet an honest examination of the range of ways that American mothers kiss, cuddle, and play with their children - and the complaints children raise about their mothers' touch-might place his behavior in a more ambiguous category, not clearly immoral or sexual in nature.

190. See, e.g., People v. Kargar, 679 A.2d 81 (Me. 1996) (dismissing sexual abuse charge against Afghan father based on finding that giving genital kisses is a common Afghan infant caregiving practice); State v. Ramirez, No. CRIM.A. CR-04-213, 2005 WL 3678032 (Me. Super. Ct. Nov. 9,2005 ) (acquitting Dominican mother on sexual abuse charge based on finding that kissing infant children's genitals is nonsexual Dominican caregiving practice). (2000).

191. See Leti Volpp, Blaming Culture for Bad Behavior, 12 YALE J.L. \& HumAN. 89, 90

192. Indeed, some work has been done urging social workers to recognize the different ways various immigrant cultures treat family intimacy and to recognize a broader range of practices. See Carol A. Cartsens, Defining the Boundaries: Social Worker Assessment of Sexual Abuse in a Cultural Context-Multivariate Analysis of Personal and Professional Factors Influencing Social Workers', Labelling of Intimacy Behaviour, 6 CHILD \& FAM. SOC. WORK 315, 316 (2001) (recognizing that definitions of sexual abuse are contested, as some family intimacy practices such as co-bathing or cosleeping are not deemed sexually abusive when interpreted based on the social norms of immigrant groups). While this development is positive in some ways, it also tends to reinforce the false view that there is wide agreement among "Americans" about the proper scope of family intimacy. 


\section{b. J.S. v. Commonwealth, Department of Public Welfare}

The last case about paternal affection again illustrates the risks of subjective sexual privacy analysis. In J.S. v. Commonwealth, Department of Public Welfare, ${ }^{193}$ a father sought the reversal of a sexual abuse judgment based on his daughter's report that his kisses had disturbed her sense of sexual privacy. In this case, the child alleged that when she was between the ages of four and eight, her father would hold her down and kiss her face and neck with an open mouth. ${ }^{194}$ The daughter's concerns about her father's conduct arose years later, in circumstances that reveal the inchoate nature of children's sexual privacy understandings. The daughter explains:

Okay. And I guess you could say I had my first real kiss and I got a weird feeling inside and it bothered me for awhile and I told my mom about it; so she said maybe we should go see someone to be sure that everything's okay. So I went in and they asked me what happened. So I told her that my father used to play these games with me, okay, and he would, from my head like around my neck area, he would kiss me, he would get on top of me and do this, and his mouth would be open and he, they weren't the types of kisses that were normal. At least they made me feel uncomfortable. ${ }^{195}$

What about the daughter's first kiss at age thirteen caused her to reinterpret her father's actions? Perhaps she had a more informed basis on which to judge the appropriate scope of fatherly conduct. Perhaps her growing sense of sexual privacy caused her to reinterpret early intimacies with her father through a sexual lens. These were critical questions, yet they went unexplored in the court's analysis. Instead, the court treated the child's complaint as direct evidence of her father's earlier illicit sexual interest and problematized mundane exchanges that could be viewed as normal displays of fatherly affection. If the court reversed the groups and instead focused on mothers, the result would likely be deeply troubling. Would the court have pathologized a mother's kiss many years after the kissing occurred, when her male child entered puberty? What role does memory play in the understanding of intimate interaction? The case revealed a number of unresolved issues in understanding how to interpret children's subjective sexual privacy complaints when they are used to question parental intentions behind intimacy and care. While J.S. was ultimately reversed on appeal, the case had already done its disciplinary work on the individual father in this case and plays the same disciplinary function for others who learn about its disposition. The case teaches men to avoid being affectionate with children, lest their enthusiastic play be misinterpreted as sexual in nature.

193. 557 A.2d 801 (Pa. Commw. Ct. 1989).

194. Id.

195. Id. at 802 . 
Taken together, the intimate care cases described above illustrate the substantial risks faced by fathers who dare to mother. Men face a higher degree of sexual suspicion when they attempt to provide affection and intimate care to their children, but in many cases they are being relied upon to perform these essential functions. The cases press us to consider the degree to which our current social understandings about fatherhood are under pressure, and to consider the ways in which our understandings of sexual privacy must change to allow men more discretion to attend to intimate care. Admittedly, the problems posed by these cases will not be easy to resolve. But the work required is made all the more difficult by courts' failure to make gender an explicit part of the analysis in child molestation cases. The project becomes even thornier when other legal decision makers proceed without acknowledging the ways in which their understandings of parenting are shaped by gender norms. The strategy offered in Part I, calling on legal decision makers to reverse the groups, will provide legal decision makers with some assistance in preventing their "common sense" understanding of gender norms from distorting their views in such cases. However, de-biasing protocols are only the first step, for men who dare to mother will continue to face a disproportionate risk of sanction unless we develop a deeper understanding of the social norms and sexual privacy understandings we are willing to enforce through child molestation law.

II.

\section{FEMINIST AND CRIMINAL RESPONSES TO CHILD MOLESTATION}

Part I demonstrates how child molestation statutes currently constrain the practice of fatherhood, in particular burdening those fathers who dare to mother. The analysis shows how the legal inquiry invites legal decision makers to resort to gendered understandings of the appropriate domain of parental touch, regardless of whether the inquiry is ostensibly about social norms or the child's subjective sense of sexual injury. Part II considers why feminists, whose primary project is to interrogate structures that compromise gender equality, have not considered the burdens that child molestation law imposes on men who dare to mother. As Part II shows, feminists' silence on this topic can be traced to the dramatically different views various feminist constituencies have about the father's role in caregiving and the degree of autonomy and discretion women should be granted in re-allocating activities traditionally considered the primary province of mothers. 


\section{A. Expanding the Concept of Injury: Feminist Interventions in Child Molestation Law and Scholarship}

Feminist scholar Kerwin Kaye explains that it was feminists who first convinced the state to take parent-child sexual abuse seriously. ${ }^{196}$ Prior to feminist interventions in the late 1970s, child sexual abuse was not regarded as a major social problem. Sexual abuse within families was particularly invisible, as it was segregated from the general problem of child sexual abuse and considered predominantly to be incest, a category of offenses that triggered surprisingly mild sanctions. ${ }^{197}$ In the 1970 s, however, dominance feminists began a period of intense activism to ensure that the danger posed by parentchild sexual abuse received a more appropriate legal response. ${ }^{198}$ Dominance feminists' first task was to challenge the popular perception that child molestation was really the problem of older men being seduced by "Lolitas"sexually precocious young girls. ${ }^{199}$ They revealed how the Lolita figure both minimized the harm suffered by sexual abuse victims and deemed victims complicit in their own violation and exploitation. ${ }^{200}$ Dominance feminists' second task was to shift the debate away from discussions about sexual activity between children and unrelated parties and to refocus the debate on how children were at risk for sexual exploitation in their own homes. Specifically, dominance feminists challenged us to consider how power dynamics in the nuclear family put mothers and children at risk for sexual exploitation by fathers. ${ }^{201}$

Dominance feminists enjoyed a number of clear victories in the effort to secure child protective legislation. Specifically, when they began their efforts to reform child molestation law, they found widespread support for their view that child molestation laws merited more attention and needed stiffer penalties. By the 1990s dominance feminists had made substantial gains, convincing legislatures to amend general-purpose child molestation statutes to prosecute parents. Social welfare authorities welcomed this shift, as the legal changes gave child welfare workers more tools and options for intervening in troubled families. ${ }^{202}$ While incest laws are still used in many jurisdictions, the modern trend is for prosecutors to rely on these more powerful general-purpose child

196. Kaye, supra note 79, at 143.

197. Andrew, supra note 32, at 1870-71.

198. Henderson, supra note 12, at 486; Kaye, supra note 79, at 144.

199. Henderson, supra note 12, at 489-90; Kaye, supra note 79, at 145 ("[Child sexual] [a]buse victims were identified as willing partners, sexual deviants who needed to be controlled.").

200. Kaye, supra note 79, at 154 (noting that dominance feminist critiques of the family were "pushed aside").

201. ViKKi BELL, INTERROGATING INCEST: FEMINISM, FOUCAULT, AND THE LAW 62 (1993) ("That [f]athers have a certain amount of . . power in the Family means that their sexual abuse of children is not so much a deviation from normal familial relations as an illustration of them.").

202. Bienen, supra note 11, at 1506 (discussing how the threat of prosecution under "vaguely defined molestation provisions or lewdness statutes" served as an effective tool for social workers and other hospital staff interested in monitoring families or restructuring living arrangements). 
molestation statutes to investigate sexually troubling interactions between parents and children.

Importantly, dominance feminists' early victories masked the degree to which their understandings about child molestation diverged from other feminist activists and scholars. Liberal feminist scholars in particular found the views of dominance feminists to be controversial, as liberal feminist analyses of social issues were not premised on dominance feminists' view that male sexuality is inherently predatory. However, dominance feminist scholars found that these claims about predatory male sexuality resonated well with conservative child welfare authorities who assumed that mothers should play the primary caretaking role. Moreover, these claims about predatory male sexuality appeared to be confirmed by empirical data showing higher incidence rates for male versus female perpetrators, which suggested that fathers had greater propensity to engage in child sexual abuse than mothers. ${ }^{203}$ Unsurprisingly then, welfare authorities began to devote their efforts to scrutinizing fathers' behavior. Unfortunately, liberal feminists failed to articulate their concerns, despite not fully hewing to these views about predatory male sexuality or the threat posed by the nuclear family. As a consequence, there was no clear dissenting feminist voice as child protection workers and advocates began to sharpen their focus on male caregivers.

The story of dominance feminists' influence on child molestation law, however, is more complicated than typically acknowledged. Scholars like Kaye have argued that dominance feminists' critiques of the nuclear family and male sexuality were not fully adopted by the state, but, instead, the more radical elements of their views were contained. Kaye argues that social welfare authorities adopted an understanding of the causes of molestation that was based on highly individualistic models drawn from psychology, models that treat sexually predatory behavior as a sign of individual deviance. ${ }^{204}$ Other feminist scholars like Vikki Bell see a closer alignment between dominance feminist arguments, the legal system, and cultural common sense. Bell convincingly argues that dominance feminists' critique of traditional male sexuality, while not formally reflected in the law, has shaped the cultural backdrop legal actors use to identify and define child molestation. ${ }^{205}$ Specifically, she suggests that the paradigmatic case that child welfare authorities and other legal actors use in identifying sexual abuse has become the molesting father who treats his children as sexual property, and this shift

203. LONDON FAMILY COURT Clinic, supra note 40, at 22; see also David Finkelhor, Current Information on the Scope and Nature of Child Sexual Abuse, 4 THE FUTURE OF CHILDREN 31 (1994) (reporting that sexual abuse is committed mostly by men — 90 percent — and by persons known to the child $-70-90$ percent - with family members constituting $30-50$ percent of the perpetrators against girls and 10-20 percent of the perpetrators against boys).

204. Kaye, supra note 79, at 161-63 (criticizing the state for its unwillingness to intervene in ways that would truly disrupt the social norms that encourage nuclear family arrangements).

205. BELL, supra note 201, at 180-84. 
demonstrates the influence that dominance feminists have had on cultural understandings. ${ }^{206}$ Indeed, while social welfare authorities do tend to turn to the psychological literature to understand the dangers of intimate parent-child contact, they do not use this literature to second guess both male and female caregivers' interaction with children. Instead, when one considers how this literature is actually used-how it shapes the consciousness of police officers, social workers, judges, and prosecutors - one sees that legal decision makers tend to scrutinize men's behavior in more detail. One way of explaining the state's selective use of psychological materials is to acknowledge that dominance feminists' representations of male sexuality have influenced legal decision makers, even as dominance feminists' critique of the nuclear family may have been cabined.

Dominance feminists' claims about predatory male sexuality gained sway in part because activists and scholars were extraordinarily effective in offering child molestation stories that became a part of the cultural backdrop used to identify and analyze molestation cases. As feminist scholar Vikki Bell explains, dominance feminists used narratives instead of theory to analyze the problem of child sexual abuse, arguing that narratives would help us to understand the wide range of ways in which sexual abuse causes harm. ${ }^{207}$ Consistent with this view, dominance feminists like Mary Becker and Lynne Henderson devoted their efforts to orienting criminal justice actors to be more accepting of victim's

206. Id. The power dominance feminists exerted over the characterization of child sexual abuse also effectively relegated to the margins the competing discourse cultural feminists attempted to initiate about children's erotic lives. Specifically, cultural feminists argued that children have the capacity for erotic experience and their own sense of sexuality, but argued that children still need to be protected from sexual exploitation by adults. For example, in the 1990s Sara Ruddick openly proclaimed that "[c]hildren's bodies, like the bodies of adults, are sexual; the distinctive pleasures and curiosities of sexuality make their appearance not as an exception to, but as an essential ingredient of childhood bodily life." Ruddick, supra note 10, at 231. She further explained that, "[t]o protect children's bodies means to protect rather than intrude upon, exploit, suppress, or unduly regiment children's desires and shifting sex/gender identities." Id. Dominance feminists, in contrast, wanted to ensure that child molestation discussions focused on preventing patriarchal fathers from projecting their sexual interests on to female children. In this environment, the risks associated with talking about children's erotic potential seemed to outweigh any productive insights that might be gained as a result of cultural feminists' claims. However, cultural studies scholars continue to argue that our refusal to acknowledge children's erotic lives prevents us from creating principled definitions of child molestation. See generally Steven Angelides, Feminism, Child Sexual Abuse, and the Erasure of Child Sexuality, 10 GLQ: J. LeSBIAN AND GAY STUD. 141 (2004); Jane Cousins Mills, 'Putting Ideas into Their Heads': Advising the Young, 28 FEMINIST REV. 163 (1988) (worrying that contemporary feminist discourse about child sexual abuse has oversimplified conversation about children's experiences); R. Danielle Egan \& Gail Hawkes, The Problem with Protection: Or, Why We Need to Move Towards Recognition and the Sexual Agency of Children, 23 ContinuUm: J. MEDIA \& CULT. STUD. 389 (2009) (arguing that the current discourse on child sexual abuse rests on an undifferentiated construct of the child that tends to oversimplify discussion of abuse issues).

207. See BELL, supra note 201, at 88-89 (explaining that narrative was a core part of dominance feminists' analyses). Dominance feminists believed that, by reducing victims' stories to component parts of an overarching theory about sexual harm, they did violence to women's understandings. 
accounts. ${ }^{208}$ Their goal was to expand the range of child molestation narratives that were deemed credible ${ }^{209}$ and thereby ensure that a broader range of child molestation injuries was recognized. By listening to victims' stories, it was argued, we could better understand how more subtle sexual conduct could be injurious to victims. These narratives typically focused attention on the extraordinary power fathers wielded in nuclear households and described a male sexuality that was predatory and exploitative, one that eroticized children precisely because they appeared vulnerable and available. ${ }^{210}$

For example, Lynne Henderson, in her article Without Narrative: Child Sexual Abuse, provides insight into how dominance feminists used narratives to convince legislators to expand their understanding of child molestation. Henderson explains that child molestation cases typically feature intensely difficult and troubling allegations, allegations that tend to make people shut out victims' stories - in particular those of female victims. ${ }^{211}$ Her goal was to shed light on how feminists were using a variety of methods, including, but not exclusively, empirical data, to "define and expand" notions of sexualized harm. ${ }^{212}$ Similarly, Mary Becker, in her article The Abuse Excuse and Patriarchal Narratives, compares different child molestation narratives to show that the legal system was selectively recognizing certain narratives about child molestation and rejecting others, with an eye toward protecting patriarchal fathers. ${ }^{213}$

In contrast, British dominance feminist scholar Liz Kelly, in her article What's in a Name: Defining Child Sexual Abuse, ${ }^{214}$ offers a limited theoretical approach to these issues. Kelly applauds feminists for petitioning lawmakers to create analytic categories that better match with female victims' lived experiences, ${ }^{215}$ but she offers little in the way of normative or theoretical principles that would allow readers to clearly identify sexually predatory or exploitative conduct. A closer examination of her analysis reveals the ways in which reliance on narrative, while it supports the drive to expand our understanding of sexual abuse, creates a host of problems that currently complicate legal decision makers' ability to sort out proper parental behavior from sexual exploitation.

208. See Becker, supra note 12, at 1459-60; Mary I. Coombs, Telling the Victim's Story, 2 Tex. J. Women \& L. 277, 280-81 (1993); Leslie Feiner, The Whole Truth: Restoring Reality to Children's Narrative in Long-Term Incest Cases, 87 J. CRIM. L. \& CRIMINOLOGY 1385, 1393 (1997); Henderson, supra note 12, at 481-82.

209. Becker, supra note 12, at 1460-75.

210. See BELL, supra note 201, at 60-62 (summarizing trends in radical or dominance feminists analyses).

211. Henderson, supra note 12, at 509.

212. Id. at 479 .

213. Becker, supra note 12 , at 1460-75.

214. See Kelly, supra note 12, at 65-73.

215. See id. at 66-67. 
Specifically, in What's in a Name, Kelly argues that child molestation definitions must be greatly expanded. She argues that "forms of sexual violence shade into one another," and notes that different victims will describe different assaults in different terms. ${ }^{216}$ Consequently, she explains that we should be wary of overly restrictive definitions of child molestation. As she makes the case for expanding the category of harms recognized as sexual injury, Kelly's analysis relies primarily on narratives from female victims complaining about the conduct of fathers and male relatives. The narratives Kelly offers include clear cases of improper conduct-fondling, masturbation, and forced intercourse - but they are offered alongside other behaviors that invite more scrutiny, including teasing, commenting about breast size, and hugging and kissing in ways that make children feel uncomfortable. ${ }^{217}$ Other examples of sexually threatening behaviors by fathers include telling a child she is beautiful and giving a child backrubs. ${ }^{218}$ Yet, Kelly offers nothing to guide us in determining when the victim's subjective sense of sexual violation constitutes proof positive of illicit sexual activity, or whether there is some other understanding based on social norms that will help legal actors to identify acts of sexual intrusion that are of legal concern.

Dominance feminists' reluctance to offer a theoretical framework for identifying sexual abuse has had costs in the long term. Narratives alone often do not provide a clear normative framework for identifying sexual abuse injuries. For example, if we assume Kelly's analysis is really an argument for changing social norms about parenting, there are important policy considerations that should be weighed if one adopts this position. One might be concerned about the way that gender norms shape our current understandings about parenting and about a social norms analysis that tends to re-establish these gendered understandings. The focus on narrative deprives us of an opportunity to consider these questions. Furthermore, Kelly's failure to explicitly discuss social norms prevents an examination of how a social norms analysis reduces female caregivers' autonomy to renegotiate the default, gendered allocation of caregiving work in their families. Alternatively, Kelly may have offered these narratives in an attempt to argue that child molestation law really should be focused on behaviors that violate the target's subjective feelings of sexual privacy. However, this sexual privacy model also runs the risk of promoting gendered understandings of touch as it allows courts and other legal players to rely on the victim's conservative gender understandings as an excuse for limiting fathers' behavior.

No one should underestimate the important role dominance feminists' narratives played in transforming child molestation law. Dominance feminists ably used abuse narratives to spur change, garnering empathy from many

216. Id. at 67 .

217. Id. at 70-71.

218. Id. at 71 . 
quarters. But the cost of the narrative approach is that dominance feminists failed to generate normative standards that would allow legislators and other legal decision makers to identify principles ex ante that would allow them today to negotiate intimate care cases. To be clear, dominance feminists succeeded in expanding our understanding of sexual harm, but they failed to provide any insight into the distinctions necessary to sort out intrusive parental care and affection from sexual molestation. Liberal feminists' voices were needed here; however, they failed to issue a call for more studied assessment of how one should use child sexual abuse narratives to enrich our understanding. Moreover, when one reviews the feminist literature during this period, one finds that, while liberal feminists remained absent from criminal law conversations with dominance feminists about molesting fathers, they were writing in other areas about a vision of progressive fatherhood that fundamentally contradicted dominance feminists' claims. The next Section further explores the vision of fatherhood offered by liberal feminist scholars.

\section{B. Fathers Wanted/Fathers Need Not Apply: The Conflict Between Liberal Feminism and Dominance Feminism over the Role of Fathers}

At the same time that dominance feminists were calling for closer scrutiny of fathers' actions in their analyses of child molestation law, liberal feminists in other contexts were calling on men to take on more childcare responsibilities. Susan Okin, a prominent liberal feminist, was one of the first to issue the call for greater involvement by fathers in childcare. Writing in the late 1980s, at the height of dominance feminists' activism, she argued that the cultural norm that saddles women with the bulk of responsibility for childcare and work in the home would doom the gender equality project and ensure that women would remain a marginal labor market constituency. ${ }^{219}$ Martha Nussbaum, another prominent liberal feminist scholar, also characterized the need for more male involvement in child rearing as an important feminist issue. ${ }^{220}$ In writings that ranged from general discussions of democratic theory to more specific discussions of workplace equality issues, liberal feminists argued that both men and women were equally capable of nurturing. ${ }^{221}$ They explained that men must be required to take on more responsibility for children in order to free women

219. Susan Moller OKIn, Justice, Gender, AND the FAmily 175-76 (1989) (proposing that "public policies and laws should generally assume no social differentiation of the sexes" and "facilitat[e] and encourag[e] . . equally shared parenting"); see also Susan Moller Okin, Justice and Gender, 16 PHIL. \& PUB. AFF. 42, 66-67 (1987).

220. See Martha C. Nussbaum, Sex and Social Justice 272-73 (1999).

221. See, e.g., Robin West, Progressive Constitutionalism: Reconstructing The FOURTEENTH AMENDMENT 114-18 (1994) (arguing that uneven parenting burdens profoundly limit women's political participation and autonomy); Naomi R. Cahn, Gendered Identities: Women and Household Work, 44 VILL. L. REV. 525, 541-42 (1999) (discussing same in the context of workplace equality concerns); Mary Joe Frug, Securing Job Equality for Women: Labor Market Hostility to Working Mothers, 59 B.U. L. REV. 55, 55-60 (1979); see also NuSSBAUM, supra note 220, at 272-73. 
to fully and fairly compete in the world of paid work and pursue other selfrealization goals. ${ }^{222}$ Louise B. Silverstein, in her article Fathering Is a Feminist Issue, made the stakes of the issue clear. She explained that "limiting the definition of fathering to the provider role in the family had been central to the problem of male privilege, and thus to the subordination of women in society at large., 223

Liberal feminists' arguments about increasing fathers' caregiving role were in part based on basic claims about fairness. However, liberal feminists also suggested that getting men more involved in caregiving would transform American society by improving our ability to construct a truly democratic polity committed to equality between the sexes. Martha Nussbaum, for example, argued that by participating in caregiving, men develop the capacities necessary for citizenship in a democratic society. ${ }^{224}$ Sociologist Scott Coltrane reported that his interviews with fathers confirmed this claim. He explained that "when fathers are more involved with child care, men are less misogynist and women have more social and political power." 225 Martha Nussbaum further argued that gender-neutral childcare is important for children's development. ${ }^{226}$ She explained that children first learn about fair treatment and justice considerations by witnessing family relations. ${ }^{227}$ Children raised in homes where childcare is equally divided are, therefore, socialized to expect and respect conditions of equality, rather than the feudal gender dynamics that shape traditional family arrangements. ${ }^{228}$ Additionally, Louise Silverstein explained that an emphasis on nurturing fathers would "actually contribute to an acceptance of diverse family forms. If fathering were seen as equivalent to mothering, then gay fathering couples and father-headed families would be more likely to be accepted as legitimate family structures." ${ }^{229}$ By viewing fatherhood and father care differently, we advance the equality interests of persons who have formed nontraditional family structures in which male caregivers play a central role.

222. See Okin, supra note 219, at 66-67; see also NUSSBAUM, supra note 220, at 272-73 (discussing workplace and larger equality concerns relevant to political theory).

223. Louise B. Silverstein, Fathering Is a Feminist Issue, 20 PSYCHOL. OF WOMEN Q. 3, 4 (1996). Other feminists, such as Sara Ruddick, would highlight the ways in which this characterization of fatherhood tends to distort our understanding of a mother's role. As she explains, "[m]aterial support is not a distinctly paternal obligation but, on the contrary, it is a fact of most women-mothers' lives and a necessary condition of any effective childcare." Ruddick, supra note 10, at 230.

224. NUSSBAUM, supra note 220, at 272.

225. SCOTT COLTRANe, FAMILY MAN: FATHERHOOD, HOUSEWORK, AND GENDER EQUiTy 191 (1996).

226. See NUSSBAUM, supra note 220 at 272-73 (implicitly adopting Susan Okin and John Stuart Mill's arguments).

227. See id.

228. See id.

229. Silverstein, supra note 223 , at 6. 
Apart from these wider social benefits, liberal feminists also promised that, by increasing fathers' nurturing obligations, men themselves would be transformed. Martha Nussbaum argued that men suffer certain emotional and cognitive losses by not participating in care work, and that these problems are alleviated when they take on mothering roles. ${ }^{230}$ More recently, Nancy Dowd has suggested that increasing fathers' roles will cause men to live more emotionally rich and satisfying lives. ${ }^{231}$ Specifically, Dowd points to research showing that when fathers take on a nurturing parenting role this shift becomes "a compensatory... corrective emotional experience that $\mathrm{c}$ [an] restructure men's relational abilities, spilling over from parenting to other arenas of life." ${ }^{232}$ Citing the work of scholars in masculinity theory to support her claims about emotional growth, ${ }^{233}$ Dowd explains that "fathering may contribute to men's development of emotional skills, and rejection or compensation for the learned responses of anger, avoidance, and lack of communication." 234 Additionally, she suggests that requiring men to take on nurturing mothering duties promises to decrease men's homophobia by reversing the stigmatization of gay men's emotional responses, such as their willingness to acknowledge the importance of the emotional dimensions of life, their ability to value interpersonal connections, and their capacity for nurturing. ${ }^{235}$

Dowd's comments reflected an interesting convergence in feminist legal theory between the views of liberal feminists and those of cultural feminists, for cultural feminists also argued that men would cultivate important and necessary moral and ethical skills if they were required to play mothering roles. ${ }^{236}$ Specifically, leading cultural feminists like Dorothy Dinnerstein have argued that shared parenting arrangements are essential to disrupting patriarchal arrangements and for making persons of both genders "fully human." 237 Additionally, Nancy Chodorow and Dinnerstein have argued that as long as women are required to bear the bulk of responsibility for childcare, they

230. See NuSSBAUM, supra note 220 at 272-73.

231. DowD, supra note 19 , at 52 .

232. Id. at 53 .

233. Id. at 42 .

234. Id. at 43. Dowd's claims rely on the work of sociologists, psychologists, and political theorists exploring fatherhood through the lens of masculinity theory. These scholars include Dorothy Dinnerstein, John Ross, John Snarey, and Scott Coltrane.

235. Id. at 192-93.

236. See, e.g., Martha Chamallas, Introduction to Feminist Legal Theory 53-57 ( $2 \mathrm{~d}$ ed. 2003) ("[C]ultural feminism aims at changing men and society by stressing female virtues."). Sociological studies of fatherhood tend to support the claim that mothering or parenting can play this transformative role. See also DOUCET, supra note 13, at 9-12 (discussing the discomfort many men feel when they participate in parenting communities with mothers); Aaron B. Rochlen et al., "I'm Just Providing for My Family:" A Qualitative Study of Stay-at-Home Fathers, 9 PsYCHOL. MEN \& MASCULINITY 1, 8-9 (2008) (describing how stay-at-home fathers' experiences made them feel more "feelings-oriented," "emotional," "aware," "nurturing," and "civilized").

237. Marianne Hirsch, Review Essay, Mothers and Daughters, 7 Signs 200, 208 (1981) (discussing the work of Nancy Chodorow and other feminists on mothers and daughters). 
will not be able to achieve their own self-realization or help their own female children achieve self-realization because of their ambivalence about their own lives. $^{238}$ Ironically, although cultural feminists played an important role in calling on men to play more of a role in childcare, they also valorized motherhood in ways that may have concomitantly discouraged male participation as well. Their work as a whole tended to naturalize intimacy practices between mothers and their children. Additionally, certain ways in which they described parent-child relations would undoubtedly raise questions for some child protection authorities today. Indeed, because cultural feminists treated mothers as beyond sexual suspicion, they felt free to discuss the orgasmic sensations of breastfeeding ${ }^{239}$ and the erotics that flow from the erosion of physical boundaries between mother and child. ${ }^{240}$

While cultural feminism has in large part retreated from conversations about parenting, ${ }^{241}$ liberal feminist scholars' calls for men to take on more childcare responsibilities have continued into the present day. However, liberal feminists have continued this conversation without any attempt to contradict the dominance feminist claim that increasing fathers' role in childcare will create grave risks for children. ${ }^{242}$ The response to dominance feminists' concerns, if any, is offered by implication rather than any direct and sustained conversation. Indeed, rather than engage this problem directly, liberal feminists like Nancy Dowd and Louise Silverstein have simply announced that

238. Id.

239. Id. at 221 .

240. Adrienne Rich's work on the mother-daughter bond has proved germinal to cultural feminists' work in this area. Analyzing her work, Suzanna Walters explains,

In [Rich's] view, mother/daughter relationships take on an almost spiritual and primordial quality, signified largely by their shared "femaleness": "Mothers and daughters have always exchanged with each other-beyond the verbally transmitted lore of female survival-a knowledge that is subliminal, subversive, preverbal: the knowledge flowing between two alike bodies, one of which has spent nine months inside the other."

SuZANnA Danuta WALTERS, LiVES TOGETHER/WORLDS APART: MOTHERS AND DAUGHTERS IN Popular CUlture 146-47 (1992) (quoting AdRIENNE RiCH, OF WOMAN BORN: MOTHERHOOD AS EXPERIENCE AND INSTITUTION 127, 220 (10th ed. 1986)). Rich continues to explore these themes, explaining:

If we consider the possibility that all women - from the infant suckling her mother's breast, to the grown woman experiencing orgasmic sensations while suckling her own child, perhaps recalling her mother's milk-smell in her own . . . to the woman dying at ninety touched and handled by women - exist on a lesbian continuum, [all of us] can see ourselves as moving in and out of this [lesbian] continuum whether we identify ourselves as lesbian or not.

Adrienne Rich, Compulsory Heterosexuality and Lesbian Existence, 5 SIGNS 631, 650-51 (1980) (quoted in Hirsch, supra note 237, at 221-22).

241. The most prominent writer that has addressed this topic in recent years is political philosopher and feminist legal theorist, Robin West. Her work, however, still has ties to the "different voice" feminism that characterized the work of cultural feminists. See ROBIN WEST, CARING FOR JUSTICE (1997) (arguing that caregiving is required for the development of moral decision making).

242. See NuSSBAUM, supra note 220, at 272-73. Nussbaum's comments rest on the assumption that there is something inherently wrong with traditional masculinity as it relates to childcare. 
"fathering" is a feminist issue, and proceeded directly to reimagining masculinity in a way that allows men to focus on nurturing. ${ }^{243}$ However, by making suggestions about how masculinity should change, both Dowd and Silverstein have implied that there is something wrong with traditional masculinity. Their work suggests that liberal feminists also have been influenced by the sexual suspicion claims made by the dominance feminist camp. $^{244}$ Certainly, liberal feminists may have unarticulated critiques of traditional masculinity that are different from those of dominance feminist scholars, but it would be worthwhile to have a sustained conversation about why liberal feminists are troubled by traditional masculinity before we begin to advocate for new models of masculinity and fatherhood.

Liberal feminists' apparent avoidance of questions regarding dominance feminists' representations of men and fathers may be understandable. Dowd offers one consideration that could explain liberal feminists' reluctance to problematize dominance feminists' accounts of masculinity and fatherly care when she discusses the disturbing claims made by fathers' rights activists about the central role that fathers should play in child rearing. ${ }^{245}$ Liberal feminists may rightly be concerned that their attempts to productively critique dominance feminists' claims about fathers may be co-opted by fathers' rights groups in ways that would support patriarchal arrangements in families. Specifically, because fathers' rights groups emphasize the central and unique role that fatherhood plays in child development, they threaten to both devalue women's contribution to childcare and complicate child custody disputes. ${ }^{246}$ Leading feminist scholar Martha Fineman, for example, worries about the current popularity of gender-neutral models of parenting. To the extent they suggest fathers and mothers are equally responsible for nurturing and care, Fineman explains, they ignore material realities. ${ }^{247}$ Fineman argues that these models prioritize formal equal treatment of the sexes over the real concerns of mothers. $^{248}$

The challenges described above are not insubstantial. However, liberal feminists' reluctance to critique dominance feminists' understandings about men and childcare has compromised their ability to offer a compelling account of how and why fatherhood must change to allow for coequal parenting. It is

243. See DowD, supra note 19, at 157-80 (discussing new model of fatherhood without engaging dominance feminist scholars' concerns); Silverstein, supra note 223, at 30-31 (discussing new ways of constructing fatherhood without discussing dominance feminists' concerns).

244. Nussbaum has argued that coequal parenting is essential to reform gender relations. She argues that children that grow up in homes where both genders participate in childcare implicitly value and prioritize gender equality. See NuSSBAUM, supra note 220, at 272-73.

245. DowD, supra note 19, at 171-72 (discussing fathers' rights movements).

246. See, e.g., Silverstein, supra note 223, at 4.

247. Martha Albertson Fineman, Fatherhood, Feminism and Family Law, 32 MCGeORGE L. REV. 1031, 1040 (2001).

248. Id. at 1034 . 
likely that liberal and dominance feminists may not agree about fathers' roles in the family; however, a more engaged acknowledgement of the competing and contrary claims made by dominance and liberal feminists would enrich both groups' analyses.

\section{Post-Dominance Feminists and Fear of the State}

While dominance feminists and liberal feminists have proceeded apace without discussing the apparent conflicts between their perspectives, a new camp of post-dominance feminist scholars has emerged. This camp makes arguments that trouble the seemingly thin areas of agreement between liberal and dominance feminist scholars. For example, dominance feminists and liberal feminists seem to agree that harnessing the power of the state is essential to ensure that family relations are not relegated to the private sphere, where women and children would be more subject to the whims of abusive fathers. ${ }^{249}$ Post-dominance feminists may argue that my approach relies on an overly sanguine view of state power. They suggest instead that state intervention in private life can be authoritarian, paternalistic, and can compromise women's autonomy.

For example, post-dominance scholars like Melissa Murray have called on us to think more deeply about so-called private sphere family relationships. As she explains, these relationships are represented as being shaped by civil law, but in fact they are strongly influenced by seemingly unrelated criminal statutes that subsidize the creation of certain family forms. ${ }^{250}$ In her article, Strange Bedfellows, Murray describes how criminal sodomy and adultery statutes historically promoted marriage (which was technically civilly defined) because these criminal statutes helped ensure that sexual activity could only legally occur within a marriage. ${ }^{251}$ Jeannie Suk also raises questions about using criminal law to regulate intimate relationships. Suk describes the ways in which prosecutors have used protective orders in domestic violence cases to effectively institute a de facto divorce between cohabitating couples that the state believes should no longer be intimate partners. ${ }^{252}$ Specifically, Suk shows that the liberal feminist response to domestic violence - to use the protective order as a shield to prevent abusers returning to the home-has had the unintended consequence of depriving women of the autonomy to make their

249. This was particularly true in the context of discussions of domestic violence. See, e.g., CATHARINe A. MACKinNon, TOWARD a Feminist THeORY of the STATE 193-94 (1989); ELIZABETH M. SCHNEIDER, BATTERED WOMEN \& FEMINIST LAWMAKING 13 (2000); Cheryl Hanna, No Right To Choose: Mandated Victim Participation in Domestic Violence Prosecutions, 109 HARV. L. REV. 1849, 1869 (1996) ("“M]uch of feminist academic discourse concerning domestic violence has centered on the argument that 'private' violence must be reconceptualized as 'public' in order to compel state intervention.").

250. See Murray, supra note 20, at 1255-56.

251. Id. at 1269.

252. Suk, supra note 20 , at 8 . 
own decisions about wanted intimate relationships. ${ }^{253}$ Prosecutors can effectively prevent couples that previously cohabitated from cohabitating again by automatically entering protective orders whenever there are domestic violence allegations, and prosecuting the returning paramour for burglary should he enter the home. ${ }^{254}$

The determinative, key feature in post-dominance feminists' work is a renewed focus on women's autonomy and liberty. Fairly viewed, their positions are only tenable because of the early work done by dominance feminists and liberal feminists. Early feminist efforts calling for state regulation effectively secured for women a certain baseline level of fair treatment, leading postdominance feminists to now explore their right to freedom in so-called private family arrangements. That being said, post-dominance feminists are rightly suspicious of state regulation, recognizing that it does not always advance women's equality. The autonomy concerns that Murray and Suk raise gain new force when we think about how tightly child molestation law regulates parenting, as it now allows parents to be sanctioned for exposing their children to primal scenes, cross-gender conduct that violates social norms, and interactions that contradict cultural beliefs about parental modesty and children's modesty. ${ }^{255}$ Post-dominance feminists would argue that when the law intervenes in these cases it is being paternalistic, and it prevents women from exercising personal agency to decide what kinds of family relationships they would like to form. Certainly, the danger is great when the law ignores private family abuse, they would argue, but it is equally dangerous when it enforces a uniform state-sponsored consistency that stamps out privately negotiated intimate relations and tramples on women's ability to renegotiate default caregiving norms in the family.

Given the disconnect between the various groups of feminist scholars writing about family relations, some general suggestions can be offered for improving feminist conversations about gender-neutral parenting and the risks children face from sexual exploitation. Arguably, the contribution that dominance feminists have made in advancing our understanding of child molestation law has dampened liberal feminists' interest in uncovering the limiting and problematic ways that dominance feminism has shaped conversations about child molestation. However, this Article shows that there is a way to enter the lion's den and move past the current impasse to some productive end. Each collective of feminist scholars writing on these questions raises important questions, but each group's arguments present challenges for the project of gender equality.

253. Id. at 62-63.

254. Id. at 31, 60-63.

255. Primal scenes are scenes that require children to acknowledge or witness their parents' sexual practices. See Okami et al., supra note 5, at 361. 
First, although dominance feminists were successful in convincing legislators to expand the category of injury in the child molestation cases, they have devoted insufficient attention to theorizing about when and how we should recognize that harm has occurred. This undertheorization problem is a key stumbling block in the prosecution of child molestation cases involving intimate care, and it leads courts to rely on gendered parenting norms and sexual privacy arguments in their analyses. Second, dominance feminists have encouraged a view of male sexuality as inherently aggressive and threatening to children. They have not considered the ways in which their suspicion of male sexuality has dovetailed with a more conservative gender project, one more associated with child welfare authorities who are fundamentally uncomfortable with men who mother. Dominance feminists are likely to hold to their initial position - that men are not welcome in the domain of intimate care. However, they must come to grips with how their recruitment of the state in enforcing this understanding reduces women's autonomy and burdens women's ability to negotiate caregiving responsibilities in ways that result in women remaining in the socially subordinate role of primary caregiver.

Liberal feminists also have a great deal of work ahead in deciding how they intend to reimagine fatherhood. They have not considered how the sexual suspicion of men at the heart of the dominance feminist critique is currently being deployed in the legal system to threaten men who have adopted an ethic of care. They have not considered the degree to which this sexual suspicion may have shaped their own understandings of traditional masculinity. Relatedly, liberal feminists need to spend more time considering whether masculinity studies can help determine how to subsidize state arrangements that encourage men to adopt models of masculinity that celebrate nurturing and care. ${ }^{256}$ They need to consider whether any features associated with traditional masculinity should be integrated into models of parenting. Only then can they advance models of parenting that do not reify motherhood as the ideal model; only then can they credibly claim that they are advocates of gender-neutral parenting.

Finally, post-dominance feminists must engage with the risks posed by their focus on autonomy issues. They should honestly address the continuing threat posed by male domination in some families, and the risk that a veil of privacy may leave some children unprotected. Feminists may want state intervention that looks judgmental and even paternalistic if it is used to provide some baseline, minimum level of protection for children. Post-dominance feminists can certainly contribute important insights by highlighting the ways in which the dominance feminist critique undercuts women's ability to renegotiate the default gender norms that allocate childcare responsibilities, a

256. See e.g., David S. Cohen, Keeping Men "Men" and Women Down: Sex Segregation, Anti-Essentialism, and Masculinity, 33 HARV. J.L. \& GENDER 509, 511 (2010) ("Without investigating the way law affects and constructs men and masculinity, equality will be illusive."). 
consideration that has thus far gone unexplored. However, autonomy and liberty arguments can function as a double-edged sword. When liberty, autonomy, and privacy claims are made in an acontextual fashion, they can mask how the background conditions of social inequality prevent full exercise of these rights or freedoms. However, post-dominance feminists appear to believe that contemporary society has sufficiently changed to allow women to exercise true autonomy and liberty when making choices about family caregiving arrangements, and the state often stands as an impediment to the exercise of these freedoms.

Feminists of all stripes should also engage with the broader theoretical questions raised in Part I about the limits of a social norms analysis and the use of sexual privacy logic in the intimate care cases. Feminist analysis is needed to negotiate how to resolve children's sexual privacy complaints and to assess the degree to which feminists are prepared to challenge sexual privacy claims that rest on established gendered social norms. Finally, contemporary feminists should begin to pay more attention to the ways in which society can subordinate and punish certain men when they become allies of feminist projects. These male allies are sympathetic to feminists' values, such as the importance of providing care, and feminists need to support and subsidize the efforts of individuals that push the boundaries of traditional gender roles. Some feminists have begun to do more work to recognize the contributions of these male allies. ${ }^{257}$ The next step is to ensure that feminist men who adopt a commitment to care do not find themselves being represented as a source of sexual threat based on outdated standards that dominance feminists called for decades ago. Consistent with this view, this Article attempts to acknowledge the debt that feminists owe to the men who have stepped beyond traditional notions of masculinity and embraced activities traditionally associated with a female-gendered understanding of care. ${ }^{258}$

In summary, I cast my lot with liberal feminist scholars who argue that we need a reconstructed vision of fatherhood that ensures that childcare obligations are divided more evenly. ${ }^{259}$ There is, in effect, a "patriarchal dividend," a natural state of affairs where childcare responsibility "naturally" falls more heavily on women, making it harder for them to participate in wage labor and

257. Specifically, some scholars have begun to deconstruct the ways in which contemporary culture romanticizes and valorizes the role of mothers and ignores fathers' role and responsibility to provide nurturing and care. See Naomi Mezey \& Cornelia T.L. Pillard, Against the New Maternalism, 18 MICH. J. GENDER \& L. 229, 237 (2012) ("We critique the way that the culture of new maternalism [in popular culture] reinforces a highly gendered, neotraditional approach to parenting and family life that makes it harder for men and women to vary from the dominant cultural scripts."); Rosenblum, supra note 10, at 59-67 (urging us to move toward models of parenting that recognize the capacity of both sexes to "mother" and revealing how technological changes promise to displace biology's oversized role in fixing mothering as an activity delegated solely to women).

258. See DowD, supra note 19, at 55-57.

259. See text and sources, supra note 19. 
professional life. However, feminists must have a more honest and open discussion about the questions and concerns raised by different feminist constituencies about the role men should play in addressing this issue. This Article offers an update to the liberal feminist account of the role of fatherhood in establishing gender equality and lays out the hard privacy and autonomy questions liberal feminists must consider if we are to advance a gender-neutral approach to parenting.

III.

\section{RECONSTRUCTING FATHERHOOD IN THE SHADOW OF CHILD MOLESTATION LAW: THEORETICAL AND PRACTICAL CHALlENGES}

Part III shifts away from the challenges feminist legal theorists face as they dialogue about the proper role of fathers in American families, to provide a descriptive account of the practice and experience of fatherhood in the shadow of child molestation law. Specifically, Part III shows how the conceptual problems that plague fathers' conduct in intimate care cases also create anxiety for fathers as they engage in the daily experience of caregiving. The discussion builds on Foucault's insights about how surveillance exerts disciplinary power over time, extending this analysis to consider the likely effects when legal and disciplinary norms are unclear. Part III shows that in these conditions, men inclined to provide care face incentives to opt out of caregiving arrangements or orchestrate their activities to ensure that they conform to conservative gendered understandings of parenting. Additionally, inchoate social anxiety about the practice of fatherhood provides cover and justification for men to opt out of caregiving roles, as there are no clear scripts or guideposts for the proper performance of fatherly caregiving duties.

\section{A. Child Molestation Law and the Disciplining of Fatherhood}

How does child molestation law affect the practice and experience of parenthood? First, I dispose of the notion that there is any simple, uncomplicated process by which fathers are educated about child molestation statutes. The majority of fathers are most likely unaware of the specifics of child molestation laws in force in their communities. Additionally, as I have argued in Part I, simple notice about the statutory requirements would not provide fathers with meaningful guidance, as child molestation provisions are so broadly worded that they could not on their face provide fathers with any fair notice about what is prohibited. Rather, I argue that fathers experience child molestation law as a form of "law in everyday life." Austin Sarat coined this phrase to describe how law is both constitutive of culture and constituted by culture. ${ }^{260}$ As applied here, Sarat's account explains that we should expect

260. Austin Sarat \& Thomas R. Kearns, Beyond the Great Divide: Forms of Legal Scholarship and Everyday Life, in LAW IN EVERYDAY LIFE 21, 55 (Austin Sarat \& Thomas R. Kearns eds., 1993). 
various social actors to frame laypersons' understandings of child molestation law based on an imperfect understanding of the law's requirements, developing a cultural common sense about child molestation law. However, Sarat explains that the law's relationship to social and cultural understandings is reciprocal, for the law also relies on cultural norms about forbidden behaviors to give substance to the broad, amorphous definitions of legally prohibited behavior in child molestation statutes. ${ }^{261}$ Sarat's work, therefore, suggests that, although many fathers never find themselves in a courtroom, they still negotiate a world in which they must conform their behavior to a highly gendered cultural common sense about the law.

Sarat's work helps us to understand that the institutional players enforcing child molestation law interpret and deploy institutional norms based on partial or inaccurate understandings. Fathers are forced to rely on these imperfect proxies to establish their understanding of child molestation law. These proxies (or institutional players) inform fathers when they have run afoul of child molestation provisions. ${ }^{262}$ Relevant proxies include teachers, principals, social workers, doctors, hospital staff, and even their spouses. Popular culture (such as disturbing child molestation stories on the news) also provides an imperfect education about what the law requires. All fathers absorb these understandings about the requirements of child molestation law. That is, all fathers are subject to a "disciplinary process" that encourages them to internalize socially conservative norms about the appropriate domain of fatherhood. ${ }^{263}$ However socially vulnerable fathers - gay, male parents, poor fathers, as well as single, widowed, and divorced fathers - will feel the threat of the law far more acutely.

In his book Discipline and Punish, Foucault provides a more detailed discussion of this disciplinary process, describing the ways in which institutional players ensure that other social actors conform their behavior to institutional requirements. ${ }^{264}$ Foucault describes three key elements of a disciplinary regime: hierarchical surveillance, normalizing judgment, and opportunities for what he calls "the examination." ${ }^{, 65}$ Each element creates incentives for the person to conform to the institutional requirements of a given disciplinary regime, and to internalize those institutional requirements through an anxiety-laden process that makes those requirements part of their "common

Sarat and Kearns argue that it is a mistake to think that one can approach the study of law as separate from culture or the study of culture as separate from law, as the two have a dialogic relationship. Id. at 55-56. They explain that "everyday life" has its own normative ideas which shape the law and in turn shape the way law is understood, resisted, and interpreted. $I d$.

261. See id. at 56-57.

262. Some studies have shown that institutional players develop group-specific and different understandings regarding what constitutes sexual abuse. See Cartsens, supra note 192, at 316 (explaining that "jurists and medical professionals" tend to rank incidents as less serious than do social workers, police officers, and teachers).

263. FOUCAULT, supra note 22, at 170-94 (outlining disciplinary processes).

264. Id.

265. Id. 
sense" thinking. ${ }^{266}$ As applied to our discussion, Foucault's analysis requires us to consider the special conditions fathers who dare to mother face regarding surveillance and "normalizing judgment," which are the processes used to determine whether a subject has conformed to institutional norms. ${ }^{267}$ Caregiving fathers face a criminal law regime that outlines the express prohibitions used to assess a father's conduct; however, the normalizing judgment arising from these prohibitions is far from uniform. Indeed, as Part I shows, the broad, vague nature of child molestation statutes - with their potential to assign error for both clearly illicit conduct and more mundane behavior-gives institutional players extraordinary discretion to interpret these requirements. Through this subjective evaluation of fathers' behavior against the measuring stick of state law, these institutional players assume the authority to police fathers' interactions with their children. Socially vulnerable fathers, who typically are already subject to a great deal of scrutiny, are subject to "examination" by a vast number of actors with very different institutional positions. These actors often have confused and conflicted understandings about the law and fathers' proper role in providing nurturing care. Again, these actors include judges, prosecutors, social workers, psychologists, school authorities, media, and sometimes even the spousal partner who shares caregiving responsibilities.

Importantly, although socially vulnerable fathers may know they are being evaluated by a person with an imperfect understanding of child molestation law, they are less likely to challenge persons in authority, as they know that a mere complaint about molestation can be a sufficient basis for criminal or civil sanction. The process of continually submitting to these institutional players' imperfect judgments tends to leave fathers with less discretion when they play mothering roles. Additionally, we must recognize that the institutional players in child molestation disputes are acting within their discretion when they use conservative gender norms to interpret fathers' behavior, as the law does not require anything more. Consequently, institutional actors tend to believe that fathers' behavior with children should be more carefully scrutinized. The cases bear out these claims. For example, a mother's kisses to her child tend not to invite scrutiny. However, as we see in Marokity, J.S., and other cases, when fathers are involved, the length of a kiss, its style, placement, and timing are all questions that invite inquiry and the potential for punishment. A mother's decision to give a child a bath typically raises little attention. Conversely, fathers must withstand inquiry into the manner in which the bath is conducted, its length or duration, and even whether a washcloth is used. On the whole, one sees that institutional players using the threat of child molestation law tend to

266. Id.

267. Id. at $170-84$. 
give fathers less discretion to engage in nurturing and intimate care than mothers. ${ }^{268}$

As Part I explains, part of the reason for the wide variance in how different institutional players interpret child molestation law stems from the undertheorized understanding of injury that informs these statutes. When the law is unclear, when underlying compliance norms are in flux, persons subject to legal prohibitions can become compulsive in their attempt to comply with legal requirements. A father who turns to social norms to understand the appropriate scope of discretion knows that the norms used by a given institutional player may not match his understandings. Similarly, the sexual privacy analysis provides no assurances of uniform interpretation, particularly when a subjective sexual privacy understanding controls. ${ }^{269}$ As a result, fathers cannot reliably count on their moral instincts or intuitions to guide them safely away from prohibited behavior.

Foucault suggests that the experience of surveillance by these institutional players and being subject to this repeated process of normalizing judgment has a powerful effect on an individual's consciousness. ${ }^{270}$ As he explains, the ideal disciplinary subject is "caught up in a power situation of which they themselves are the bearers." 271 In short, fathers have been properly "disciplined" when they have internalized institutional norms that tell them they should be sexually suspicious or wary of their own conduct. They have been properly disciplined when they learn that they must be ever vigilant to whether they are experiencing arousal while nurturing or, conversely, that their children may experience the caregiving they provide as causing a kind of sexual violation. Consequently, one expects to find that fathers spend more time parsing their interactions with children to ensure that they do not engage in behavior that seems sexually arousing or sexually motivated. Importantly, when properly disciplined, fathers will engage in this constant reflexive process of internal

268. Cf. Vicki Schultz, The Sanitized Workplace, 112 YALE L.J. 2061 (2003) (explaining that institutional actors may institute voluntary compliance norms that exceed what the law actually requires). For example, social workers accustomed to nurturing care being the province of mothers may interpret child molestation standards in ways that strongly reinforce gender norms, and that would be rejected by many judges and prosecutors. See Jodi Denell Jones, Sexual Offender, Sexual Abuse Victim, and Generalist Population Therapists' Perceptions of Permissive Parent-Child Sexual Boundaries and Altered Perceptions of Self, Others, and Adaptation to the World as a Result of Vicarious Trauma 52 (June 2008) (unpublished Ph.D. dissertation, Ohio University) (on file with the California Law Review) (describing findings showing that social workers' readings of allegedly abusive behavior often did not match those of lawyers and judges).

269. For example, if one believes that child molestation law is motivated by concerns about children's sexual privacy, then a child who dislikes the manner in which he is bathed may have a valid claim of harm. But if the law is purely concerned about social norms, the same bath, despite the child's cries, would not be a basis for punishment.

270. FOUCAULT, supra note 22, at 200-01 (describing the effects of surveillance and judgment through the Panopticon).

271. Id. at 201. 
review, regardless of whether they are actually being watched by a third party when providing care.

In the end, I argue that this review produces a special kind of anxiety that discourages men from providing care. One can expect to find that many fathers only provide nurturing care when it aligns with well-accepted gender-specific social norms about parenting, as this tends to decrease the risk of suspicion. Alternatively, fathers may entirely opt out of providing nurturing or intimate care to avoid the risk of punishment. Socially vulnerable fathers, however, are trapped, as they are both subject to more suspicion and fully aware that they cannot opt out of a caregiving role. Consequently, the scrutiny they endure results in fathers feeling unwelcome or socially suspect, even as they perform essential mothering functions.

Foucault's analysis also helps us understand the "mystery" that confounds sociologists and feminist legal scholars - why is it that men have not become more actively involved in providing childcare, despite the shift in gender norms that encourages them to take on more childcare responsibilities? ${ }^{272}$ Given the broad cultural confusion about the proper place of men in providing intimate care, fathers have incentives and, indeed, even cover to justify why their behavior tends to hew toward social stereotypes that would limit their caregiving role. Gender stereotypes effectively provide safe harbor because these stereotypes reflect gendered understandings that keep men safely away from the messy intimate care tasks that constitute "mothering." Widespread social anxiety about child molestation allows men to rely on strong essentialist claims about women and female children's need for sexual privacy or homophobic understandings about boys' sensitivity to male touch as a way to explain and justify their refusal to assist with intimate caregiving.

Proof of this anxiety and fathers' search for safe harbor is readily apparent when one carefully reads child molestation cases. ${ }^{273}$ One father, accused of molesting his developmentally disabled son during a diaper change, explained that he tended to avoid diaper changes because "he was afraid of trying or possibly getting into abuse." ${ }^{274}$ A father accused of penetrating his toddler-age daughter during her bath reported that he was so confused by the allegation and traumatized by the prospect of having committed abuse that he could not give a

272. See Lyn Craig, Does Father Care Mean Fathers Share? A Comparison of How Mothers and Fathers in Intact Families Spend Time with Children, 20 GENDER \& SOC'Y 259, 270 (2006) (offering data showing that women tend to spend half of their time on intimate care such as bathing, feeding, and dressing children while men spend less of their time on such activities); Alice S. Rossi, Gender and Parenthood, 48 AM. SOC. REV. 1 (1984) (suggesting that men distance themselves from children in early infant care).

273. Fathers sometimes seek safe harbor by simply refusing to provide certain kinds of care. For example, in In re David P. v. Joshua P., one father explains, "I did not touch my daughter. I don't even ... bathe her or wipe her because I want [her] to know it's not okay for everybody to do that. . . . I would never do any sick [thing] like that to my own daughter." No. B217350, 2010 WL 2045194, at *2 (Cal. Ct. App. May 25, 2010).

274. State v. Lansberry, No. 20101, 2010 WL 22308, at *3 (Ohio Ct. App. Jan. 10, 2001). 
coherent account of his actions. ${ }^{275}$ Other cases also show that fathers willingly submit to and seek out the authorizing judgment of a female caregiver as a way of demonstrating the legitimacy of their own conduct. ${ }^{276}$ They attempt to justify a controversial diaper change by arguing that it was only performed because it was authorized by a female caregiver, or was conducted according to her precise instructions, or was conducted under appropriate female supervision. ${ }^{277}$ Yet even fathers who willingly submit to surveillance and seek authorization find that their approach is not foolproof, for the sexual privacy cases are populated by men who have imperfectly performed tasks authorized and assigned by maternal caregivers.

Some feminists may have reservations about this Foucauldian reading of fatherhood. They argue that it was not so long ago that feminists did the hard work necessary to reveal patriarchal privilege in the family and to demonstrate its connection to child molestation. ${ }^{278}$ Dominance feminists in particular may be disturbed by the way this discussion focuses on the "microdynamics" of power as they affect individual fathers. Indeed, Foucault's work has been rejected by many feminists for this reason, as well as a concern that some of his discussions express a cultural relativist attitude about child molestation law that is deeply disturbing. ${ }^{279}$ However, my goal here is to show how the microdynamics of power tell us a great deal about why structural arrangements have not changed. By examining the microdynamics of these anxieties on the ground, we can better understand why most families have not embraced the gender-neutral parenting model urged by liberal feminists. ${ }^{280}$

\section{B. Disciplinary Authority in Practice: Anxieties on the Ground}

The theoretical account provided above makes clear the risk that current child molestation standards pose to fathers; however, the real world consequences of these standards are less apparent. Certainly, the cases suggest that some fathers are anxious, but how widespread is this problem? Skeptics will ask, where is the empirical evidence to establish the importance of this

275. In re R.A., 403 N.W.2d 357, 361 (Neb. 1987).

276. See, e.g., Hicks v. Larson, 884 N.E.2d 869, 875-76 (Ind. Ct. App. 2008) (describing grandfather's justification for his actions by relying on instructions from the child's grandmother to apply diaper cream); Rice v. Va. Dep't of Soc. Serv., No. 0413-06-2, 2007 WL 895753, at *4-6 (Va. Cir. Ct. Mar. 27, 2007) (finding that a reasonable person would conclude that a father would request that his parents watch him insert suppositories into his daughter to ensure sexual interest was not presumed).

277. See cases cited supra note 276.

278. See Vanessa E. Munro, Legal Feminism and Foucault: A Critique of the Expulsion of Law, 28 J.L. \& SOC'Y 546 (2001).

279. See BELL, supra note 201, at 14-57.

280. See Lynne A. Haney, Feminist State Theory: Applications to Jurisprudence, Criminology, and the Welfare State, 26 ANN. REV. SOC. 641, 658 (2000) (arguing that a more layered approach, one that recognizes inconsistencies in application and approach by various segments of the state, would better serve feminists). 
issue? Isn't fathers' resistance to providing intimate care better explained by laziness or lack of interest, rather than the risk of criminal sanction?

While no comprehensive large-scale empirical studies of fatherhood have focused on fathers' anxieties about claims of sexual impropriety, word from the trenches suggests that there is a fair degree of concern in many quarters. ${ }^{281}$ In Do Men Mother?, Andrea Doucet offers data from over one hundred fathers who are primary caregivers to their children, many of whom report having anxiety about social misperceptions regarding their interactions with their female children. ${ }^{282}$ Doucet's interviews suggest that fathers' anxiety is at its peak when children reach the preteen or teenage years, ${ }^{283}$ but other evidence suggests that there is anxiety about younger children as well.

Indeed, other scholars have observed that fathers experience substantial discomfort with intimate care for infants and toddlers, particularly if their behavior is likely to be scrutinized by social workers or distrustful partners. ${ }^{284}$ Some fathers may engage in caregiving with less obvious alarm, but they selfdiscipline and perform certain tasks inadequately to avoid being perceived as having acted inappropriately. ${ }^{285}$ Empirical studies suggest that fathers are right to be concerned. Studies show that third parties demonstrate far more acceptance for women to engage in intimacy and caregiving with children, but grant fathers far less leeway. ${ }^{286}$ These studies help explain why fathers believe that they are subject to a presumption that they are not supposed to be physically close with children. Fathers writing on the progressive blog Daddy

281. DOUCET, supra note 13, at 191-92 (discussing individual cases). Close review of the intimate care cases reveals fathers avoiding certain intimate care tasks, either because they are afraid that they are violating social norms or because they may inadvertently do something that a child finds traumatic. See, e.g., State v. Lansberry, No. 20101, 2010 WL 22308, at *3 (Ohio Ct. App. Jan. 10, 2001) (accused father explains that he didn't change son's diaper because "he was afraid of trying or possibly getting into abuse").

282. DOUCET, supra note 13 , at 121.

283. Id. at 120-21. One father commented:

When puberty arrives, the entire dynamic changes. You don't think much of the physical thing that goes on with your kids until then. Embracing and hugging. I am trying to think about the parallel with a mother and son. Obviously the same thing happens to a degree, yet far less starkly.

Id. at 121 .

284. See Sharon Heller, The Vital Touch 5 (1997) (discussing parent's avoidance of intimacy with children when there is partner mistrust); Notes, Working with Young Fathers Workshop, www.rcm.org.uk/EasysiteWeb/getresource.axd?AssetID=9119 (last visited Mar. 16, 2013) (discussing young fathers' intimacy-avoidance behavior with young children because of fear of social worker accusations); see also DOUCET, supra note 13, at 190 (discussing fathers' perceptions of suspicion and accusation from infant massage instructor).

285. See BabyCenter Member, How Can I Make My Husband Comfortable with Changing our Daughter's Diapers?, BABY CTR. MOM ANSwERS (Oct. 21, 2003), http://www.babycenter.com 1400_how-can-i-make-my-husband-comfortable-with-changing-our-daug_500596_1.bc?startIndex= 20\&sortFieldName $=$.

286. See, e.g., Jacquie Hetherton \& Lynn Beardsall, Decisions and Attitudes Concerning Child Sexual Abuse: Does the Gender of the Perpetrator Make a Difference to Child Protection Professionals?, 22 CHILD ABUSE \& NEGLECT 1265 (1988); Johnson \& Hooper, supra note 15, at 121. 
Dialectic openly talk about the suspicion and gender bias they encounter when interacting with children. Discussions between white fathers suggest that their experiences are akin to the racial profiling African Americans face from police. They argue the scrutiny black men receive for "driving while black," is similar to the scrutiny all men receive for "parenting while male."287 And while published accounts tend to focus on fathers' anxieties about being accused of molesting other people's children, the fathers' comments on the web suggest that it is all too easy for people to transfer that same sexual suspicion to a father's interactions with his own child as well. ${ }^{288}$

Indeed, currently, the blogosphere provides the most detailed evidence of fathers' anxieties about interactions with young children. Websites like Baby Center and Mamapedia offer confused and anguished questions from mothers about when it is appropriate for fathers to provide care and how to address their male partners' anxieties about molestation. ${ }^{289}$ One mother explains,

My husband refuses to wash our baby girl or wipe her well enough when he changes her diaper. He thinks that if he "touches" her, people are going to think badly of him. How can I help him get over his fear and start taking care of our baby correctly? ${ }^{290}$

Responses feature a range of perspectives, many reflecting the view that fathers should only provide intimate care in a narrow band of circumstances. Confusion over these issues is not surprising, as research suggests that there is great social variation in understandings regarding the appropriate range of intimacy and contact between family members. ${ }^{291}$

287. Jeremy Adam Smith, Parenting While Male: 74 Fathers Talk About Playground Discrimination, DADDY DiAleCTIC (Jan. 27, 2011), http://daddy-dialectic.blogspot.com/2011/01 /parenting-while-male-74-fathers-talk.html.

288. Id. (discussing concerns about molestation allegations involving their own children).

289. See, e.g., Is It Ok to Let Daddy Change Newborn Baby Girl Diapers?, YAHOO! ANSWERS (Feb. 03, 2010, 12:24 AM), http://answers.yahoo.com/question/index?qid=20100202162 445AA19v20 (expressing concern about whether it is appropriate for a husband to change a newborn baby girl's diaper). Most responses indicated that it was appropriate, but others established a clear boundary point during the toddler years when toileting duties should become solely the mother's province. Id.; see also L.Z., At What Age Does My Husband Stop Giving Our Daughter Diaper Change \&/Or Baths?, MAMAPEDIA (Mar. 05, 2009), http://www.mamapedia.com/article/at-what-agedoes-my-husband-stop-giving-our-daughter-diaper-change-or-baths (advocating gender-neutral approach and offering a range of perspectives).

290. See BabyCenter Member, supra note 285 (discussing father's anxiety over touching genitals of infant daughter). One of the more helpful responses reveals that mothers have a more relaxed attitude about cross-gender infant conduct, but have the potential to feel anxious as well:

I wonder if there's a father out there who had a baby girl and didn't feel this way. I think it's totally normal. If he has friends with daughters send him out with the guys and encourage him to ask if they had fears. He'll realize how normal he is. Talk positively with him about his feelings, and be understanding. Remind him, however, that it's not about being inappropriate, it's about not wanting her to get an infection. Only time and practice will help him overcome his anxiety. I myself still feel funny changing my son if he gets a smile on his face while I'm wiping his penis ... let's face it, it's just uncomfortable. But we do what we have to do as parents and that includes the hard or embarassing [sic] stuff.

Id.

291. See Johnson \& Hooper, supra note 15. 
Certainly, it is easy to assume that fathers' lower rate of participation in childcare is due to "lack of interest"; however, there is a wealth of qualitative evidence that rebuts this claim. Moreover, as feminist legal scholar Vicki Schultz has warned, the lack-of-interest trope is often used to hide institutional arrangements that play a role in promoting gendered arrangements in society. ${ }^{292}$ I merely suggest that the cultural anxiety about male caregiving and concerns about sexual abuse share a dialogic relationship with the law, feeding off that cultural anxiety and adding to it, by giving interested parties a basis for social interventions. While not all fathers feel this disciplinary pressure in precisely the same way, many fathers - particularly those who are committed to and think deeply about caregiving - find themselves negotiating this anxiety on a regular basis.

\section{Reimagining Fatherhood}

Given this understanding regarding the challenges fathers face, it is time to return to our primary concern: how to reconstruct fatherhood in the shadow of child molestation law. Liberal feminist scholar Nancy Dowd has made significant efforts to reimagine fatherhood, specifically to identify legal reforms that will allow fatherhood to evolve beyond its current focus on breadwinning and make men more inclined to value and take on nurturing activities. In her book Redefining Fatherhood, Dowd notes that "[n]othing in the law supports fathers' nurturing nor sanctions the lack thereof." ${ }^{, 93}$ While she argues that a gender-neutral model of parenting should be our goal, she also recognizes that the "vision of neutrality and its presumed link to gender equality remains unclear." 294 Dowd urges us to move toward an understanding of parenting that recognizes mothers and fathers as having equal responsibilities for caregiving, an androgynous model that recognizes both men and women as equally capable of care. ${ }^{295}$ However, she rightly notes that " $[\mathrm{t}]$ here is remarkably little discussion regarding our understanding of the current context of fatherhood, what the goal of fatherhood is, and what the means are of achieving that [gender-neutral] goal." ${ }^{, 296}$ Dowd therefore calls on scholars to carefully examine the "legal structures and concepts that reflect our legal vision of fatherhood," and to consider the "changes in the law [that] are necessary to a redefined fatherhood." 297 This Article is a response to her call for greater feminist attention to this issue.

292. See generally Vicki Schultz, Telling Stories About Women and Work: Judicial Interpretations of Sex Segregation in the Workplace in Title VII Cases Raising the Lack of Interest Argument, 103 HARV. L. REV. 1749, 1840-43 (1990).

293. DowD, supra note 19, at 7.

294. Id.

295. Id. at 8-9 (explaining that both sexes can mother and that nothing about nurturing parenthood is sex related or sex specific); see also DOUCET, supra note 13, at 135.

296. DowD, supra note 19 , at 8.

297. Id. 
Dowd's project, while impressive, has a limited scope, as her primary focus is on how we can change family law and workplace law (including family leave policies) in ways that would encourage fathers to enter the domain of care. ${ }^{298}$ Her work represents a welcome beginning to feminist legal discussions about the way the law imagines and shapes fatherhood; however, her failure to discuss the impact child molestation law has on fathers' discretion to provide care is curious in the extreme. Indeed, even as she urges us to move to an androgynous or gender-neutral model of parenting, ${ }^{299}$ she fails to consider that child molestation law is the area in which we see the most sustained engagement by legal actors in regulating fathers' practice of providing care. By leaving this area of law unexplored, Dowd misses a critical opportunity to explore cultural and legal resistance to a nurturing fatherhood by failing to consider how child molestation law subsidizes and rests on gender-specific norms that prevent the evolution of gender-neutral parenting models.

Dowd's reform model also presents certain difficulties. Where she does provide an understanding of what a new, "nurturing" model of fatherhood might look like, she runs the risk of reinstantiating the view that mothers are the only true ideal caregivers. Indeed, although Dowd acknowledges that men's current practices have something to teach us, she believes that, in practice, nurturing fatherhood looks substantially similar to what we see when "we look to the model of motherhood." 300 Dowd explains that motherhood is the touchstone because fathers who provide care are basically emulating mothers. ${ }^{301}$ In her view, "the motherhood role gives us a richer, fuller context to draw from in constructing a nurturing model, because more mothers have lived the practice of nurturing and because mothers have been more closely studied than fathers." ${ }^{\prime 302}$ Yet, as we see in the intimate care cases, this conceptual move can create equally serious problems, since men's behavior is often compared to specific mothers' behavior and found wanting.

Despite my reservations about Dowd's use of mothering as a touchstone, I believe that this approach may be an important conceptual way station for legal actors interested in giving fathers negotiating room to take on caregiving activities. Indeed, my intervention from Part I, calling on skeptics to reverse the groups, also runs the risk of reinstantiating motherhood as the ideal norm. To be clear, in Part I, I encouraged readers to consider whether fathers have acted improperly in particular intimate care cases by considering whether a mother who engaged in the identical practices would be equally subject to sexual suspicion. However, rather than compare a father against a specific mother in

298. Id. at $10,157-213$.

299. Id. at 7.

300. Id. at 8.

301. Id.

302. Id. at 8, 230 (proposing a "gender specific, gender conscious model that uses mothering as a touchstone to produce a "gender-neutral but gender diverse end"). 
an individual case, my analysis calls on legal actors to consider the wide range of mothering practices, and determine whether a father's purpose or practice in a particular case would seem reasonable if offered by a mother. I offer this approach based on the understanding that mothers enjoy a fairly broad range of discretion in selecting caregiving behaviors, suggesting that fathers should be given the same latitude as well. However, Dowd questions whether mothers actually enjoy such freedom. ${ }^{303}$ She argues that, rather than enjoying broad discretion, mothers know that there is an "ideal" version of motherhood to which their actions are compared. ${ }^{304}$ Therefore, she argues that we might question whether this ideal model of motherhood, when applied to test men's behavior, will be experienced as oppressive in the same way that the ideal motherhood model has been experienced by some women. ${ }^{305}$

While my views are similar to Dowd's in important ways, my approach is distinct in that it emphasizes the ways in which attention to fatherhood will unsettle motherhood. I assume that motherhood itself will change once we begin to incorporate the caregiving insights produced by male caregivers. ${ }^{306}$ My goal is to allow us to more openly consider the ways in which affection and intimate care may affect the dignity and privacy interests of a child, and whether this kind of rights-based analysis truly has any real utility when a child is of tender years. However, the only way to fairly conduct this inquiry is to ensure that caretaking practices are regarded in a gender-neutral fashion, separated from the cultural backdrop that renders them invisible, "traditional" practices of mothering. In this way, my analysis calls for pursuit of a true

303. Id. at 10 .

304. Id.

305. Id.

306. I recognize that the term "mothering" also may trigger strong resistance from male primary parents or "hands-on" fathers. Feminist philosopher Sara Ruddick encountered the same problem more than twenty years ago as she attempted to problematize and theorize about the scope and substance of currently gendered models of parenting. Ruddick explains:

In making the case for "mothering" as a gender-inclusive and therefore genderless activity, [one] ha[s] been struck by the resistance even of those men who fully engage in childtending. As a feminist, I am aware of the dangers of "saming" ... that is, denying the objectified other - in this case the male parent - the right to his difference, submitting the other to the laws of maternity. But I do not understand what men fear to lose. ... [W] hat makes a parent a "father"?

Ruddick, supra note 10, at 230 (internal quotation marks omitted). Twenty years later, despite the numerous anthropological and sociological studies of the practice of fatherhood, we have advanced very little in our understanding of this issue. While these studies show that we have moved away from the reductionist notion that fathers are mere economic providers, feminists have not in any sustained manner evaluated how different models of masculinity may shape parenting, considered our stance in evaluating these differences, nor considered the potential these differences offer in building a model of parenthood that is not marked by the gendered disciplining norms middle-class motherhood has imposed on many mothers. For a discussion criticizing the naturalization of onerous demands at the heart of proper "middle-class motherhood," see Camille Gear Rich, Race-ing Motherhood: A Response to Darren Rosenblum 's "Unsex Mothering: Toward a Culture of New Parenting," HARV. J.L. \& GENDER COLLOQUY (Feb. 6, 2012), http://harvardjlg.com/2012/02/unsex-mothering-responsescamille-gear-rich/. 
gender-neutral analysis in the intimate care cases, as my goal is to ensure that the parenting inquiry in child molestation cases is conducted in a way that moves us toward identifying and disrupting current gender relations. My emphasis on the questions we must resolve with regard to social norms and sexual privacy sets a different agenda than the partial accommodation Dowd and other scholars endorse when they discuss how fathers may change parenting norms. My view is that gender-neutral parenting will require new approaches to sexual privacy, ones that feminist scholars simply have not wrestled with in their discussions. Without recognizing the ways in which caregiving practices are currently gendered, legal actors sidestep the hard work required in sorting through how and why we believe children are injured in particular circumstances.

Moreover, courts that currently use mothering as an ideal default norm in a way that allows mothers to play a gatekeeping role fail to apply a genderneutral approach. By allowing fathering practices to unsettle mothering practices, I ensure that we do not adopt a new gender-neutral model of parenting that is too rigid and constrains both mothers' and fathers' conduct. Instead, a proper gender-neutral inquiry must begin with consideration of the social norms and sexual privacy understandings that inform intimate care cases, with an understanding that gender currently plays a role in defining intimate care. In considering these issues we must ask hard questions about whether and why we are defining injury in a particular case in a way that tends to reinstantiate gendered understandings.

Dowd raises other important questions about how we conduct the genderneutral inquiry in the intimate care cases by recognizing that gender-neutral changes to assist fathers may compromise the well being of women and children. ${ }^{307}$ As many feminist scholars have noted, when fathers are given more authority to provide care, courts may rule in ways that ignore the substantial contributions mothers have made to raise their children. ${ }^{308}$ In child molestation cases, this may mean the court fails to respect a mother's wishes, even as she continues to do the majority of labor to raise her child. It may mean that the court ignores the well-developed preferences a child has for the kind of care given by a mother in a particular case. Instead, a responsible inquiry in the intimate care cases must consider these issues in the context of a social norms inquiry or an inquiry about sexual privacy issues. However, these questions must be honestly acknowledged and addressed in order to grant men more latitude to engage in caregiving activities.

Andrea Doucet, in her book Do Men Mother?, offers different insights about the barriers faced by liberal feminists interested in adopting a genderneutral parenting approach. She generally advocates for gender-neutral

307. DowD, supra note 19, at 11 .

308. See generally Fineman, supra note 248, at 1031. 
parenting, but argues that some gender-based limitations are required because in some instances "embodiment matters." "309 She explains, "At certain times and in certain sites, differently gendered bodies cannot simply be substituted for each other." 310 Doucet argues, "When a father is attending to children-by cuddling, feeding, reading, bathing, or talking to them - gendered embodiment can be largely negligible. But there are also times when embodiment can come to matter a great deal," for example, when a father wants to host a girls' sleepover for his teenage daughter. ${ }^{311}$ Doucet's discussion of embodiment, however, could be characterized as an attempt to make biology or physicality a substitute for a studied analysis of the gender norms that attach to particular bodies and our unwillingness to interrogate these understandings in certain circumstances. Her reservations demonstrate the problems associated with the absence of sustained feminist critique and discussion of the sexual privacy questions that shape our understanding of when and how men can provide nurturing and care, as well as sexual suspicion or anxiety that is associated with men's actions.

If liberal feminists are prepared to fully reject the sexual suspicion dominance feminism brings to fathers' touch, they can advance a project that truly allows us to reimagine fatherhood. Yet this will require us to make substantial space to accept men's understandings of caregiving, understandings that may not stack up neatly within the boundaries established by models of maternal care. Doucet agrees, recognizing in her discussion that granting space for fatherhood may not simply result in men providing mothering care, but may lead to changes in our understanding of the range of appropriate parenting practices. $^{312}$ She argues, “[We] need to provide space for men's narratives of caregiving and resist the impulse to measure, judge, and evaluate them through maternal standards." "313 She notes that, by adopting this approach "with room for theoretical or empirical surprises," we may develop "innovative ways of describing and theorizing men's nurturing practices and ultimately novel ways of thinking about emotional responsibility." 314 Accordingly, the next step would be to more explicitly consider how these additional ways of relating to children might enrich our understanding more generally of what it means to adopt a truly gender-neutral and comprehensive understanding of providing care. ${ }^{315}$ Also, by recognizing men's ability to craft different approaches to caregiving, feminists will provide greater protection to men who adopt

309. DOUCET, supra note 13, at 41.

310. Id. at $41-42$.

311. Id. at 41 .

312. DOUCET, supra note 13, at 242-45.

313. Id. at 28 .

314. Id.

315. Id. at 133 (discussing how fathers' nurturing focus on encouraging physical activity and fostering independence should widen notions of caregiving). 
"marginalized masculinities." ${ }^{\text {"316 }}$ Indeed, perhaps the greatest way that feminism has failed caregiving men is by failing to credit them when they develop alternate ways of relating to children, and looking past the sanctions they face from other men for failure to comply with traditional gender roles. Feminists should devote more attention to this issue, as men can be easily dissuaded from doing this kind of work, despite evidence that they are both capable and interested in providing care during the early stages of their children's lives. ${ }^{317}$

IV.

\section{CONCERNS, CRITIQUES, AND SOLUTIONS}

Part IV surveys what I anticipate will be the most likely concerns about the gender inequality claims made in this Article. Some have argued that there are empirical, conceptual, and practical issues that should complicate this account of how the law affects fathers' caregiving practices. Part IV.A addresses the concern that my arguments about gender bias against fathers must be weighed against the substantial empirical evidence showing that fathers are far more likely than mothers to sexually abuse their children. I suggest that this empirical data may be infected by gendered understandings and highlight the ways in which this argument raises the specter of gender profiling. Part IV.B acknowledges and evaluates the concern that in equalizing the treatment of mothers and fathers we are inviting further scrutiny of mother's conduct in ways that may compromise mothers' ability to provide care.

Part IV.C addresses the claim that the cases I have offered here are more properly understood as skirmishes in custody disputes, rather than a larger commentary on the risk of gender stereotyping in evaluating fathers' caregiving. I agree that many of these cases arise in circumstances of family dissolution and reformation, but my claim is that these moments are key periods in which gendered understandings of parenting are challenged. As newly separated fathers take on new roles and newly separated mothers take on new male partners who are willing to provide childcare, masculinity is being renegotiated in important ways.

Part IV.D turns to the concern that race, class, and sexual orientation should play a more central role in my analysis, as the Article is premised on the understanding that vulnerable minorities are at heightened risk for scrutiny. Indeed, gay fathers of all races, fathers from minority groups, and poor and working-class fathers are particularly subject to suspicion, but some commentators have raised the concern that these groups are insufficiently

316. Id. at 241-42 (discussing how primary caregiving fathers can help break the gender imbalances between powerful spheres (work) and private spheres (home)).

317. Anthony McMahon, Male Readings of Feminist Theory: The Psychologization of Sexual Politics in the Masculinity Literature, 22 THEORY \& SOC'Y 675, 679 (1993) (discussing studies showing parents of both sexes have similar emotional reactions to their newborns but men opt out of care when allowed to do so). 
featured in the cases discussed in Part III. Finally, Part IV.E turns to causation challenges, in particular claims that there are extralegal reasons why many fathers have opted out of providing nurture and care.

\section{A. Recognizing Risk: Masculinity as a Risk Factor for Sexual Abuse}

\section{Gender Profiling and the Empirical Case Against Fathers}

Some have questioned the wisdom of this piece in light of the substantial empirical evidence indicating that the majority of child molesters are male and most are related to or known by their victims. ${ }^{318}$ Logically, then, critics argue, the data suggests that we should more closely scrutinize fathers' actions or, at the very least, believe children who report that they were made uncomfortable by a father's touch. Curiously, although gender and racial profiling arguments are harshly attacked in other legal contexts, the profiling justification attracts little notice in discussions of child molestation. Progressives tend to shrug and claim they are just facing reality. However, the case against gender profiling is clear. For basic fairness reasons, we cannot subject all fathers to more surveillance simply because a subset of fathers engages in illicit behavior. Bernard Harcourt's work on racial profiling allows us to see the ways in which gender profiling allows perpetrators who do not fit the established profile more freedom to engage in criminal behavior. ${ }^{319}$ Consequently, we must understand that our emphasis on troubling fathers' behavior leaves mothers with more latitude to engage in questionable conduct.

Second, we have not truly considered the costs imposed by our casual reliance on gender profiling in child molestation cases, as this tendency toward stereotyping profoundly discourages men from providing care. ${ }^{320}$ What reasonable father will take responsibility for the more intimate aspects of childcare if he knows that well-intentioned missteps by mothers are routinely ignored, but the same missteps, if committed by fathers, trigger legal scrutiny and sanction? Why would any father, other than those required to do so by necessity, push back against gendered parenting norms? Third, and perhaps most importantly, feminists' apparent tolerance of gender profiling in the child sexual abuse context puts the credibility of feminist legal theory at stake. Liberal feminists for years have urged men to provide care for children, arguing that it is a transformative, valuable experience. ${ }^{321}$ The very least we can do is credit men who adopt these understandings, and ensure that they receive individualized consideration if and when disputes arise.

318. See LONDON FAMILY COURT ClinIC, supra note 40, at 22; Finkelhor, supra note 203.

319. See Bernard E. Harcourt, Against Prediction: Profiling, Policing, and PUNISHING IN AN ACTUARIAL AGE 235-37 (2007).

320. See Kelly, supra note 12, at 65.

321. See supra notes 205-11 regarding liberal feminist scholars. 
Additionally, the empirical arguments made in support of scrutinizing fathers' conduct should infuriate feminist scholars. Close examination of these seemingly neutral studies shows that they are based on gendered understandings of sexual abuse, and consequently may simply fail to count many of the behaviors psychologists would identify as maternal abuse. This phenomenon, coupled with the well-established fact that victims and third-party reporters tend to ignore, explain away, or disregard clear acts of maternal sexual abuse, makes it incredibly complicated to talk about the higher male base rates for child sexual abuse. Taken together, the presence of gendered definitions of abuse and the underreporting of abusive maternal behavior should make us question the "common sense" claim that men as a group are more at risk of sexually abusing children. ${ }^{322}$ Indeed, once we become aware of these issues, along with the fact that scholars often employ dramatically different definitions of child molestation from study to study, we can understand why different scholars make such different claims about the incidence and prevalence of paternal sexual abuse. Why would one study report that only 13.5 percent of victims are sexually abused by fathers and stepfathers, while another posits that 68 percent of victims are abused by fathers or stepfathers? Rather than accepting these studies at face value, we must begin to think more deeply about what it is that we hope to capture in performing these quantitative studies.

\section{A More Nuanced Form of Empiricism: Men, Masculinity, and Fatherhood}

While there are valid concerns about the current empirical studies on child molestation, empirical work in this area can still play a critical role in developing our understanding. My challenge to the claims of gender-based risk in the current empirical literature is simply intended to remind scholars to maintain a critical distance from this literature. This is because many scholars seem to use the current empirical data as a seemingly palatable, politically correct cover for the dubious claim that there is something about male desire that simply makes men more likely to engage in illicit conduct with children. Certainly, dominance feminists historically have been much more comfortable making this claim explicitly. ${ }^{323}$ However, the claim has become so naturalized that most empirical studies rest on this understanding, and some even make this claim explicitly. ${ }^{324}$ Yet even if we conclude that men are more likely to be

322. See Peter, supra note 86 (discussing the impact of maternal sexual abuse).

323. See EliZABETH WARD, FATHER-DAUGHTER RAPE 194-95 (1984) ("[Molesters] are not aberrant males: they are acting within the mainstream of masculine sexual behavior which sees women as sexual commodities and believes men have a right to use/abuse these commodities how and whenever they can.”); see also BELL, supra note 201, at 73.

324. See Margolin \& Craft, supra note 43, at 453 (“[M] ale caregivers appeared responsible for 8 times more sexual abuse than female caregivers, confirming that gender explains a considerable portion of the sexual abuse which occurred. Nonetheless, the overrepresentation of male perpetrators was not constant across each caregiver category. . . This extreme variability in the ratio of male to 
accused of or involved in child molestation, that does not mean that we must retreat to reactionary understandings of gender. Unfortunately, analyses based on the rigid understanding of masculinity promoted by dominance feminism are insufficiently dynamic to deal with the wide range of male behavior. Empirical studies that have been shaped by dominance feminism's understandings suffer from this problem as well. The rigid, categorical characterization of men in the current empirical data rests on a kind of gender stereotyping that should be intolerable to the liberal feminist movement, and there is ample research on men's different experiences of masculinity in masculinity theory that warns us away from such simple characterizations. ${ }^{325}$

In short, many of the current problems in the empirical scholarship on child sexual abuse can be addressed if feminists encourage empirical scholars to construct studies that acknowledge the multiple masculinities present at any given time and the ways these different versions of masculinity shape the practice and experience of fatherhood. Sociologists have done a great deal of productive work in this area, showing how men's understandings of masculinity fundamentally inform men's understanding of care. ${ }^{326}$ This sociological work on multiple masculinities attempts to explore features of masculinity that make certain men more or less trustworthy male caregivers. Empirical work that adopts this more nuanced approach will yield more accurate results than facilely assuming that all male caregivers pose risks to children. Moreover, as we hone in on the problematic characteristics of certain forms of masculinity that forecast abuse, we may ultimately find that the same problematic characteristics are present in both genders. This more nuanced empirical work on gender is critical if we intend to continue using gender as a variable of interest in child molestation analyses.

female perpetrators suggests that the effects of gender on child sexual abuse are strongly influenced by the social structures associated with each caretaking group."). The authors recognize that the caregiving relationship seems to be strongly probative (perhaps even more so than gender) as a risk factor for abuse, but they continue to hew to the common-sense understanding of gender as a key "cause" even as they recognize other variables. See id.

325. Some feminist scholars have discussed the emergence of multiple masculinities and that these different strains of masculinity should be explored in the analysis of dominance feminists, but they have declined to take on this project themselves. See, e.g., Becker, supra note 12, at 1459 (recognizing but not exploring repercussions of multiple masculinities for feminist analyses of child molestation law).

326. These studies on masculinity often feature surprising results about which masculine forms are attracted to childcare. See Kristy Krivickas, Masculinity and Men's Intimate and Fathering Relationships: A Focus on Race and Institutional Participation 142 (Dec. 2010) (unpublished Ph.D dissertation, Bowling Green State University) (on file with the California Law Review) (discussing study findings showing that hyper-masculine men were the most involved with their children in contrast to men classified as "contemporary" masculine men and "traditionally" masculine men). The author notes that her finding is consistent with other research data showing that economically marginal men value the physical and emotional connection they have with their children more than many other men, noting that hyper-masculine men have the most difficulty finding long-term work in today's labor market. Id. 


\section{B. The Dangers of Gender-Neutral Parenting Models}

\section{Burdening Mothers}

Critics of liberal feminism may have concerns about the arguments made here, recognizing them as part of the steady march toward androgynous parenting models. Martha Fineman, perhaps the most famous of the group, worries that androgynous parenting models on the whole tend to work to women's disadvantage. ${ }^{327}$ Her concerns bear fruit as we examine how the demand for gender neutrality might be operationalized in the intimate care cases. If we assume that current understandings of sexual abuse are gendered in ways that target men, we invite the state to cast a bright light on mothers' intimacy and care practices, and therefore invite more state intrusion into family life. Indeed, I recognize that it is not at all clear that subjecting motherchild intimacies to this same regime of suspicion that governs male caregivers will benefit children in the long run. Rather, intrusive state inquiries might drive parents of both genders to adopt a standardized model of care and engage in a kind of reflexive second guessing that will seem unbearably oppressive to both genders. Instead, I would agree that our history of more relaxed enforcement with caregiving mothers suggests that children flourish when we give their caregivers some reasonable latitude in discharging their care obligations. My view is that, by viewing contemporary mothering and fathering practices in the abstract as parenting practices, we can begin to develop a more principled approach to the social norms and sexual privacy questions at the heart of the intimate care cases. At present these mothering and fathering practices are informed by gender stereotypes and concerns about male and female embodiment; they shape parenting norms in thus far unexamined ways that tend to instantiate conservative understandings.

Some have made the opposite claim, that giving fathers the same discretionary space as mothers to negotiate family intimacy would place more children at risk for sexual exploitation. Proponents of this view argue that, if psychologists believe that a fair degree of maternal abuse is being ignored, it makes little sense then to grant fathers the same latitude to engage in inappropriate conduct. However, my goal is not to create more space for abuse, but rather to encourage the development of a legal inquiry that examines intimacy practices in a more concrete, principled, and gender-neutral fashion. Some of the current intimacy practices of mothers that are not problematized may be when they are viewed in a distanced, gender-neutral fashion. Some fathers' practices, when viewed in the abstract, may seem more mundane and not the proper subject of inquiry. My argument is that by reversing the groups in child molestation cases, we create more space for us to engage in a more

327. Fineman, supra note 247, at 1040. 
careful analysis of the parental behavior at issue and our commitment (or lack thereof) to certain gendered understandings.

By reversing the groups and examining parenting practices in the abstract, legal scholars and laypersons will be required to more directly consider the various interests being vindicated in child molestation cases, including the child's interest in sexual privacy, the family's interest in autonomy with regard to its caregiving practices, and the state's interest in ensuring that children receive a certain minimum standard of appropriate care. With the stakes made clear in this manner, my expectation is that state actors will bear a heavier burden when they claim that certain intimacy practices are impermissible. In this way, my gender-neutral approach is attentive to the post-dominance feminists' view that state intervention in the private sphere is not always the sanguine development imagined. Additionally, a gender-neutral examination of parenting practices will require us to wrestle with the degree to which embodiment matters in understanding children's sexual privacy, and the ways in which conservative approaches to gender difference often find shelter in sexual privacy arguments. These conversations are essential to developing our understanding of gender-neutral parenting.

\section{Burdening and Unburdening Culture}

Some may argue that the push toward androgynous parenting roles will claim another casualty: cultural minorities. As we attempt to ungender parenting practices and view these practices in a more neutral fashion, we will discover that many of these gendered performances are marked by culture as well. Specifically, as we examine mothering and fathering practices through a gender-neutral lens we will inevitably be confronted with the different ways in which so-called gendered parenting is performed in culturally specific ways. We will be called upon to evaluate the practices of the Dominican mother who kisses her child's genitals and the Afghan father who does the same. ${ }^{328} \mathrm{My}$ analysis challenges us to ask from a gender-neutral perspective whether the practice of kissing the genitals of young children offends our understanding of the objective sexual privacy norms of children. My belief is that the answer should be the same regardless of the parent and child's gender and whether the child happens to be born into an immigrant community with different gender norms. My hope is that in conducting this inquiry we will discover that the practices of these so called "other" groups are not really so "other" after all, and that similar behavior (perhaps varying in intensity and degree) occurs in assimilated American families. My hope is that by recognizing these more unusual or unexpected practices, the range of recognized childcare practices expands to allow for a greater degree of discretion in the absence of evidence that the childcare is affirmatively harmful. This conversation is necessary to

328. See cases discussed supra note 190. 
ensure that child molestation law does not become yet another site for reinstantiating the difference between other "foreign" families and the childcare practices of "American" families.

Post-dominance feminists may argue that this is an overly sanguine view of state power and that cultural minorities will inevitably fall prey to social dynamics that cause their practices to be pathologized and sanctioned. However, as Austin Sarat explained, diverse societies are constantly negotiating a process of accommodating diversity while ensuring that there is sufficient commonality to create an understanding of community. ${ }^{329}$ Debates over child molestation law and family intimacy practices function in precisely this way, although at present scrutiny has tended to focus on more socially subordinated families, rather than exploring the ways in which members of socially privileged families may encourage their members to relate to other family members' bodies in ways that might require pause. That is, by opening this dialogue we learn that certain otherized practices are engaged in more broadly by many different kinds of American families. With this understanding we can begin to more carefully consider whether a given practice is in fact harmful and should be prohibited, regardless of whether the practice involved might be regarded as a cultural practice. Instead of making exceptions for culture, our emphasis should be on whether the practice is harmful, either because it fundamentally conflicts with American caretaking norms because the practice may psychologically injure a child, or because objectively viewed the physical practice is highly likely to result in injury.

\section{The Role of Social Context in Understanding the Intimate Care Cases}

\section{Family Dissolution and Reformation}

Readers of this Article sometimes worry that the cases featured do not accurately portray the stresses of fatherhood because the intimate care cases involving fathers tend to grow out of divorce and custody disputes. They recognize that these disputes sometimes motivate parties to make false or overblown accusations about a former partner. Indeed, one conventional account of the intimate care cases is that these cases are manufactured by distressed mothers, angry at being abandoned by their male partners. At a minimum, this Article establishes that this conventional narrative is insufficient to account for all the intimate care cases. In fact, these cases clearly reveal a much more complex web of evolving relationships. For example, in addition to mothers raising questions about the intimate care a father provides to a child, the cases show fathers challenging their newly estranged female partner's decision to allow another man to care for their children. Specifically, cases like Julia $B$. show that fathers can and do use child molestation allegations as a

329. Sarat \& Kearns, supra note 260 , at 30-31. 
means of exercising control over their former girlfriends and wives. ${ }^{330}$ These allegations are an effective weapon that can prevent a former wife or girlfriend from cohabitating with or sharing caregiving activities with a new male partner. Therefore, even if we think the intimate care cases involve a disproportionate number of bad faith claims, we should acknowledge that both parents mobilize social anxieties about child sexual abuse as a way of controlling their former partners.

The bad faith account of the intimate care cases, however, is a distraction that has caused us to miss the more significant story told by these cases. Indeed, there are reasons that we see more cases accusing fathers and other male caregivers of illicit sexual motivations when a family is being dissolved or is being reformed with a new male partner. We must recognize that family dissolution produces a context in which two caregiving parents, now alienated from one another, may be more inclined to read ambiguous acts as evidence that the partner has an illicit sexual interest in a child. A parent who may "put up" with unorthodox parenting practices while they are in the home may come to view these practices quite differently when they do not feel that they are available to exercise supervision on a regular basis. Indeed, the Marokity case, in which a newly married mother accuses her former husband of child molestation for the way he kisses her children, is best explained as an example where a formal marital partner's previous indulgence of her partner's idiosyncrasies evaporates once the marital bond is severed. ${ }^{331}$

Additionally, these moments of family formation and dissolution are critical when gendered notions of parenting are being challenged. When heterosexually partnered parents separate and establish different residences, the children (who likely have grown accustomed to a certain gendered approach to parenting) suddenly find themselves forced to allow a male caregiver to attend to intimate tasks that previously were the sole province of their mothers. It seems logical that we would see a large number of subjective sexual privacy complaint cases from children involving toileting and bathing in these circumstances. Additionally, men may be more unfamiliar with the practices now required of them and may make mistakes that seem ridiculous to a more experienced caregiver, but are certainly not sexually motivated. The toileting scenarios in both Montgomery and In re D.C. feature fathers who may fall below the high standard of care set for mothers, but are not engaged in illicit sexual activity. ${ }^{332}$

Finally, heterosexual mothers who separate from a male partner who does not provide care may find themselves more inclined in their next relationship to partner with a man who has adopted a progressive version of masculinity that

330. See In re Julia B., No. A125775, 2010 WL 2620806, at *8 (Cal. Ct. App. June 30, 2010).

331. People v. Marokity, No. B213631, 2010 WL 779778 (Cal. Ct. App. Mar. 9, 2010).

332. See Montgomery Cnty. Dep't of Health and Human Servs. v. P.F., 768 A.2d 112 (Md. Ct. Spec. App. 2001); In re D.C., 648 A.2d 816 (Vt. 1993). 
encourages him to take on a caregiving role. The intimate care cases, then, may involve conflicts between a biological father and a new father about the masculinity norms that will govern in a family. Courts, social workers, and prosecutors may naively intervene in these disputes, based on their concerns about the new father's alleged "sexual interest" in a child, and end up reinstantiating traditional notions about gendered care. By focusing on the way gendered parenting roles are being shaped during custody and divorce cases, we can understand the child molestation allegations produced in such cases in a profoundly different way.

\section{Family Dissolution and Family Sexual Boundaries}

Scholars studying child molestation should also expect intimate care cases to arise in divorce and custody proceedings because family dissolution creates opportunities for the state and other social actors to evaluate the family's decisions regarding the maintenance of sexual boundaries in the family. As explained in Part I, the term sexual boundaries refers to a range of family practices, including parental nudity, children's nudity, exposing children to primal scenes (such as sex) and other sexual materials, and exposing children to frank and open discussions or jokes about sexual matters. The concern about families maintaining poor sexual boundaries is based on an understanding that children's sexual innocence must be maintained. When children in divorce, custody, and neglect proceedings demonstrate knowledge of sexual matters or an interest in sex to school officials, social workers, or even another parent, their behavior often triggers inquiries about the newly single father's ability to maintain these boundaries, or his intimacy or nurturing practices. ${ }^{333}$

Indeed, when one looks at the intimate care cases, one finds that many of them are triggered by a child demonstrating sexual knowledge in a way that violates social taboos. Cases may be triggered by a child who masturbates, displays an interest in his or her body, or the body of a parent, or pantomimes sex. All of these activities may trigger the concern that the child has been sexually abused. This dynamic is deeply problematic, as psychologists' work shows that children, as part of normal development, often display sexualized behaviors or take pleasure in their own bodies. This dynamic is also concerning because there is little agreement about what kinds of intimacy practices

333. See, e.g., In re Martha R., No. B152839, 2002 WL 1155481 (Cal. Ct. App. May 31, 2002). Disputes about family sexual boundaries and their effects on a child are not uncommon. In In re Martha R., a father who could not economically support his child had his visitation rights curtailed because of his failure to attend to the ways in which the foster mother was trying to shape the child's attitudes toward affection. $I d$. at *2. The father specifically complained that the child's "spirit" was being broken because her foster mother had required that she be placed in therapy because she was too affectionate with other people. Id. The court concluded that the father's visitation rights should be more closely monitored after he allowed the child to bathe in the hot tub during a visit at his home. Id. at *1. The court explained that his behavior was likely an attempt to undermine the therapist's attempts to make the child recognize appropriate sexual boundaries. $I d$. at *2. 
constitute abuse. A father who has co-bathed with his child while married may find himself reevaluating this practice if he is the sole caregiver for the child during a given period. If a child displays curiosity about his body while he is part of the nuclear family unit, he is more likely to find safe harbor than if he is caring for her alone. Last, fathers are strongly incentivized to ensure that there is no trace or evidence of their existence as sexual beings while they are serving the role of caregiver, lest they be accused of abuse. The neutered father joins the neutered mother as the paradigmatic caregiver. ${ }^{334}$

\section{Intersectional Disadvantage and Stereotyping of Fathers}

Although persuaded by my analysis, some may feel that the project would benefit from a more detailed exploration of the intersectional dimensions of gender stereotyping - namely, the ways that race, sexual orientation, and class work together to increase the risk of gender stereotyping, as well as activate specific anxieties about fathers and child molestation. The concern is, in the absence of a clear discussion of these intersectional risks, the reader will by default assume that my project is primarily concerned with protecting the interests of the most visible group of father caregivers: white, middle-class, stay-at-home fathers, a relatively privileged social group that has taken on parenthood by choice. Some have argued that this group is certainly not in need of special protection. They are celebrated for their efforts to provide care, rather than painted with the brush of sexual suspicion. ${ }^{335}$ Yet, as Part III shows, many of these fathers do feel that their efforts are scrutinized and their presence questioned in childcare settings. Moreover, many of them recognize that they are but one divorce, custody dispute, or emergency room visit away from an interaction with state actors who could trigger a more searching inquiry. Additionally, cases demonstrate that the class privilege that we assume middleclass fathers enjoy does not immunize fathers from sexual suspicion in the intimate care cases. Marokity involved a father who was a medical doctor, yet

334. Importantly, liberal feminists raised concerns decades ago about models of parenthood that denied women the right to live their lives as sexualized beings. The 1999 film The Good Mother, which chronicles a female divorcee's loss of custody of her child after accidentally exposing the child to a primal scene, squarely presents us with this question. We are invited to sympathize with this mother who leaves a frigid marriage for a healthier sexual relationship, allows the child to crawl into bed with her and her boyfriend, and is found to be a "bad mother" as a result. Indeed, some might argue that in this second set of cases, child molestation law is being used to ensure that mothers do not enjoy intimacy with any person other than her children. Strangely, twenty years later, liberal feminists have little to say when courts sanction fathers for behaving in ways that allow their children to be aware of a parent's capacity to be a sexual being. In order to address the challenges of the intimate care cases, feminists must recognize that the display of sexuality by mothers and fathers equally can be the basis for sanction, and the refusal to create space for sexual fathers is part of the cultural project to desexualize parenthood more generally, with disastrous consequences for mothers.

335. See, e.g., Rochlen et al., supra note 236 (discussing study conducted with white middleclass fathers). 
he faced the same questions about his intimacy and care practices as fathers in professions with far less social standing. ${ }^{336}$

While all of the variables mentioned above work together to produce a father's particular experience of parenting, each variable should be assessed to consider its distinct role. For example, race likely plays a key role in the stereotypes activated in the intimate care cases involving fathers. However, it is also a particularly thorny intersectional variable when talking about child molestation, since the "standard" child-molesting father in the cultural imagination is a white, middle or working-class male breadwinner ${ }^{337}$ in a family with clear patriarchal norms. However, this stereotype circulates concurrently with other historically established stereotypes about African American and Latino male hypersexuality that also may be activated in cases in which minority fathers are accused of molestation in the course of routine care. ${ }^{338}$ Race-based otherization also likely plays a role when we evaluate the actions of Asian, and Middle Eastern fathers, or men of other races, particularly when plaintiffs call cultural defenses into play. While some work has been done on how race shapes men's perspectives on masculinity and their relationship to fatherhood, ${ }^{339}$ there has been little discussion of how racial stereotypes affect our understanding of fathers' discretion to provide intimate care. ${ }^{340}$ In light of the existing work in this area, we must be particularly mindful of the ways in which racially inflected stereotypes about men can affect a man's discretion to nurture, as well as the ways in which a minority father may be subject to conflicting stereotypes about his racial group.

Some of the most interesting scholarship on intersectional stereotyping and the experience of fatherhood examines how discrimination based on sexual orientation affects gay men's ability to parent. ${ }^{341}$ Using a sample of nearly 200

336. See Marokity, 2010 WL 779778, at*1.

337. See Nancy E. Dowd, Masculinities and Feminist Legal Theory, 23 WIS. J.L. GenDER \& SoC'Y 201, 241 n.167 (2008).

338. Nancy Dowd has recognized the role that racial stereotyping plays in the construction of fatherhood and the ability to provide care. See DowD, supra note 19, at 65 (recognizing fathers of color are "stigmatized and denigrated" in ways that interfere with the ability to be represented as nurturing). Although she does not explicitly discuss "hypersexuality," she explains that certain minority fathers are associated with patriarchal models of fatherhood and machismo, which affect social perceptions about their capacity as fathers. See id. at 74 (discussing Latino fathers). Dowd explains that these stereotypes oversimplify minority fathers' experiences. Id. Dowd's work, like much of the literature on race and fatherhood, tends to focus on Black and Latino fathers. However, Dowd also recognizes that there is a need for inquiry into the ways in which men of other races are subject to racially inflected stereotypes about masculinity and the ways in which these stereotypes distort perceptions about their ability to act as fathers and provide care. See id. (recognizing the need for research on Asian fathers); see also Silverstein, supra note 223, at 19-20 (discussing the need for further research to create studies exploring fathers in other racial and cultural groups).

339. DowD, supra note 19, at 71-74 (describing studies on race and fatherhood).

340. Wayne Miller \& Sarah Maiter, Fatherhood and Culture: Moving Beyond Stereotypical Understandings, 17 J. ETHNIC \& CULTURAL DIVERSITY IN SOC. WORK 279, 289 (2008).

341. See DowD, supra note 19 , at $75-80$ (describing studies on homosexuality and fatherhood). 
child custody cases involving gay parents, Clifford Rosky demonstrates how stereotypes about gay men limit their ability to nurture as people tend to assume that gay men are at higher risk of committing child molestation, particularly with their male children. ${ }^{342}$ These anxieties about homoerotic desire are particularly acute when fathers are involved in routine care. Sexual orientation-based stereotyping, similarly, plays a complicated role in the intimate care cases, since gay men may also sometimes be stereotyped in ways that give them more space to nurture, as many will claim that they have a greater affinity for nurturing and providing care. As Rosky explains, the gender and sexual orientation stereotypes called into play are determined by the relational context in which the case arises: the gender of the judge, of the child, and of the caregiver. ${ }^{343} \mathrm{He}$ notes that male judges analyzing cases involving gay fathers and male children tend to show more concern about the potential for abuse. ${ }^{344}$

Rather than take up specific questions about the various kinds of stereotypes that might be deployed, my work attends to intersectional questions by focusing on the structural variables that make working-class, poor, and minority men more at risk for child molestation. Specifically, the cases selected are intended to explore the phenomenon of social fatherhood - an increasingly common social arrangement under which men who are not married to a child's mother or are not biologically related to a child serve as the child's father or caregiver for practical purposes. ${ }^{345}$ The man serving as a social father may be the mother's boyfriend, the child's uncle or grandfather, or a family friend. This phenomenon of social fatherhood is a constitutive part of most African American and working-class children's experiences, given the low marriage rates in African American communities and the decreasing marriages rates in American communities more generally. ${ }^{346}$ While empirical research suggests that children are most at risk from men in this category, cultural trends suggest more and more men will be asked to play this role. Consequently, we would benefit from empirical research that stops relying on gender as a proxy for danger, and instead focuses more on identifying the characteristics that make certain men inappropriate candidates to serve as social fathers.

Additionally, my work is particularly attentive to class because it does not focus on fathers who have self-consciously elected to become stay-at-home, primary caregivers, but rather men who provide care out of necessity rather than choice. Specifically, the cases featured for discussion involve fathers who

342. Clifford J. Rosky, Like Father, Like Son: Homosexuality, Parenthood, and the Gender of Homophobia, 20 Yale J.L. \& Feminism 257, 297-99 (2009).

343. Id. at 313.

344. Id.

345. DowD, supra note 19, at 71 (noting that 60 percent of children in black families that did not have a resident biological father nonetheless had a functional father figure in their lives).

346. Id. at 71-72 (discussing the rise in female-headed households in black communities and the corresponding decrease in black men's employment rates). 
are providing care on a temporary basis, because they have either separated from the child's mother or because the child's mother is working outside the home. $^{347}$ Many involve apparently working-class fathers, a particularly important group. Research suggests that these fathers are increasingly being required to do substantial amounts of maternal work to provide coverage for mothers in the workforce; however, these fathers also often hold very traditional attitudes about gender. ${ }^{348}$ Consequently, working-class fathers in particular may acutely feel the sexual suspicion that surrounds male nurture and care. Additionally, the issues explored in this discussion are important for economically vulnerable fathers who cannot use the economic breadwinner model to "perform fatherhood," particularly low wage African American fathers. ${ }^{349}$ Many of these fathers provide care even when they cannot provide economic support. ${ }^{350}$ The sexual suspicion that child molestation law promotes about men certainly burdens these economically vulnerable fathers as well.

\section{E. Causation Challenges}

\section{Potential Versus Actual Abuse}

Some may argue that this Article artfully demonstrates the potential for abuse, but does not establish that child molestation is interpreted in the troubling fashion described here in the vast majority of parental intimate care cases. To be clear, this Article has not attempted to provide a comprehensive empirical survey that charts the gender repercussions of child molestation law enforcement efforts across the nation. This kind of vast empirical project might be helpful, but it is not necessary to my argument. Rather, my goal is to provide a selection of cases that shows the kind of abuses that can and do occur, and question whether we feel that a system that allows for such abuse, for both symbolic and practical reasons, is a regime we feel comfortable preserving. My concern is that, even if actual cases are isolated, institutional actors can and do mobilize these understandings about child molestation in ways that discourage fathers from providing care.

347. See Shows \& Gerstel, supra note 26, at 181-82 (showing that working-class fathers (EMTs) were involved in more hands-on and daily parenting activities than middle-class fathers (physicians) and explaining that the EMTs often were members of dual wage-earning couples and therefore were required to act as primary caregivers when their spouses were at work).

348. Francine M. Deutsch, Equally Shared Parenting, 10 CURRENT DIRECTIONS PSYCHOL. SCI. 25, 26 (2001). But see Shows \& Gerstel, supra note 26, at 181 (noting that working-class sample did not experience caretaking work as a "threat" to masculinity perhaps because they had other sites in which they could have their masculinity recognized).

349. Performing fatherhood or proving one's worth as a father has historically been based on serving in a breadwinning role. See DowD, supra note 19, at 71-73 (commenting on the strain African American unemployed fathers face because of fathers' historically established breadwinning role).

350. Id. 


\section{Extralegal Reasons for Fathers' Failure to Provide Childcare}

Others may raise the concern that, even if this threat exists, most fathers are wholly unaware of the danger presented by these statutes. They would argue that this Article fails to show that the law plays a critical role in shaping fathers' reluctance to provide childcare. These readers would note that many men suffer from a pre-existing, natural, and cultural discomfort with providing childcare. This natural discomfort may be the result of gender role socialization, they argue, but it would be a mistake to believe that either the expansive and vague criminal law prohibitions or their inconsistent application play any substantial role in discouraging men from providing childcare. This claim, however, is based on the mistaken idea that there is a stark divide between the law and the realities of social life. As explained in Part III, the law is not just the law of statute books and court opinions; rather, it is the commonsense understanding of the law as it is interpreted and deployed by various social actors in many different contexts. The law is what teachers say it is during parent-teacher conferences and what instructors, mothers, and fathers say it is in "Mommy and Me" classes or playgroups. The law is produced when social workers discuss childcare with families after a visit to the hospital or when they respond to a neighbor who has reported alleged child abuse. The premise of this Article is that child molestation law is an effective disciplinary tool because social actors are invited to rely on cultural understandings about the appropriate scope of parental intimacy or the gendered nature of care to make claims about what the law requires. Consequently, the pre-existing reservations many people have about men providing childcare become part of the network of legal understandings to which men respond. As explained in Part III, we must begin to understand the way the "law of everyday life" plays an important role in gender role socialization, even for persons who never find themselves the subject of a criminal or civil case, or an official inquiry or investigation. ${ }^{351}$ These legal understandings create special risks for fathers who would challenge gender roles.

\section{CONCLUSION}

We end back where we began our journey-the case of State v. Emmett. However, we arrive at the finish line somewhat less innocent as a result of our inquiries. Instead of asking the more superficial question of whether the Emmett court reached the right result, this Article invites the reader to share in a meta-analysis that asks how and why child molestation law has become so invested in regulating the mundane aspects of parenting. It further asks whether we have critically evaluated the way in which child molestation laws, by inviting reliance on common sense and gender-specific social norms about parenting, encourage and instantiate various forms of gender stereotyping.

351. See Sarat \& Kearns, supra note 260, at 55. 
The Emmett case also helps us realize that, in order to unpack the problems associated with gender stereotyping in child molestation cases, we will need to have a broader and deeper discussion about how we define and charge child molestation. At present, prosecutors, judges, and juries are negotiating a wide range of cases, including purposeful assaults, parents who violate social norms, and parents who either unwittingly or not invade children's subjective understandings of sexual privacy. Cases like Emmett teach us that many of these cases cannot be addressed by quick answers and kneejerk affirmations about the importance of prosecuting child molestation. These cases challenge us to more closely examine how we identify the prohibited and what interests are served by the definitions we currently use.

Certainly, we can and should make reform efforts, directing our attention to identifying de-biasing protocols that can make prosecutors, judges, jurors, and social workers aware of the ways in which their understanding of parenting may be shaped by gender-role stereotypes. One of the easiest interventions is to require courts to consider, as a formal part of the legal analysis in intimate care cases, how the practice of parenting has been shaped by gender norms. However, reform cannot focus solely on changing the doctrinal analysis or the language of statutes. As the late William Stuntz observed, "the law on the street may remain unchanged even as the law on the books changes dramatically." "352 Instead, we must create legal tools that force decision makers to disrupt the "natural" and gendered cultural assumptions legal decision makers rely on when they refer, charge, try, and adjudicate cases. In effect, we must change the mind of the average man or woman on the street about the appropriate scope of fatherhood, so that when men like Emmett are charged, they need not solely rely on enlightened judges to vindicate their efforts.

352. Stuntz, supra note 76 , at 508 . 